\title{
Air-snow transfer of nitrate on the East Antarctic Plateau - Part 2: An isotopic model for the interpretation of deep ice-core records
}

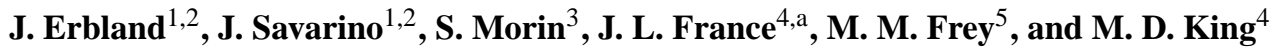 \\ ${ }^{1}$ Université Grenoble Alpes, LGGE, 38000 Grenoble, France \\ ${ }^{2}$ CNRS, LGGE, 38000 Grenoble, France \\ ${ }^{3}$ Météo-France - CNRS, CNRM - GAME UMR 3589, CEN, Grenoble, France \\ ${ }^{4}$ Department of Earth Sciences, Royal Holloway University of London, Egham, Surrey, TW20 0EX, UK \\ ${ }^{5}$ British Antarctic Survey, Natural Environment Research Council, Cambridge, UK \\ ${ }^{a}$ now at: School of Environmental Sciences, University of East Anglia, Norwich, NR4 7TJ, UK
}

Correspondence to: J. Savarino (joel.savarino@ujf-grenoble.fr)

Received: 9 January 2015 - Published in Atmos. Chem. Phys. Discuss.: 10 March 2015

Revised: 1 September 2015 - Accepted: 7 September 2015 - Published: 30 October 2015

\begin{abstract}
Unraveling the modern budget of reactive nitrogen on the Antarctic Plateau is critical for the interpretation of ice-core records of nitrate. This requires accounting for nitrate recycling processes occurring in near-surface snow and the overlying atmospheric boundary layer. Not only concentration measurements but also isotopic ratios of nitrogen and oxygen in nitrate provide constraints on the processes at play. However, due to the large number of intertwined chemical and physical phenomena involved, numerical modeling is required to test hypotheses in a quantitative manner. Here we introduce the model TRANSITS (TRansfer of Atmospheric Nitrate Stable Isotopes To the Snow), a novel conceptual, multi-layer and one-dimensional model representing the impact of processes operating on nitrate at the air-snow interface on the East Antarctic Plateau, in terms of concentrations (mass fraction) and nitrogen $\left(\delta^{15} \mathrm{~N}\right)$ and oxygen isotopic composition $\left({ }^{17} \mathrm{O}\right.$ excess, $\left.\Delta^{17} \mathrm{O}\right)$ in nitrate. At the airsnow interface at Dome C (DC; $\left.75^{\circ} 06^{\prime} \mathrm{S}, 123^{\circ} 19^{\prime} \mathrm{E}\right)$, the model reproduces well the values of $\delta^{15} \mathrm{~N}$ in atmospheric and surface snow (skin layer) nitrate as well as in the $\delta^{15} \mathrm{~N}$ profile in DC snow, including the observed extraordinary high positive values (around $+300 \%$ ) below $2 \mathrm{~cm}$. The model also captures the observed variability in nitrate mass fraction in the snow. While oxygen data are qualitatively reproduced at the air-snow interface at DC and in East Antarctica, the simulated $\Delta^{17} \mathrm{O}$ values underestimate the observed $\Delta{ }^{17} \mathrm{O}$ values by several per mill. This is explained by the simplifications made in the description of the atmospheric cycling
\end{abstract}

and oxidation of $\mathrm{NO}_{2}$ as well as by our lack of understanding of the $\mathrm{NO}_{x}$ chemistry at Dome $\mathrm{C}$. The model reproduces well the sensitivity of $\delta^{15} \mathrm{~N}, \Delta^{17} \mathrm{O}$ and the apparent fractionation constants $\left({ }^{15} \varepsilon_{\text {app }},{ }^{17} E_{\text {app }}\right)$ to the snow accumulation rate. Building on this development, we propose a framework for the interpretation of nitrate records measured from ice cores. Measurement of nitrate mass fractions and $\delta^{15} \mathrm{~N}$ in the nitrate archived in an ice core may be used to derive information about past variations in the total ozone column and/or the primary inputs of nitrate above Antarctica as well as in nitrate trapping efficiency (defined as the ratio between the archived nitrate flux and the primary nitrate input flux). The $\Delta{ }^{17} \mathrm{O}$ of nitrate could then be corrected from the impact of cage recombination effects associated with the photolysis of nitrate in snow. Past changes in the relative contributions of the $\Delta^{17} \mathrm{O}$ in the primary inputs of nitrate and the $\Delta^{17} \mathrm{O}$ in the locally cycled $\mathrm{NO}_{2}$ and that inherited from the additional $\mathrm{O}$ atom in the oxidation of $\mathrm{NO}_{2}$ could then be determined. Therefore, information about the past variations in the local and long-range processes operating on reactive nitrogen species could be obtained from ice cores collected in lowaccumulation regions such as the Antarctic Plateau. 


\section{Introduction}

Ice cores from the East Antarctic Plateau provide long-term archives of Earth's climate and atmospheric composition such as past relative changes in local temperatures and global atmospheric $\mathrm{CO}_{2}$ levels (EPICA community members, 2004, for example). Soluble impurities have been used in such cores as tracers of biogeochemical processes. As the end product of the atmospheric oxidation of $\mathrm{NO}_{x}\left(\mathrm{NO}+\mathrm{NO}_{2}\right)$, nitrate $\left(\mathrm{NO}_{3}^{-}\right)$is a major ion found in Antarctic snow (Wolff, 1995). Its primary origins are a combination of inputs from the stratosphere and from low-latitude sources (Legrand and Delmas, 1986; Legrand and Kirchner, 1990). Stratospheric inputs of nitrate are believed to be mostly caused by the sedimentation of polar stratospheric clouds (PSCs) in winter (Seinfeld and Pandis, 1998; Jacob, 1999). The interpretation of nitrate deep ice-core records remains elusive (e.g., Wolff et al., 2010), mainly because its deposition to the snow is not irreversible (Traversi et al., 2014, and references therein) at low-accumulation sites such as Dome C or Vostok $\left(78^{\circ} 27^{\prime} \mathrm{S}\right.$, $106^{\circ} 50^{\prime} \mathrm{E}$; elevation $3488 \mathrm{~m}$ a.s.1.).

Nitrate loss from snow can occur through the physical release of $\mathrm{HNO}_{3}$ (via evaporation and/or desorption, also referred to as simply "evaporation") or through the UV photolysis of the $\mathrm{NO}_{3}^{-}$ion (Röthlisberger et al., 2000). At wavelengths $(\lambda)$ below $345 \mathrm{~nm}, \mathrm{NO}_{3}^{-}$photolyzes to form $\mathrm{NO}_{2}$ (Chu and Anastasio, 2003) or $\mathrm{NO}_{2}^{-}$ion (Chu and Anastasio, 2007), which can form HONO at $\mathrm{pH}<7$. Nitrate photolysis is quantitatively represented by its rate constant $(J)$ expressed as follows:

$J=\int \Phi(\lambda, T) \sigma(\lambda, T) I(\lambda, \theta, z) \mathrm{d} \lambda$,

with $\Phi$ the quantum yield, $\sigma$ the absorption cross section of $\mathrm{NO}_{3}^{-}, I$ the actinic flux, $\lambda$ the wavelength, $T$ the temperature, $\theta$ the solar zenith angle and $z$ the depth. Two recent laboratory studies have investigated nitrate photolysis in Dome C (DC; $75^{\circ} 06^{\prime} \mathrm{S}, 123^{\circ} 19^{\prime} \mathrm{E}$ ) snow. Meusinger et al. (2014) reported the quantum yields for the photolysis of either photolabile or buried nitrate. The terms "photolabile" and "buried" were introduced by Meusinger et al. (2014) as different "domains", i.e., different physicochemical properties of the region around the nitrate chromophore. Berhanu et al. (2014a) reported the absorption cross section of ${ }^{14} \mathrm{NO}_{3}^{-}$and ${ }^{15} \mathrm{NO}_{3}^{-}$ in Antarctic snow at a given temperature, using a new semiempirical zero-point energy shift ( $\triangle \mathrm{ZPE})$ model.

Nitrate deposition to the snow can occur through various mechanisms, including co-condensation and dry deposition (Röthlisberger et al., 2000; Frey et al., 2009). Within the snowpack, nitrate can be contained as $\mathrm{HNO}_{3}$ in the gas phase, adsorbed on the surface or dissolved in the snow ice matrix. It can be exchanged between these compartments by adsorption, desorption or diffusion processes (Dominé et al., 2007), which can lead to a redistribution of nitrate inside the snowpack, a process which tends to smooth the nitrate mass fraction profiles (Wagenbach et al., 1994). Phase change and recrystallization processes (snow metamorphism) can further promote the mobility of nitrate, thus potentially modifying the location of nitrate (Dominé and Shepson, 2002; Kaempfer and Plapp, 2009), with implications for its availability for photolysis and desorption processes (Dominé and Shepson, 2002). For instance, it is more available for photolysis when adsorbed on the snow ice matrix surface, where cage recombination effects are less likely to occur (Chu and Anastasio, 2003; Meusinger et al., 2014, and references therein).

The photolysis of nitrate has been identified to be an important mechanism for nitrate mass loss in the snow on the Antarctic Plateau (Frey et al., 2009; France et al., 2011). One consequence of the release of nitrogen oxides through this process is the complex recycling of nitrate at the airsnow interface (Davis et al., 2008). Here we refer to "nitrate recycling" as the combination of $\mathrm{NO}_{x}$ production from nitrate photolysis in snow, the subsequent atmospheric processing and oxidation of $\mathrm{NO}_{x}$ to form atmospheric nitrate, the deposition (dry and/or wet) of a fraction of the product, and the export of another fraction. Davis et al. (2008) and Frey et al. (2009) suggested the following conceptual model for nitrate recycling in the atmosphere-snow system for the Antarctic Plateau, where annual snow accumulation rates are low. The stratospheric component of nitrate is deposited to the surface in late winter, in a shallow surface snow layer of approximately uniform concentration (Savarino et al., 2007). The increase in surface UV radiation in spring initiates a photolysis-driven redistribution process of $\mathrm{NO}_{3}^{-}$, which continues throughout the sunlit season, resulting in the almost complete depletion of the bulk snow nitrate reservoir. In summer, this results in a strongly asymmetric distribution of total $\mathrm{NO}_{3}^{-}$within the atmosphere-snow column as previously noted by Wolff et al. (2002), with the majority of the mass of nitrate residing in a "skin layer" (the top millimeter of snow, often in the form of surface hoar) and only a small fraction in the atmospheric column above it or in the snow below.

The post-depositional processes as described above thus strongly imprint the stable isotopic composition of nitrate in snow at low-accumulation sites (Blunier et al., 2005; Frey et al., 2009; Erbland et al., 2013). Nitrate is composed of $\mathrm{N}$ and $\mathrm{O}$ atoms and has the following stable isotope ratios: ${ }^{15} \mathrm{~N} /{ }^{14} \mathrm{~N},{ }^{17} \mathrm{O} /{ }^{16} \mathrm{O}$ and ${ }^{18} \mathrm{O} /{ }^{16} \mathrm{O}$, from which isotopic enrichment values of $\delta^{15} \mathrm{~N}, \delta^{17} \mathrm{O}$ and $\delta^{18} \mathrm{O}$ can be computed. The $\delta$ scale is defined as $\delta=R_{\text {spl }} / R_{\text {ref }}-1$, with $R$ denoting the isotope ratios, the references being $\mathrm{N}_{2}$-AIR for $\mathrm{N}$ and VSMOW for $\mathrm{O}$. The quantification of the integrated isotopic effects of post-depositional processes is achieved by calculating apparent fractionation constants $\left({ }^{15} \varepsilon_{\text {app }},{ }^{17} \varepsilon_{\text {app }}\right.$ and ${ }^{18} \varepsilon_{\text {app }}$ ) from isotopic and mass fraction profiles of nitrate in the top decimeters of snow (Blunier et al., 2005; Frey et al., 2009; Erbland et al., 2013). For instance, ${ }^{15} \varepsilon_{\text {app }}$ is calculated from the following equation, which represents a Rayleigh model and assumes a single loss process and the 
immediate and definitive removal of the lost nitrate fraction:

$\ln \left(\delta^{15} \mathrm{~N}_{f}+1\right)={ }^{15} \varepsilon_{\mathrm{app}} \times \ln f+\ln \left(\delta^{15} \mathrm{~N}_{0}+1\right)$,

with $\delta^{15} \mathrm{~N}_{f}$ and $\delta^{15} \mathrm{~N}_{0}$ the $\delta$ value in the remaining and initial snow nitrate and $f$ the remaining mass fraction. Comparison of apparent fractionation constants obtained in the field to the fractionation constants associated with the physical and photochemical nitrate loss processes has demonstrated that the UV photolysis of nitrate is the dominant mass loss process on the Antarctic Plateau (Erbland et al., 2013). As a consequence, $\delta^{15} \mathrm{~N}$ in nitrate archived beyond the snow photic zone (the zone of active photochemistry) on plateau sites depends on ${ }^{15} \varepsilon_{\text {pho }}$, the ${ }^{15} \mathrm{~N} /{ }^{14} \mathrm{~N}$ fractionation constant associated with nitrate photolysis (Frey et al., 2009; Erbland et al., 2013) and the magnitude of the loss $(1-f)$ (Eq. 2). Because of its link with the residence time of nitrate in the photic zone, a strong relationship has been found between the snow accumulation rate $(A)$ and the degree of isotopic fractionation $\delta^{15} \mathrm{~N}$ in the archived (asymptotic, "as.") nitrate (Freyer et al., 1996; Erbland et al., 2013). At a given actinic flux $I$, the ${ }^{15} \mathrm{~N} /{ }^{14} \mathrm{~N}$ fractionation constant induced by nitrate photolysis is calculated as the ratio of the photolysis rate constants:

${ }^{15} \varepsilon_{\mathrm{pho}}=\frac{J^{\prime}}{J}-1$

with $J$ and $J^{\prime}$ the photolytic rate constants of ${ }^{14} \mathrm{NO}_{3}^{-}$and ${ }^{15} \mathrm{NO}_{3}^{-}$, respectively. The Rayleigh distillation model applied to a single process in an open system gives the $\delta^{15} \mathrm{~N}$ values in the remaining fraction by applying Eq. (2) using ${ }^{15} \varepsilon_{\text {pho. }}$.

The three stable isotopes of oxygen allow to define a unique tracer, $\Delta^{17} \mathrm{O}=\delta^{17} \mathrm{O}-0.52 \times \delta^{18} \mathrm{O}$, which is referred to as "oxygen isotope anomaly" or "17 O excess". An apparent fractionation constant $\left({ }^{17} E_{\text {app }}\right)$ can be computed for $\Delta^{17} \mathrm{O}$ using Eq. (2), similar to what can be done for isotopic enrichment values $(\delta)$. Most oxygen-bearing species feature $\Delta^{17} \mathrm{O}=0 \%$, but some species such as atmospheric nitrate can partially inherit the large positive oxygen isotope anomaly transferred from ozone, thus reflecting the relative contribution of various oxidants involved in its formation (Michalski et al., 2003; Morin et al., 2007, 2008, 2009, 2011; Kunasek et al., 2008; Alexander et al., 2009).

Erbland et al. (2013) documented year-round measurements of $\Delta^{17} \mathrm{O}$ in atmospheric and skin layer nitrate at Dome $\mathrm{C}$ and on the Antarctic Plateau, which revealed a photolytically driven isotopic equilibrium between the two compartments, i.e., the $\Delta^{17} \mathrm{O}$ atmospheric signal is mostly conserved in the skin layer. In contrast to $\delta^{15} \mathrm{~N}$, post-depositional processes have a small impact on $\Delta^{17} \mathrm{O}$ in nitrate snow profiles (Frey et al., 2009), so that a large portion of the atmospheric signature is transferred in snow nitrate at depth despite a small dampening effect (Erbland et al., 2013). Indeed, laboratory studies have shown that although nitrate photolysis in snow has a purely mass-dependent isotopic effect (i.e., in theory not impacting the $\Delta^{17} \mathrm{O}$ ), this process leads to a lower $\Delta^{17} \mathrm{O}\left(\mathrm{NO}_{3}^{-}\right)$in the remaining phase because of the cage recombination (hereafter termed "cage effects") of the primary photo-fragment of $\mathrm{NO}_{3}^{-}$(McCabe et al., 2005). Immediately following nitrate photolysis, a fraction of the photo-fragment $\mathrm{NO}_{2}$ reacts back with $\mathrm{OH}$ radicals to form $\mathrm{HNO}_{3}$, but some of the $\mathrm{OH}$ radicals exchange $\mathrm{O}$ atoms with water molecules in the ice lattice, so that the recombined $\mathrm{HNO}_{3}$ contains an oxygen atom replaced by one originating from $\mathrm{H}_{2} \mathrm{O}$ and featuring $\Delta{ }^{17} \mathrm{O}\left(\mathrm{H}_{2} \mathrm{O}\right)=0 \%$.

This article is a companion paper to "Air-snow transfer of nitrate on the East Antarctic Plateau - Part 1: Isotopic evidence for a photolytically driven dynamic equilibrium in summer", published in the same journal (Erbland et al., 2013). In this study, we test the nitrate recycling theory and evaluate it in light of the field isotopic measurements presented in Erbland et al. (2013) and obtained at the air-snow interface at Dome $\mathrm{C}$ as well as in several shallow snow pits collected at this site and on a large portion of the East Antarctic Plateau. Testing this theory requires the building of a numerical model which represents nitrate recycling at the airsnow interface and describes the evolution of the nitrogen and oxygen stable isotopic composition of nitrate with various constraints from key environmental variables such as the solar zenith angle and the available UV radiation. Various models have been developed to investigate the physical and chemical processes involving nitrate in snow and their impact on the atmospheric chemistry in Antarctica (Wang et al., 2007; Liao and Tan, 2008; Boxe and Saiz-Lopez, 2008) and in Greenland (Jarvis et al., 2008, 2009; Kunasek et al., 2008; Thomas et al., 2011; Zatko et al., 2013). Those models are adapted to short time periods (hours to days, typically) and focus on processes at play in the atmosphere and in the nearsurface snowpack. In this article, we present a new model called TRANSITS (TRansfer of Atmospheric Nitrate Stable Isotopes To the Snow), which shares some hypotheses with the modeling effort of Wolff et al. (2002) and the conceptual model of Davis et al. (2008). Together with a more realistic representation of some processes, the main novelty brought by the TRANSITS model is the incorporation of the oxygen and nitrogen stable isotopic ratios in nitrate as a diagnostic and evaluation tool in the ideal case of the East Antarctic Plateau, where snow accumulation rates are low and where nitrate mass loss can be mostly attributed to UV photolysis. The following key questions are addressed in this work:

1. Is the theory behind the TRANSITS model compatible with the available field measurements?

2. What controls the mass and isotopic composition $\left(\delta^{15} \mathrm{~N}\right.$ and $\left.\Delta^{17} \mathrm{O}\right)$ of the archived nitrate?

The model is first described. Then it is evaluated by comparing its outputs to observations in the case of simulations at the air-snow interface at Dome $\mathrm{C}$ as well as in East Antarctic sites. A framework for the interpretation of the nitrate isotope 
record in deep ice cores is then given in light of sensitivity tests of the model.

\section{Description of the TRANSITS model}

\subsection{Overview}

TRANSITS is a multi-layer, 1-D isotopic model which represents a snow and atmosphere column with an arbitrary surface area and shape such that, conceptually, there is a net lateral export (e.g., the column covers a part of the East Antarctic Plateau). The snowpack is set to a constant height of $1 \mathrm{~m}$ and a snow density $(\rho)$ is assumed to be constant. The $1 \mathrm{~m}$ snowpack is divided into 1000 layers of a $1 \mathrm{~mm}$ thickness, which means that the snow mass is the same in each layer. The atmospheric boundary layer (ABL) is represented by a single box of a constant height.

The aim of the model is to conceptually represent nitrate recycling at the air-snow interface (UV photolysis of $\mathrm{NO}_{3}^{-}$, emission of $\mathrm{NO}_{x}$, local oxidation, deposition of $\mathrm{HNO}_{3}$ ) and to model the impact on nitrogen and oxygen stable isotopic ratios in nitrate in both reservoirs. For the sake of simplicity, we will focus on $\Delta^{17} \mathrm{O}$ and $\delta^{15} \mathrm{~N} ; \delta^{18} \mathrm{O}$ is not included in the TRANSITS model. The TRANSITS model is neither a snowpack nor a gas-phase chemistry model and it does not aim at representing all the mechanisms responsible for nitrate mobility, neither at the snowpack scale nor at the snow microstructure scale.

Figure 1 provides an overview of the TRANSITS model. The loss of nitrate from snow is assumed to only occur through UV photolysis, because the physical release of $\mathrm{HNO}_{3}$ is negligible (Erbland et al., 2013). TRANSITS does not treat different nitrate domains in snow, and it is hypothesized that nitrate photolysis only produces $\mathrm{NO}_{2} \cdot \mathrm{NO}_{2}$ undergoes local cycling with $\mathrm{NO}$, which modifies its oxygen isotope composition while the $\mathrm{N}$ atom is preserved. One computed year is divided into 52 time steps of approximately 1 week $(\Delta t=606877 \mathrm{~s})$, a time step sufficiently long to assume quantitative oxidation of $\mathrm{NO}_{2}$ into $\mathrm{HNO}_{3}$. The chosen time step also allows for operation at the annual timescale, which is best suited to long simulation durations. For simplicity, we assume that $\mathrm{NO}_{2}$ oxidation occurs through reaction with $\mathrm{OH}$ radicals. The deposition of atmospheric $\mathrm{HNO}_{3}$ is assumed to occur by the uptake at the surface of the snowpack. Nitrate diffusion is assumed to occur in the snowpack at the macroscopic scale and is solved at a time resolution 50 times shorter than the model main time resolution (i.e., approximately $3.4 \mathrm{~h}$ ).

The lower limit of the modeled snowpack is set at $1 \mathrm{~m}$ depth, a depth below which the actinic flux is always negligible. Below this depth, nitrate is considered to be archived. At every time step, the new snow layer accumulated at the top pushes a layer of snow below $1 \mathrm{~m}$ depth. This snow layer is archived and its nitrate mass fraction is frozen (and denoted
$\omega(\mathrm{FA}))$, thus allowing the calculation of the archived nitrate mass flux (FA, the product of $\omega(\mathrm{FA})$ and the archived snow mass during one time step). Table 1 provides a glossary of the abbreviations used in this paper, as well as their definition.

\subsection{Mass-balance equations}

In each box, the model solves the general "mass-balance" equation, which describes the temporal evolution of the concentration of the species $X$ (i.e., nitrate or $\mathrm{NO}_{2}$ ):

$\frac{\mathrm{d}}{\mathrm{d} t}[X]=\Sigma_{i} P_{i}-\Sigma_{j} L_{j}$.

The isotopic mass-balance equations are written as (Morin et al., 2011)

$$
\begin{gathered}
\frac{\mathrm{d}}{\mathrm{d} t}\left([X] \times \delta^{15} \mathrm{~N}\right)=\Sigma_{i}\left(P_{i} \times \delta^{15} \mathrm{~N}_{i}(X)\right)- \\
\left(\Sigma_{j}\left(L_{j} \times\left(\delta^{15} \mathrm{~N}(X)-{ }^{15} \varepsilon_{j}\right)\right)\right), \\
\frac{\mathrm{d}}{\mathrm{d} t}\left([X] \times \Delta^{17} \mathrm{O}\right)=\Sigma_{i}\left(P_{i} \times \Delta^{17} \mathrm{O}_{i}(X)\right) \\
-\left(\Sigma_{j} L_{j}\right) \times \Delta \Delta^{17} \mathrm{O}(X),
\end{gathered}
$$

where $P_{i}$ and $L_{j}$ respectively represent sources and sinks rates and $\delta^{15} \mathrm{~N}_{i}(X)$ and $\Delta{ }^{17} \mathrm{O}_{i}(X)$ the isotopic compositions of the $i$ sources. A ${ }^{15} \mathrm{~N} /{ }^{14} \mathrm{~N}$ fractionation constant $\left({ }^{15} \varepsilon_{j}\right)$ can be associated with loss process $j$. Within each box, incoming fluxes are positive and outgoing fluxes are negative. The concentration of nitrate in a snow layer is handled as "nitrate mass fraction", which is denoted $\omega\left(\mathrm{NO}_{3}^{-}\right)$.

For simplicity, fluxes will be hereafter denoted "FY", with "Y" a chain of capital letters. The primary input of nitrate to the modeled atmosphere is denoted FPI and is the combination of a stratospheric flux (FS) and the horizontal longdistance transport (FT) of nitrate. Therefore, FPI $=$ FS + FT. The two primary origins of nitrate are defined by constant $\Delta \Delta^{17} \mathrm{O}$ and $\delta^{15} \mathrm{~N}$ signatures denoted $\Delta^{17} \mathrm{O}(\mathrm{FS}), \Delta^{17} \mathrm{O}(\mathrm{FT})$, $\delta^{15} \mathrm{~N}(\mathrm{FS})$ and $\delta^{15} \mathrm{~N}(\mathrm{FT})$. The secondary source of nitrate to the atmosphere is the local oxidation of $\mathrm{NO}_{2}$ occurring after nitrate photolysis in the snow (FP).

Nitrate is removed from the atmospheric box via two processes. Large-scale horizontal air masses movement can lead to a loss of nitrate, hereafter named "horizontal export flux" (FE). The export of nitrate is assumed to preserve the $\Delta^{17} \mathrm{O}$ and $\delta^{15} \mathrm{~N}$ values. Nitrate can also be lost via deposition (FD) to the snow, which is the sole nitrate source to the snowpack. This flux is obtained by solving the mass balance in the atmospheric box and is added to the topmost layer of the snowpack at each model time step.

The loss of nitrate from the snowpack is assumed to occur through nitrate UV photolysis only. Within the snowpack, nitrate is redistributed by macroscopic diffusion, which is assumed to preserve $\Delta^{17} \mathrm{O}$ and $\delta^{15} \mathrm{~N}$. 

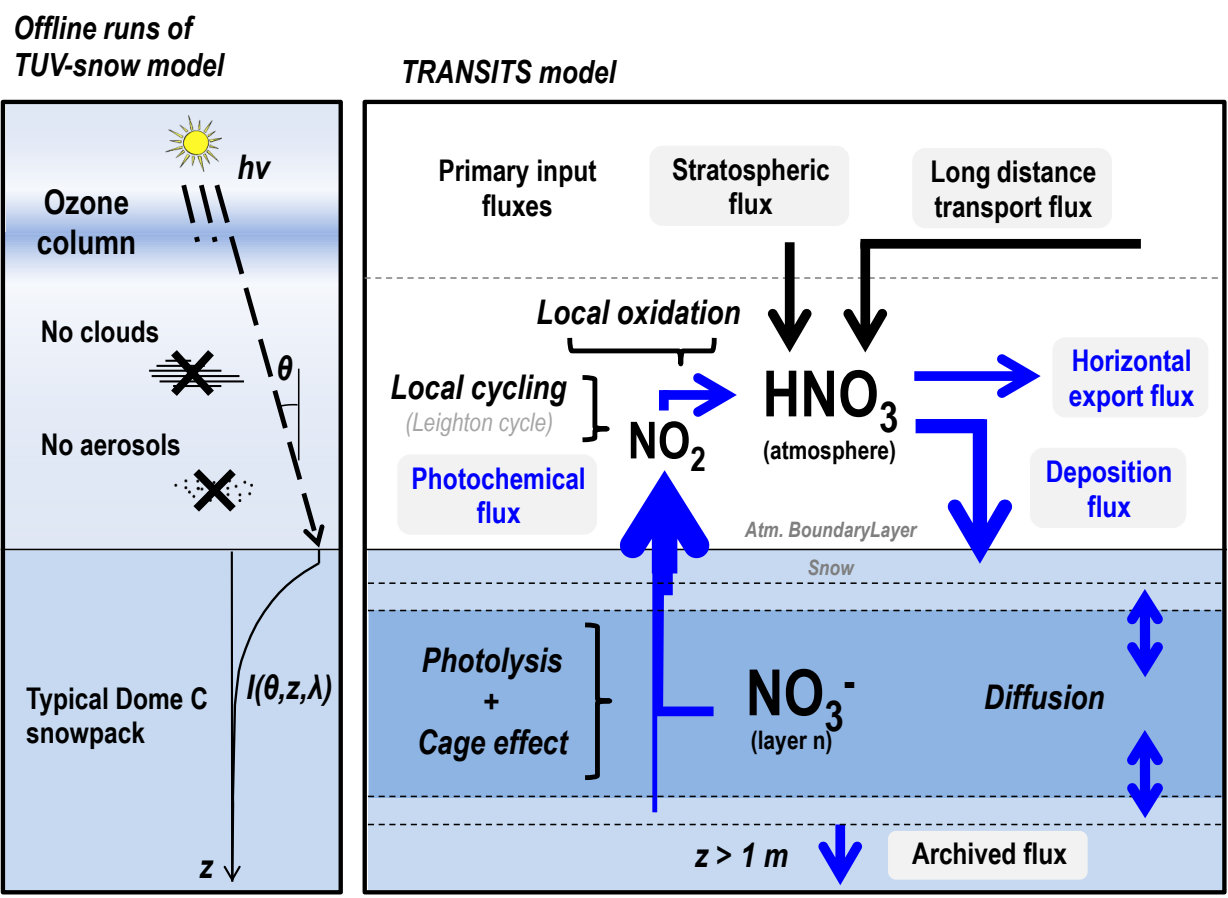

Figure 1. Overview of the TRANSITS model.

\subsection{Physical properties of the atmosphere and the snowpack}

The height of the ABL is denoted $h_{\mathrm{AT}}$. This single atmospheric box is assumed to be well mixed at all times, which is justified at the time resolution of the model (ca. 1 week). Hereafter we denote $\gamma\left(\mathrm{NO}_{3}^{-}\right)$the nitrate concentration in the atmospheric box. In TRANSITS, the time evolution of this variable is prescribed by observations.

Physical properties of the snowpack influencing radiative transfer in snow are fixed, according to a typical Dome C snowpack with a constant layering throughout the year as defined in France et al. (2011): it is made of 11 and $21 \mathrm{~cm}$ of soft and hard windpack snow at the top and hoar-like snow below with their respective snow densities, scattering and absorption coefficients at $350 \mathrm{~nm}$. At Dome $\mathrm{C}$, the $e$-folding attenuation depths (denoted $\eta$ ) for the three snow layers are fairly constant in the range 350-400 $\mathrm{nm}$ (France et al., 2011), and unpublished data from the same experiments show that this observation can be extended to $320-350 \mathrm{~nm}$. The snow optical properties taken at $350 \mathrm{~nm}$ are therefore assumed to be valid for the whole $280-350 \mathrm{~nm}$ range of interest for nitrate photolysis. This hypothesis is supported twofold. First, $e$ folding attenuation depths measured at Alert, Nunavut, show no significant sensitivity to wavelengths in the $310-350 \mathrm{~nm}$ range (King and Simpson, 2001). Secondly, $\eta$ values measured in a recent laboratory study only show a weak (10\%) decrease from 350 to $280 \mathrm{~nm}$ (Meusinger et al., 2014). Under Dome $\mathrm{C}$ conditions, the absorption of UV by impurities is small and the depth attenuation of UV light is mostly driven by light scattering (France et al., 2011). As a consequence, $\eta$ is assumed to be independent of the impurities content in the snow - in this case nitrate itself.

While optical calculations are based on a realistic snowpack, nitrate mass and isotopic computations are performed assuming a constant snow density, which simplifies the computation. One consequence of this simplification is that our modeled $e$-folding depths are independent of snow density, which we acknowledge is not realistic (Chan et al., 2015).

Assuming that the snow density is constant means that the snowpack does not undergo densification. For simplicity, we also hypothesize that no sublimation, wind redistribution, melt or flow occur and that the surface of the snowpack is assumed to be flat and insensitive to erosion.

\subsection{Parameterization of chemical processes}

Figure 2 provides an overview of the physical and chemical processes included in TRANSITS as well as the parameters and input variables of interest for each process. Table 2 lists the chemical and physical processes included or not in the model. A description of the parameterization of each process is given below.

\subsubsection{Nitrate UV photolysis}

Nitrate photolysis is at the core of the model. At each time step, the photolyzed nitrate mass in a layer equals $e^{-J \Delta t} \times m$, where $m$ is the initial nitrate mass in the layer and $J$ is the photolysis rate constant of $\mathrm{NO}_{3}^{-}$(Eq. 1). The UV actinic 
Table 1. List of the abbreviations used in this paper.

\begin{tabular}{|c|c|c|c|}
\hline Compartment & Abbreviation & Unit & Definition \\
\hline \multirow[t]{22}{*}{ Atmosphere } & FS & $\mathrm{kgN} \mathrm{m}^{-2} \mathrm{a}^{-1}$ & Stratospheric input flux \\
\hline & FT & $\mathrm{kgN} \mathrm{m}^{-2} \mathrm{a}^{-1}$ & Tropospheric input flux \\
\hline & FPI & $\mathrm{kgN} \mathrm{m}^{-2} \mathrm{a}^{-1}$ & Primary input flux $(\mathrm{FPI}=\mathrm{FS}+\mathrm{FT})$ \\
\hline & FE & $\mathrm{kgN} \mathrm{m}^{-2} \mathrm{a}^{-1}$ & Exported flux $(\mathrm{FE}=\mathrm{FPI}-\mathrm{FA})$ \\
\hline & FA & $\mathrm{kgN} \mathrm{m}^{-2} \mathrm{a}^{-1}$ & Archived flux \\
\hline & FD & $\mathrm{kgN} \mathrm{m}^{-2} \mathrm{a}^{-1}$ & Deposited flux \\
\hline & FP & $\mathrm{kgN} \mathrm{m}^{-2} \mathrm{a}^{-1}$ & Photolytic flux \\
\hline & $\delta^{15} \mathrm{~N}(\mathrm{FX})$ & $\%$ & $\delta^{15} \mathrm{~N}$ in flux $\mathrm{FX}$ \\
\hline & $\Delta^{17} \mathrm{O}(\mathrm{FX})$ & $\%$ & $\Delta^{17} \mathrm{O}$ in flux FX \\
\hline & $\gamma\left(\mathrm{NO}_{3}^{-}\right)$ & $n g m^{-3}$ & Atmospheric nitrate concentration \\
\hline & $h_{\mathrm{AT}}$ & $\mathrm{m}$ & Height of the ABL \\
\hline & $f_{\exp }$ & Dimensionless & Exported fraction of the incoming fluxes to the atmospheric box \\
\hline & $T$ & $\mathrm{~K}$ & Near-ground atmospheric temperature \\
\hline & $P$ & mbar & Near-ground atmospheric pressure \\
\hline & ${ }^{15} \varepsilon_{\mathrm{dep}}$ & $\%$ & ${ }^{15} \mathrm{~N} /{ }^{14} \mathrm{~N}$ fractionation constant associated with nitrate deposition \\
\hline & $J\left(\mathrm{NO}_{2}\right)$ & $\mathrm{s}^{-1}$ & Photolytic rate constant of $\mathrm{NO}_{2}$ \\
\hline & $\alpha$ & Dimensionless & Leighton cycle perturbation factor \\
\hline & $\Delta^{17} \mathrm{O}\left(\mathrm{O}_{3}\right)_{\text {bulk }}$ & $\%$ & ${ }^{17} \mathrm{O}$ excess in bulk ozone \\
\hline & $\theta$ & & Solar zenith angle \\
\hline & $I$ & $\mathrm{~cm}^{-2} \mathrm{~s}^{-1} \mathrm{~nm}^{-1}$ & Actinic flux \\
\hline & $q$ & Dimensionless & Actinic flux enhancement factor \\
\hline & PSS & - & Photochemical steady state \\
\hline \multirow[t]{20}{*}{ Snow } & $A$ & $\mathrm{~kg} \mathrm{~m}^{-2} \mathrm{a}^{-1}$ & Annual snow accumulation rate \\
\hline & $\rho$ & $\mathrm{kg} \mathrm{m}^{-3}$ & Snow density \\
\hline & $f_{\text {cage }}$ & Dimensionless & Cage effect factor \\
\hline & $D$ & $\mathrm{~m}^{2} \mathrm{~s}^{-1}$ & Diffusion coefficient \\
\hline & $\omega\left(\mathrm{NO}_{3}^{-}\right)$ & $\mathrm{ng} \mathrm{g}^{-1}$ & Nitrate mass fraction \\
\hline & $m_{50 \mathrm{~cm}}\left(\mathrm{NO}_{3}^{-}\right)$ & $\mathrm{mgN} \mathrm{m}^{-2}$ & Nitrate mass in the top $5 \mathrm{~cm}$ \\
\hline & $\Delta^{17} \mathrm{O}_{50 \mathrm{~cm}}\left(\mathrm{NO}_{3}^{-}\right)$ & $\%$ & $\Delta^{17} \mathrm{O}$ of nitrate in the top $5 \mathrm{~cm}$ \\
\hline & $\delta^{15} \mathrm{~N}_{50 \mathrm{~cm}}\left(\mathrm{NO}_{3}^{-}\right)$ & $\%$ & $\delta^{15} \mathrm{~N}$ of nitrate in the top $5 \mathrm{~cm}$ \\
\hline & $\Phi$ & Dimensionless & Quantum yield in nitrate photolysis \\
\hline & $\sigma$ & $\mathrm{cm}^{2}$ & Absorption cross section of ${ }^{14} \mathrm{NO}_{3}^{-}$ \\
\hline & $\sigma^{\prime}$ & $\mathrm{cm}^{2}$ & Absorption cross section of ${ }^{15} \mathrm{NO}_{3}^{-}$ \\
\hline & $k$ & Dimensionless & Photic zone compression factor \\
\hline & $J$ & $\mathrm{~s}^{-1}$ & Photolytic rate constant of ${ }^{14} \mathrm{NO}_{3}^{-}$ \\
\hline & $J^{\prime}$ & $\mathrm{s}^{-1}$ & Photolytic rate constant of ${ }^{15} \mathrm{NO}_{3}^{-}$ \\
\hline & $\eta$ & $\mathrm{m}$ & $e$-folding attenuation depth \\
\hline & ${ }^{15} \varepsilon_{\text {app }}$ & $\%$ & Apparent ${ }^{15} \mathrm{~N} /{ }^{14} \mathrm{~N}$ fractionation constant \\
\hline & ${ }^{17} E_{\text {app }}$ & $\%$ & ${ }^{17} \mathrm{O}$-excess apparent fractionation constant \\
\hline & ${ }^{15} \varepsilon_{\text {pho }}$ & $\%$ & ${ }^{15} \mathrm{~N} /{ }^{14} \mathrm{~N}$ fractionation constant associated with nitrate photolysis \\
\hline & CYCL & Dimensionless & Average number of recyclings in a box \\
\hline & $\mathrm{ANR}(\mathrm{FA})$ & Dimensionless & Average number of recyclings undergone by the archived nitrate \\
\hline
\end{tabular}

fluxes $(I)$ required for the calculation of $J$ have been computed in the 280-350 nm range using offline runs of the TUVsnow radiative transfer model (Lee-Taylor and Madronich, 2002). TUV-snow has been run for the DC location and snowpack for various dates (i.e., solar zenith angle, $\theta$ ), assuming a clear aerosol-free sky and using the extraterrestrial irradiance from Chance and Kurucz (2010) and a constant Earth-Sun distance as that of 27 December 2010. Ozone pro- files from 25 to $500 \mathrm{DU}$ with a resolution of $25 \mathrm{DU}$ have been used to run the radiative transfer model. Next, we denote $k$ the "photic zone compression factor", which represents variations in depth of the photic zone under the effect of changes in physical properties of the snowpack due to snow metamorphism or in chemical properties. In Eq. (1), the term " $z$ " is therefore replaced by " $z / k$ ". A typical Dome $\mathrm{C}$ snowpack is represented by a $k$ value of 1 . Lower $k$ values mean that the 


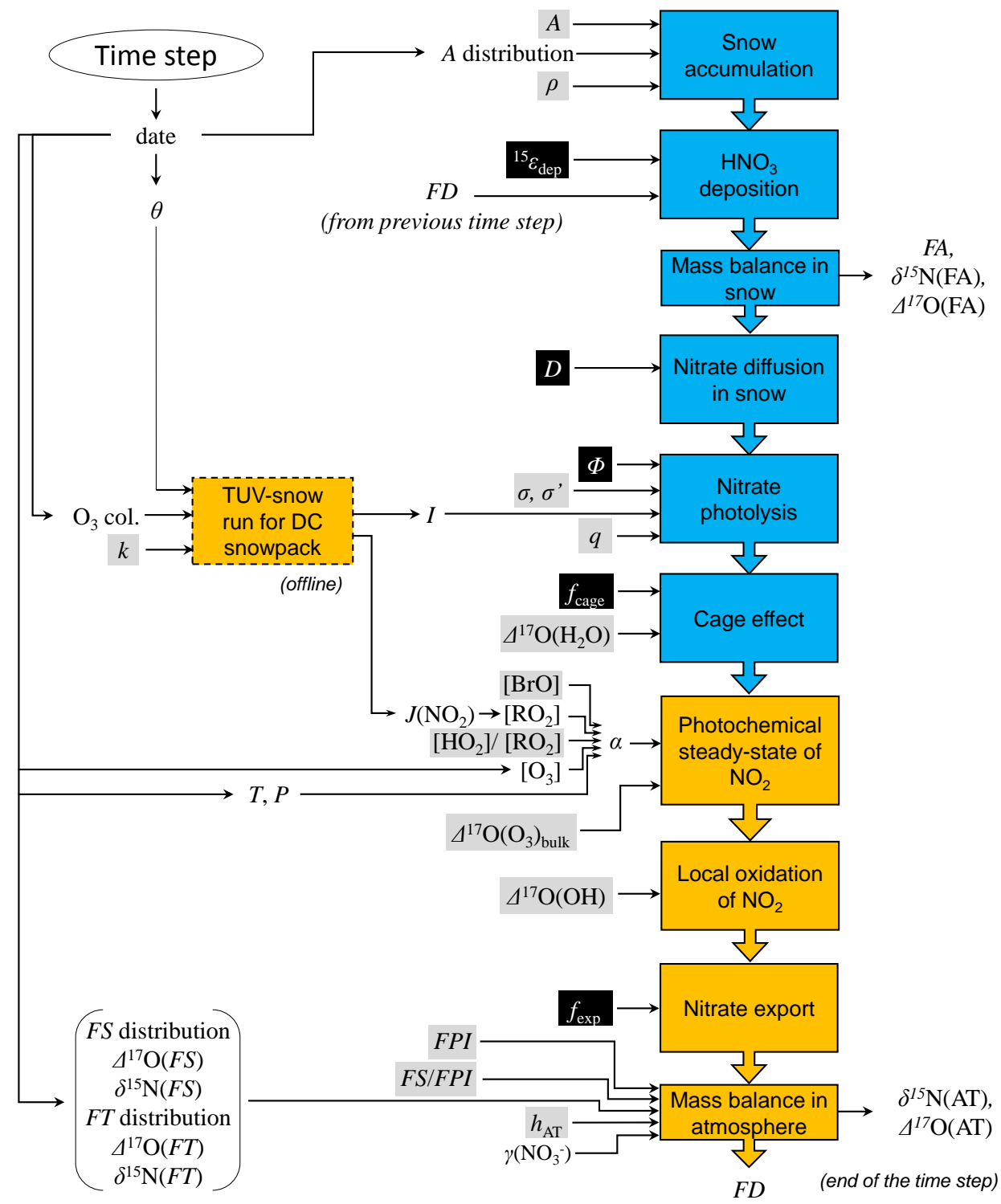

Figure 2. Schematic view of the processes included in TRANSITS (one time step is shown). The orange and blue boxes represent processes occurring in the atmosphere and the snowpack, respectively. Arrows entering from the left and leaving to the right represent inputs and outputs for each process. For the sake of clarity, we only display the input time variables (black font on white background), the fixed parameters (black on grey) and the adjustment parameters (white on black).

UV radiation is extinguished more rapidly with depth. Last, we denote $q$ the "actinic flux enhancement factor", which accounts for variations in the actinic flux received at the snow surface and hence at depth. This parameter represents changes in the actinic flux emitted from the Sun or changes in the Earth-Sun distance due to variations in the Earth's orbit. In Eq. (1), the term " $I$ " is therefore replaced by " $q \times I$ ". In the modern DC case, $q$ is set to 1 .

Another key control on $J$ is the quantum yield $(\Phi)$, a parameter which is strongly governed by nitrate location in the snow ice matrix and which corresponds to nitrate availability to photolysis. Nitrate is assumed to deposit to the snow under the form of $\mathrm{HNO}_{3}$, but its adsorption and/or dissociation to $\mathrm{NO}_{3}^{-}+\mathrm{H}^{+}$are not explicitly represented. Indeed, modeling nitrate location in the snow is well beyond the scope of the present study, and a recent molecular dynamic study demonstrated the fast ionization of $\mathrm{HNO}_{3}$ (picosecond timescale) at the ice interface (Riikonen et al., 2014). For the sake of simplicity, we assume that nitrate location in the snow ice matrix is constant. Therefore, $\Phi$ is set to a constant value.

Nitrate photolysis is assumed to only produce $\mathrm{NO}_{2}$. We acknowledge that other volatile nitrogen species such as $\mathrm{NO}$ or HONO may be produced. However, the photolysis of HONO in the atmosphere would rapidly produce NO, which would 
Table 2. List of the physical and chemical processes included and excluded in TRANSITS. Physical and chemical processes are written in roman and italic font, respectively.

\begin{tabular}{|c|c|c|}
\hline & Processes included & Processes excluded \\
\hline \multirow[t]{7}{*}{ Snow } & Snow accumulation & Snow densification \\
\hline & Macroscopic nitrate diffusion & Snow metamorphism (sublimation, melting) \\
\hline & & Snow erosion \\
\hline & & Snowpack ventilation \\
\hline & Nitrate UV photolysis & Nitrate location changes \\
\hline & Cage recombination effects & Nitrate saturation \\
\hline & & Physical release of $\mathrm{HNO}_{3}$ \\
\hline \multirow[t]{6}{*}{ Atmosphere } & Nitrate export & Variation of $\mathrm{ABL}$ \\
\hline & & Change in actinic flux due to clouds and aerosol \\
\hline & Primary nitrate inputs (strato. and tropo.) & \\
\hline & $\mathrm{HNO}_{3}$ dry deposition & \\
\hline & Local cycling of $\mathrm{NO}_{2}$ (conceptual) & Nitrate wet deposition \\
\hline & Location oxidation of $\mathrm{NO}_{2}$ by $\mathrm{OH}$ (conceptual) & Formal atmospheric chemistry \\
\hline
\end{tabular}

contribute to the $\mathrm{NO} / \mathrm{NO}_{2}$ cycle, similar to the $\mathrm{NO}_{2}$ production.

In the model, ${ }^{15} \varepsilon_{\text {pho }}$ is explicitly calculated at each time step and in each snow layer using Eq. (3). Because the layering of the physical properties of snow is fixed, ${ }^{15} \varepsilon_{\text {pho }}$ is constant with time. In the UV spectral range $(280-350 \mathrm{~nm})$, we have earlier assumed that $e$-folding depth is constant with wavelength; therefore, even though $\rho$ modulates the $e$ folding depth, ${ }^{15} \varepsilon_{\text {pho }}$ is independent of $\rho$ as well as depth, in agreement with the laboratory study of Berhanu et al. (2014a) and the field study of Berhanu et al. (2014b). As a consequence, the modeled ${ }^{15} \varepsilon_{\text {pho }}$ is entirely determined by the spectral distribution of the UV radiation received at the surface of the snowpack. The Rayleigh fractionation model applied to nitrate photolysis allows for the $\delta^{15} \mathrm{~N}$ in the photolyzed nitrate to be calculated, applying Eq. (2) with the use of ${ }^{15} \varepsilon_{\text {pho }}$, and $\delta^{15} \mathrm{~N}$ in the remaining nitrate by simple mass balance. Nitrate photolysis is assumed to be a massdependent process, so that the $\Delta^{17} \mathrm{O}$ in the initial, photolyzed and remaining nitrate is kept the same.

\subsubsection{Cage effect}

A constant fraction of the photolyzed nitrate (denoted $f_{\text {cage }}$ ) is assumed to undergo cage recombination, so that the photofragment $\mathrm{NO}_{2}$ reacts back with $\mathrm{OH}$ to re-form $\mathrm{HNO}_{3}$. In the cage effect process, $\mathrm{OH}$ is assumed to undergo an isotopic exchange with the water molecules of the ice lattice, so that the recombined $\mathrm{HNO}_{3}$ contains an oxygen atom originating from $\mathrm{H}_{2} \mathrm{O}$ and featuring $\Delta^{17} \mathrm{O}\left(\mathrm{H}_{2} \mathrm{O}\right)=0 \%$ (McCabe et al., 2005).

\subsubsection{Emission of $\mathrm{NO}_{2}$ and photochemical steady state}

The total photolytic flux (FP) represents the potential emission of $\mathrm{NO}_{2}$ from the snow to the atmosphere in accordance with the terminology used in France et al. (2011) and is the sum of the photolytic fluxes originating from each snow layer. A simple isotopic mass balance is applied to calculate the $\delta^{15} \mathrm{~N}$ and $\Delta^{17} \mathrm{O}$ of the photolytic loss flux. The extraction of $\mathrm{NO}_{2}$ from the snowpack is assumed to preserve its chemical and isotopic integrity - i.e., it does not undergo any chemical reaction or any isotopic fractionation in the snowpack.

Atmospheric chemistry is not explicitly modeled but only conceptually represented. $\Delta^{17} \mathrm{O}\left(\mathrm{NO}_{2}\right)$ is calculated following the approach of Morin et al. (2011), i.e., assuming photochemical steady state (PSS) of $\mathrm{NO}_{x}$ (when the photolytic lifetime of $\mathrm{NO}_{x}$ is shorter than $10 \mathrm{~min}$ ), an assumption which is valid for most of the sunlit season $\left(\tau\left(\mathrm{NO}_{2}\right)<10 \mathrm{~min}\right.$ from 27 September to 7 March; Frey et al., 2013, 2015). We therefore denote $\Delta^{17} \mathrm{O}\left(\mathrm{NO}_{2}\right.$, PSS $)$, the $\Delta^{17} \mathrm{O}$ value harbored by $\mathrm{NO}_{2}$ after its local cycling, which is represented by (Morin et al., 2008, 2011)

$\Delta^{17} \mathrm{O}\left(\mathrm{NO}_{2}, \mathrm{PSS}\right)=\alpha \times \Delta^{17} \mathrm{O}_{\mathrm{O}_{3}+\mathrm{NO}}\left(\mathrm{NO}_{2}\right)$,

with $\alpha$ a variable which accounts for the perturbation of the Leighton cycle by various radicals such as peroxy radicals $\left(\mathrm{RO}_{2}\right)$ and halogen oxides. For simplicity, we only consider $\mathrm{BrO}, \mathrm{HO}_{2}$ and $\mathrm{CH}_{3} \mathrm{O}_{2}$ to be the species perturbing the Leighton cycle. The $\alpha$ variable is calculated at each time step as in Eq. (8) assuming $\Delta^{17} \mathrm{O}\left(\mathrm{HO}_{2}\right)=\Delta^{17} \mathrm{O}\left(\mathrm{CH}_{3} \mathrm{O}_{2}\right)=$ $0 \%$ (Morin et al., 2011). Recent observations at DC seem to support the assumption $\Delta^{17} \mathrm{O}\left(\mathrm{CH}_{3} \mathrm{O}_{2}\right)=0 \%$ because $\mathrm{CH}_{3} \mathrm{O}_{2}$ may entirely originate from the reaction $R+\mathrm{O}_{2}$ or photolysis of species $\left(\mathrm{CH}_{3} \mathrm{CHO}\right)$ featuring $\Delta^{17} \mathrm{O}=0 \%$ (Kukui et al., 2014). The assumption $\Delta^{17} \mathrm{O}\left(\mathrm{HO}_{2}\right)=0 \%$ is 
also supported by the same observations, although $5 \%$ of $\mathrm{HO}_{2}$ originates from the reaction $\mathrm{O}_{3}+\mathrm{OH}$, which leads to $\Delta^{17} \mathrm{O}\left(\mathrm{HO}_{2}\right)>0 \%$. For simplicity, we stick to the assumption $\Delta^{17} \mathrm{O}\left(\mathrm{HO}_{2}\right)=0 \%$.

$\alpha=$

$\frac{k_{\mathrm{O}_{3}+\mathrm{NO}} \cdot\left[\mathrm{O}_{3}\right]+k_{\mathrm{BrO}+\mathrm{NO}} \cdot[\mathrm{BrO}]}{k_{\mathrm{O}_{3}+\mathrm{NO}} \cdot\left[\mathrm{O}_{3}\right]+k_{\mathrm{HO}_{2}+\mathrm{NO}} \cdot\left[\mathrm{HO}_{2}\right]+k_{\mathrm{CH}_{3} \mathrm{O}_{2}+\mathrm{NO}} \cdot\left[\mathrm{CH}_{3} \mathrm{O}_{2}\right]+k_{\mathrm{BrO}+\mathrm{NO}} \cdot[\mathrm{BrO}]}$,

with temperature- and pressure-dependent kinetic rate constants from Atkinson et al. $(2004,2006,2007)$ and the mixing ratios of $\mathrm{O}_{3}, \mathrm{BrO}, \mathrm{HO}_{2}$ and $\mathrm{CH}_{3} \mathrm{O}_{2}$ at the surface. Savarino et al. (2008) found that $\mathrm{O}_{3}$ preferentially transfers one of its terminal $\mathrm{O}$ atom when oxidizing $\mathrm{NO}$ with a probability of $92 \%$, which translates into the following equation:

$$
\begin{array}{r}
\Delta{ }^{17} \mathrm{O}_{\mathrm{O}_{3}+\mathrm{NO}}\left(\mathrm{NO}_{2}\right) \times 10^{3}= \\
1.18 \times \Delta^{17} \mathrm{O}_{(}\left(\mathrm{O}_{3}\right)_{\text {bulk }} \times 10^{3}+6.6,
\end{array}
$$

with $\Delta^{17} \mathrm{O}\left(\mathrm{O}_{3}\right)_{\text {bulk }}$ the isotopic anomaly of local bulk ozone. The $\mathrm{O}$ atom in $\mathrm{BrO}$ originates from the terminal oxygen atom of ozone through its reaction with bromine (Morin et al., 2007, and references therein). For simplicity, we assume that the $\mathrm{O}$ atom transferred during the $\mathrm{NO}$ oxidation by $\mathrm{O}_{3}$ and $\mathrm{BrO}$ is identical.

\subsubsection{Local oxidation of $\mathrm{NO}_{2}$}

$\mathrm{NO}_{2}$ is directly converted to $\mathrm{HNO}_{3}$ with the preservation of the $\mathrm{N}$ atom. However, a local additional oxygen atom is incorporated. This is a reasonable assumption given the short chemical lifetime of $\mathrm{NO}_{x}$ with respect to $\mathrm{NO}_{2}+\mathrm{OH}$ (on the order of hours) in comparison with the approximately 1-week time step used in the model. The $\Delta{ }^{17} \mathrm{O}$ of $\mathrm{HNO}_{3}$ is given by Eq. (10):

$\Delta^{17} \mathrm{O}\left(\mathrm{HNO}_{3}\right)=\frac{2}{3} \Delta^{17} \mathrm{O}\left(\mathrm{NO}_{2}\right)+\frac{1}{3} \Delta^{17} \mathrm{O}($ add. $\mathrm{O})$.

Similar to the local cycling of $\mathrm{NO}_{2}$, the local oxidation of this species is only conceptually represented. For simplicity, we assume that the formation of $\mathrm{HNO}_{3}$ only occurs through the pure daytime channel, i.e., the reaction of $\mathrm{NO}_{2}$ and $\mathrm{OH}$ : $\Delta{ }^{17} \mathrm{O}($ add. $\mathrm{O})=\Delta \Delta^{17} \mathrm{O}(\mathrm{OH})$.

In the framework of the OPALE campaign, $\Delta^{17} \mathrm{O}(\mathrm{OH})$ has been discussed in a submitted paper (Savarino et al., 2015). The results of this study show that $\Delta^{17} \mathrm{O}(\mathrm{OH})$ varies in a narrow range, between 1 and $3 \%$, around summer solstice 2011-2012. As a result, we set $\Delta^{17} \mathrm{O}(\mathrm{OH})=3 \%$ o throughout the entire sunlit season.

\subsection{Parameterization of physical processes}

\subsubsection{Snow accumulation}

The snow accumulation thickness depends on the snow accumulation rate $(A)$ as well as on snow density $(\rho)$. Older layers are buried, preserving their nitrate mass and isotopic composition. Immediately after snow accumulation, the modeled snowpack is resampled at a $1 \mathrm{~mm}$ resolution $(\Delta z=1 \mathrm{~mm})$.

\subsubsection{Nitrate horizontal export}

The export flux (FE) is modeled as a constant fraction of all incoming nitrate fluxes to the atmosphere $\mathrm{FE}=f_{\exp } \times(\mathrm{FP}+$ $\mathrm{FS}+\mathrm{FT}$ ), assuming that $\mathrm{NO}_{x}$ conversion to $\mathrm{HNO}_{3}$ is instantaneous and that nitrate is homogeneous in the atmospheric box, at the chosen time step.

\subsubsection{Nitrate deposition to the snow}

The deposited flux (FD) and its isotopic composition $\left(\Delta^{17} \mathrm{O}(\mathrm{FD})\right.$ and $\left.\delta^{15} \mathrm{~N}(\mathrm{FD})\right)$ are obtained by solving Eqs. (4) to (6) (Fig. 2). For the sake of simplicity, the downward deposition flux is modeled assuming a pure physical deposition of $\mathrm{HNO}_{3}$ on the top layer of the snowpack. The deposition process is assumed to preserve $\Delta^{17} \mathrm{O}$. This process is associated with a ${ }^{15} \mathrm{~N} /{ }^{14} \mathrm{~N}$ fractionation constant $\left({ }^{15} \varepsilon_{\mathrm{dep}}\right)$.

\subsubsection{Nitrate diffusion in the snowpack}

Nitrate diffusion in the snowpack leads to changes in nitrate mass fraction and isotope profiles in the snowpack, and it is represented by the use of a diffusivity coefficient denoted $D$ and by a zero-flux boundary condition at the top and bottom of the snowpack $(z=1 \mathrm{~m})$ :

$$
\left\{\begin{array}{l}
\frac{\partial \omega(z, t)}{\partial t}=D \frac{\partial^{2} \omega(z, t)}{\partial z^{2}} \\
\frac{\partial \omega \text { (top., } t)}{\partial z}=0 \\
\frac{\partial \omega \text { (bot., } t)}{\partial z}=0
\end{array}\right.
$$

where $\omega(z, t)$ is the nitrate mass fraction in each layer and $z$ and $t$ are space and time, respectively. Given the assumption of a constant snow density and a uniform mesh grid, Eq. (11) also applies to the snow mass in the layer $(m)$. Equation (11) is solved at a time step of $3.4 \mathrm{~h}$ (i.e., 50 times shorter than the main time step of the model), which must respect the following: $\frac{(\Delta z)^{2}}{3.4 \mathrm{~h}} \ll D$. Space and time derivatives are approximated by the finite-difference method.

\section{Model evaluation}

\subsection{Method: observational constraints, model setup and runs}

To evaluate the model, we study its ability to reproduce the present-day observations at Dome $\mathrm{C}$ and across East Antarc- 
tica. To this end, a realistic simulation of TRANSITS is compared to the data observed at the air-snow interface at Dome $\mathrm{C}$ and in the top $5 \mathrm{~cm}$ of snow in East Antarctica.

\subsubsection{Observational constraints}

Most of the observed data originate from Erbland et al. (2013). Atmospheric nitrate concentration and isotopic measurements were measured $2 \mathrm{~m}$ above ground at Dome $\mathrm{C}$ during the years 2007-2008 (Frey et al., 2009) and 20092010 (Erbland et al., 2013). In this second study, nitrate mass fraction and isotopic composition have also been measured in

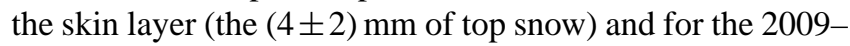
2010 period. Nitrate mass fractions and isotopic profiles are available from three $50 \mathrm{~cm}$ snow pits sampled at Dome C during the austral summers 2007-2008 and 2009-2010 (Frey et al., 2009; Erbland et al., 2013). From these snow-pits data and from the DC mean snow density profile given by Libois et al. (2014), we calculate $m_{50 \mathrm{~cm}}\left(\mathrm{NO}_{3}^{-}\right), \delta^{15} \mathrm{~N}_{50 \mathrm{~cm}}\left(\mathrm{NO}_{3}^{-}\right)$ and $\Delta^{17} \mathrm{O}_{50 \mathrm{~cm}}\left(\mathrm{NO}_{3}^{-}\right)$, the integrated nitrate mass and isotopic composition per unit horizontal surface area in the top $5 \mathrm{~cm}$ of the snowpack. $\mathrm{NO}_{x}$ emission fluxes were measured at Dome C from 22 December 2009 to 28 January 2010 (Frey et al., 2013).

Forty-five $50 \mathrm{~cm}$ deep snow profiles were collected at DC from February 2010 to February 2014 and nitrate mass fractions were measured as in Erbland et al. (2013). These previously unpublished profiles were collected approximately every month by the DC overwintering team. From the fifty-one $50 \mathrm{~cm}$ snow pits collected at DC (45 unpublished and 6 published in Röthlisberger et al., 2000; Frey et al., 2009; France et al., 2011; Erbland et al., 2013), we also calculate $m_{50 \mathrm{~cm}}\left(\mathrm{NO}_{3}^{-}\right)$as well as $\delta^{15} \mathrm{~N}_{50 \mathrm{~cm}}\left(\mathrm{NO}_{3}^{-}\right)$and $\Delta^{17} \mathrm{O}_{50 \mathrm{~cm}}\left(\mathrm{NO}_{3}^{-}\right)$for the snow pits where $\delta^{15} \mathrm{~N}$ and $\Delta^{17} \mathrm{O}$ data are available.

In East Antarctica, nitrate isotopic and mass fraction measurements are available from twenty-one $50 \mathrm{~cm}$ depth snow pits, including the three DC snow pits presented above (Erbland et al., 2013). They were sampled along two transects which link D10 (a location in the immediate vicinity of the French Dumont d'Urville (DDU) station) to DC and DC to Vostok. The sample collection and analysis as well as the data reduction are described in Erbland et al. (2013). Reduced data include the asymptotic mass fraction $(\omega($ as. $))$ and isotopic composition $\left(\delta^{15} \mathrm{~N}(\right.$ as. $)$ and $\Delta^{17} \mathrm{O}($ as. $\left.)\right)$, which represent nitrate below the zone of active nitrate mass loss in the top decimeters of snow, and ${ }^{15} \varepsilon_{\text {app }}$ and ${ }^{17} E_{\text {app }}$ apparent fractionation constants.

\subsubsection{TRANSITS simulations}

\subsubsection{Simulation at the air-snow interface at Dome $\mathrm{C}$}

Table 3 gives a summary of the parameters and variables used for the TRANSITS DC realistic simulation. Below, we dis- cuss their choice. Note that the adjustment parameters $(\Phi$, $f_{\text {exp }}, f_{\text {cage }}, D$ and ${ }^{15} \varepsilon_{\text {dep }}$ ) were adjusted manually and not set by an error minimizing procedure.

The thickness of the atmospheric boundary layer is set to a constant value of $50 \mathrm{~m}$, a value which sits between the median wintertime value (ca. $30 \mathrm{~m}$ ) simulated by Swain and Gallée (2006) and the mean value simulated around 27 December 2012 (Gallée et al., 2015). The time series of the nitrate concentration in the atmospheric box was obtained by smoothing the atmospheric measurements performed at Dome C in 2009-2010 (Erbland et al., 2013).

Stratospheric denitrification is responsible for the input of an estimated nitrogen mass of $(6.3 \pm 2.6) \times 10^{7} \mathrm{kgN}$ per year (Muscari and de Zafra, 2003), a value 3 times higher than the estimate of Wolff et al. (2008). Taking into account the area inside the Antarctic vortex where intense denitrification occurs $\left((15.4 \pm 3.0) \times 10^{6} \mathrm{~km}^{2}\right.$; Muscari and de Zafra, 2003), this gives a flux of FS $=(4.1 \pm 2.5) \times 10^{-6} \mathrm{kgN} \mathrm{m}^{-2} \mathrm{a}^{-1}$. The modeled stratospheric flux is set to occur constantly for a duration of 12 weeks (approximately 3 months) from 21 June to 13 September, the period when the mean air temperature at $50 \mathrm{mb}$ allows the formation of PSCs of type I $\left(T<-78^{\circ} \mathrm{C}\right)$ (NOAA observations in 2008 , available at http://www.cpc.ncep.noaa.gov/products/stratosphere/ polar/polar.shtml). Transitions before and after the 12-week $\mathrm{FS}(t)$ plateau are assumed to be linear and to last 4 weeks (Fig. 4a). The $\delta^{15} \mathrm{~N}(\mathrm{FS})$ value is set to $19 \%$ as estimated by Savarino et al. (2007) based on computations from chemical mechanisms, fractionation factors, and isotopic measurements. No direct measurement of $\Delta^{17} \mathrm{O}$ in stratospheric nitrate exists. Savarino et al. (2007) estimated that $\Delta^{17} \mathrm{O}$ is higher than $40 \%$, and we set $\Delta^{17} \mathrm{O}(\mathrm{FS})$ to $42 \%$.

There is no estimate of the nitrogen mass flux received on the Antarctic continent by long-range transport (FT). In the absence of such information and for simplicity, we assume that, annually, FS / FPI $=50 \%$. This means that the annual fluxes FT and FS are equal. We also assume a uniform distribution of FT throughout the year. We agree that this hypothesis is debatable given that air mass movement into the Antarctic Plateau may be hampered at times when the polar vortex is strongest. As for the flux, the $\delta^{15} \mathrm{~N}$ and $\Delta^{17} \mathrm{O}$ of this nitrate source are not known. However, we assume that it features $\delta^{15} \mathrm{~N}(\mathrm{FT})=0 \%$ and $\Delta{ }^{17} \mathrm{O}(\mathrm{FT})=30 \%$, which represent averaged values for tropospheric nitrate in pristine areas in low/middle latitudes (Morin et al., 2009). Annual snow accumulation rates measured at Dome $\mathrm{C}$ vary considerably at the interannual timescale as a result of snow redistribution by the wind (Libois et al., 2014). For example, years with net ablation are as frequent as $15 \%$. The same process also affects the distribution of snow accumulation rates at a subannual timescale. For the sake of simplicity, the annual snow accumulation rate is set to a constant value of $28 \mathrm{~kg} \mathrm{~m}^{-2} \mathrm{a}^{-1}$ ( $93 \mathrm{~mm}$ of snow per year for $\rho=300 \mathrm{~kg} \mathrm{~m}^{-3}$ ), which is representative of the Dome C site (Frezzotti et al., 2004; Libois et al., 2014). We also assumed a uniform distribution of snow 
Table 3. Parameters and variables used for the realistic simulation of TRANSITS. Input time variables and fixed parameters are written in bold.

\begin{tabular}{|c|c|c|}
\hline Process & & Realistic, DC Realistic, EAP \\
\hline \multirow[t]{3}{*}{ Snow accumulation } & $\rho /\left(\mathrm{kg} \mathrm{m}^{-3}\right)$ & 300 \\
\hline & $\boldsymbol{A} /\left(\mathrm{kg} \mathrm{m}^{-2} \mathrm{a}^{-1}\right)$ & [20 to 600] \\
\hline & Accu distribution & Uniform throughout the year \\
\hline $\mathrm{HNO}_{3}$ deposition & $10^{3} \times{ }^{\mathbf{1 5}} \varepsilon_{\text {dep }}$ & +10 \\
\hline Nitrate diffusion in snow & $\boldsymbol{D} /\left(\mathrm{m}^{2} \mathrm{~s}^{-1}\right)$ & $1.0 \times 10^{-11}$ \\
\hline \multirow{3}{*}{$\begin{array}{l}\text { TUV-snow parameters and vari- } \\
\text { ables }\end{array}$} & Optical \& physical prop. snowpack & DC snowpack, from France et al. (2011) \\
\hline & $\mathrm{O}_{3}$ column & DC observations 2000-2009 \\
\hline & $\boldsymbol{k}$ & 1 \\
\hline \multirow[t]{3}{*}{ Nitrate photolysis } & $\Phi$ & 0.026 \\
\hline & $\sigma$ and $\sigma^{\prime}$ & From Berhanu et al. (2014a) \\
\hline & $q$ & 1 \\
\hline \multirow[t]{2}{*}{ Cage effect } & $f_{\text {cage }}$ & 0.15 \\
\hline & $10^{3} \times \Delta^{\mathbf{1 7}} \mathbf{O}\left(\mathbf{H}_{2} \mathbf{O}\right)$ & 0 \\
\hline \multirow[t]{6}{*}{ Cycling/oxidation of $\mathrm{NO}_{2}$} & {$[\mathrm{BrO}] / \mathrm{pptv}$} & 2.5 (Frey et al., 2015) \\
\hline & {$\left[\mathbf{R O}_{2}\right] /\left(\right.$ molecule $\left.\mathrm{m}^{-3}\right)$} & $=7.25 \times 10^{15} \times\left(J\left(\mathrm{NO}_{2}\right) / \mathrm{s}^{-1}\right)$ (Kukui et al., 2014) \\
\hline & {$\left[\mathrm{HO}_{2}\right] /\left[\mathrm{RO}_{2}\right]$} & 0.7 (Kukui et al., 2014) \\
\hline & {$\left[\mathrm{O}_{3}\right] / \mathrm{ppbv}$} & From Legrand et al. (2009) \\
\hline & $10^{3} \times \Delta^{17} \mathbf{O}\left(\mathbf{O}_{\mathbf{3}}\right)_{\text {bulk }}$ & 25.2 (Savarino et al., 2015) \\
\hline & $10^{3} \times \Delta^{\mathbf{1 7}} \mathbf{O}(\mathbf{O H})$ & 3 (Savarino et al., 2015) \\
\hline \multirow[t]{2}{*}{ Atmospheric properties } & $T / \mathrm{K}$ & Concordia AWS (8989) in 2009-2010 \\
\hline & $P /$ mbar & Concordia AWS (8989) in 2009-2010 \\
\hline Nitrate export & $f_{\exp }$ & $20 \%$ \\
\hline \multirow[t]{10}{*}{ Mass balance in the atmosphere } & $\mathbf{F P I} /\left(\mathrm{kgN} \mathrm{m}^{-2} \mathrm{a}^{-1}\right)$ & $8.2 \times 10^{-6}$ (Muscari and de Zafra, 2003) \\
\hline & FS/FPI & $50 \%$ \\
\hline & FS distribution & Plateau from 16 May to 18 October \\
\hline & FT distribution & Uniform throughout the year \\
\hline & $\boldsymbol{h}_{\mathrm{AT}} / \mathrm{m}$ & 50 \\
\hline & $\gamma\left(\mathrm{NO}_{3}^{-}\right)$ & Idealized DC \\
\hline & $10^{3} \times \Delta^{17} \mathrm{O}(\mathrm{FS})$ & 42 \\
\hline & $10^{3} \times \delta^{15} \mathrm{~N}(\mathrm{FS})$ & 19 \\
\hline & $10^{3} \times \Delta^{17} \mathrm{O}(\mathrm{FT})$ & 30 \\
\hline & $10^{3} \times \delta^{15} \mathrm{~N}(\mathrm{FT})$ & 0 \\
\hline
\end{tabular}

accumulation within the computed year. Snow densities also vary considerably at the decimeter scale both horizontally and vertically (Libois et al., 2014). To simplify, the snow density has been set to $300 \mathrm{~kg} \mathrm{~m}^{-3}$, the average value found for the snow top layers at Dome C (France et al., 2011). This value is close to the average value $\left(316 \mathrm{~kg} \mathrm{~m}^{-3}\right)$ observed in a mean $25 \mathrm{~cm}$ depth DC profile (Libois et al., 2014). We note that our choice of snow density for the nitrate mass and isotopic calculations is consistent with that used for the optical calculations in the soft windpack layer at the surface, where most of the action occurs.

The adjustment parameter ${ }^{15} \varepsilon_{\text {dep }}$ (representing the ${ }^{15} \mathrm{~N} /{ }^{14} \mathrm{~N}$ fractionation associated with $\mathrm{HNO}_{3}$ deposition) is set to a value of $+10 \%$ in order to match the shift in $\delta^{15} \mathrm{~N}$ between observed atmospheric and skin layer nitrate (Erbland et al., 2013). The diffusivity coefficient is set to $1.0 \times 10^{-11} \mathrm{~m}^{2} \mathrm{~s}^{-1}$. The fraction of nitrate fluxes which is horizontally exported from the atmospheric box is adjusted to a constant value of $f_{\exp }=20 \%$. The parameter $\Phi$ is adjusted to a constant value of 0.026 and the magnitude of the cage effect is adjusted using a constant parameter of $f_{\text {cage }}=0.15$, which means that $15 \%$ of the photolyzed nitrate undergoes cage recombination and isotopic exchange with water

We used absorption cross sections of ${ }^{14} \mathrm{NO}_{3}^{-}$and ${ }^{15} \mathrm{NO}_{3}^{-}$ in snow recommended by Berhanu et al. (2014a). The TUVsnow model used to model the actinic flux in the DC snowpack was run using constant $k$ and $q$ parameters set to 1. An additional input is the ozone column and we used 
the measurements at Dome C over the 2000-2009 period. The 2000-2005 data were derived from the measurements made by the Earth Probe Total Ozone Mapping Spectrometer (EP/TOMS) and processed by the NASA (data obtained at http://ozoneaq.gsfc.nasa.gov/). The 2007-2009 data were obtained from the Système d'Analyse par Observation Zénithale (SAOZ) observation network at the surface (data obtained at http://saoz.obs.uvsq.fr/index.html). Weekly averages have been calculated over the 2000-2009 period and converted to obtain the same resolution (25 DU) as that used for the offline runs of the TUV-snow model (Fig. 3).

The variable $\alpha$ has been calculated from Eq. (8) using weekly average mixing ratios of $\mathrm{O}_{3}$ measured at Dome C in 2007-2008 (Legrand et al., 2009). During the OPALE campaign, Frey et al. (2015) measured $\mathrm{BrO}$ mixing ratios of 2-3 pptv. We assume that $[\mathrm{BrO}]$ is constant throughout the year and equal to $2.5 \mathrm{pptv}$. Air temperatures and pressures at each time step were calculated from the $3 \mathrm{~h}$ observations from the Concordia Automatic Weather Station (AWS 8989) in 2009-2010 (University of WisconsinMadison, data available at ftp://amrc.ssec.wisc.edu/pub/aws/ $\mathrm{q} 3 \mathrm{~h} /$, accessed 4 July 2013). Mixing ratios of $\mathrm{HO}_{2}$ and $\mathrm{CH}_{3} \mathrm{O}_{2}$ were deduced from those of $\mathrm{RO}_{2}$ assuming $\mathrm{RO}_{2}=$ $\mathrm{HO}_{2}+\mathrm{CH}_{3} \mathrm{O}_{2}$ and $\left[\mathrm{HO}_{2}\right] /\left[\mathrm{RO}_{2}\right]=0.7$ (Kukui et al., 2014). Mixing ratios of $\mathrm{RO}_{2}$ were estimated from their linear relationship with $J\left(\mathrm{NO}_{2}\right)$ : $\left[\mathrm{RO}_{2}\right] /\left(\right.$ molecule $\left.\mathrm{m}^{-3}\right)=$ $7.25 \times 10^{15} \times\left(J\left(\mathrm{NO}_{2}\right) / \mathrm{s}^{-1}\right)$ (Fig. 3b in Kukui et al., 2014). The time series of $J\left(\mathrm{NO}_{2}\right)$ was calculated with the TUV model for the appropriate solar zenith angle.

We note that Frey et al. (2015) have measured high $\left[\mathrm{NO}_{2}\right]$ / [NO] ratios which are not consistent with other measurements available at Dome $\mathrm{C}$. The authors suggest that either an unknown mechanism which converts $\mathrm{NO}$ into $\mathrm{NO}_{2}$ or interferences in the $\mathrm{NO}_{x}$ measurements are responsible for the discrepancy observed. Given that the oxidant budget is not yet fully resolved at DC, we stick to our simple parameterization of the local resetting of the oxygen isotopic composition of $\mathrm{NO}_{2}$ (Eq. 7). We note here that we have made various simplifications in the description of the local cycling and oxidation of $\mathrm{NO}_{2}$. These assumptions include $\Delta \Delta^{17} \mathrm{O}\left(\mathrm{HO}_{2}\right)=$ $0 \%$, the simplified description of $\Delta^{17} \mathrm{O}(\mathrm{OH})$, the simplified $\mathrm{NO}$ to $\mathrm{NO}_{2}$ conversion reaction scheme (and the potential greater influence of $\mathrm{O}_{3}$ ) and, also, the neglected nighttime $\mathrm{NO}_{2}$ oxidation pathway at the beginning and end of the sunlit season (which, again, involves $\mathrm{O}_{3}$ ). For these reasons, we anticipate that the $\Delta^{17} \mathrm{O}$ values simulated by TRANSITS at DC will represent the lower bound of the observations, because $\mathrm{O}_{3}$-dominated oxidation will imply larger $\Delta^{17} \mathrm{O}$ values.

\subsubsection{Simulations across East Antarctica}

Sampled sites on the D10-DC-Vostok route are characterized by a wide range of annual snow accumulation rates which gradually drop from $558 \mathrm{~kg} \mathrm{~m}^{-2} \mathrm{a}^{-1}$ close to the coast (D10) to $20 \mathrm{~kg} \mathrm{~m}^{-2} \mathrm{a}^{-1}$ high on the plateau (around Vos- tok) (Erbland et al., 2013). In the simulation of nitrate in East Antarctic snowpacks and the investigation of TRANSITS's ability to reproduce such wide snow accumulation conditions, we consider 10 test sites, whose snow accumulation rates are $[20,25,30,40,50,75,100,200,300$, $600] \mathrm{kg} \mathrm{m}^{-2} \mathrm{a}^{-1}$, respectively. For simplicity, we consider that $A$ is the sole variable used to characterize different sites from the coast to the plateau in East Antarctica. All the other parameters and variables are kept the same as those for DC. TRANSITS is therefore run in the DC realistic configuration described above. This means that we do not consider changes in latitude, elevation or ozone column conditions which would impact the TUV-modeled actinic fluxes. Also, the physical, optical and chemical properties of the snowpacks are considered constant. No changes in atmospheric temperature (which would affect $D$ ) and local atmospheric chemistry are taken into account, and the horizontal export of nitrogen from locations on the plateau to those close to the coast is not modeled. Last, we hypothesize that the time series of atmospheric nitrate concentrations are the same as that measured at DC. This assumption is supported by the observation of Savarino et al. (2007), who show comparable atmospheric nitrate concentration time series at the coastal DDU station and at DC.

The parameters and variables used for the DC realistic simulation as well as those used for the simulations across East Antarctica are given in Table 3.

\subsubsection{Model initialization and output data}

The $1 \mathrm{~m}$ snowpack is initialized with a constant nitrate profile of $\omega\left(\mathrm{NO}_{3}^{-}\right)=50 \mathrm{ngNO}_{3}^{-} \mathrm{g}^{-1}, \Delta^{17} \mathrm{O}\left(\mathrm{NO}_{3}^{-}\right)=30 \%$ and $\delta^{15} \mathrm{~N}\left(\mathrm{NO}_{3}^{-}\right)=50 \%$. The atmosphere box is initialized with $\gamma\left(\mathrm{NO}_{3}^{-}\right)=5 \mathrm{ngNO}_{3}^{-} \mathrm{m}^{-3}$ and $\Delta^{17} \mathrm{O}$ and $\delta^{15} \mathrm{~N}$ values of 30 nd $5 \%$, respectively.

The model is run for a time sufficiently long to allow it to converge (e.g., 25 years for DC conditions). Raw data generated by the model are processed to obtain the time series of concentration and isotopic composition of atmospheric nitrate and in a top skin layer of $4 \mathrm{~mm}$, the depth profiles of mass fraction, $\delta^{15} \mathrm{~N}$ and $\Delta{ }^{17} \mathrm{O}$ in snow nitrate, and the time series of the $\mathrm{NO}_{2}$ flux from the snow to the atmosphere.

From the simulated profiles of nitrate mass and isotopic composition in snow, we calculate the apparent fraction constants $\left({ }^{15} \varepsilon_{\text {app }}\right.$ and $\left.{ }^{17} E_{\text {app }}\right)$ as in Erbland et al. (2013). Also, the nitrate mass and isotopic composition in the top $5 \mathrm{~cm}$ are calculated. We note here that the model also computes the simulated mass fraction and isotopic composition in the archived nitrate, which can be compared to the observed asymptotic values.

\subsection{Results}

In this section, we briefly describe the simulated results. A comparison between the model results and the observations 


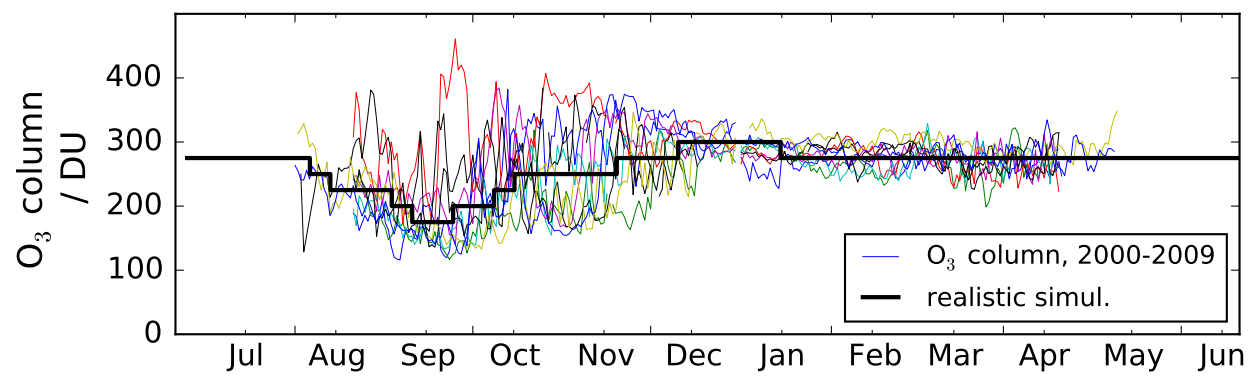

Figure 3. Driving ozone column data for the DC realistic simulation versus observed annual time series for years over the $2000-2009$.

data will be given in the "Evaluation and discussion" section. We note that the model results are insensitive to the values used for the model's initialization.

\subsubsection{Simulation results at the DC air-snow interface}

Figure 4 gives the results at the air-snow interface for the DC-like realistic simulation: simulated nitrate concentrations, $\delta^{15} \mathrm{~N}$ and $\Delta^{17} \mathrm{O}$ in both the atmospheric and skin layer compartments, and the simulated fluxes (FD, FE, FP) together with the observations at Dome C in 2007-2008 and 2009-2010. Table 4 gives a summary of averages and minimum/maximum of the simulated values in the atmosphere and skin layer.

In the atmospheric compartment, the average nitrate concentration is $32 \mathrm{ng} \mathrm{m}^{-3}$, which represents an average mass of $3.6 \times 10^{-4} \mathrm{mgN} \mathrm{m}^{-2}$. Atmospheric concentrations start to rise by the beginning of August and peak at $110 \mathrm{ng} \mathrm{m}^{-3}$ at the end of November, returning to winter background values $\left(5 \mathrm{ng} \mathrm{m}^{-3}\right)$ in March. The simulated annual weighted $\delta^{15} \mathrm{~N}$ value is $+0.2 \%$. Simulated atmospheric $\delta^{15} \mathrm{~N}$ values first show a $20 \%$ decrease in spring from the winter mean value of approximately $+10 \%$, which concurs with the beginning of the increase in atmospheric concentrations (mid-August to mid-October) and then an increase at a rate of approximately $10 \%$ per month. The highest atmospheric $\delta^{15} \mathrm{~N}$ value is approximately $+20 \%$ and is simulated in early February. The simulated annual weighted $\Delta^{17} \mathrm{O}$ value is $23.7 \%$. The highest atmospheric $\Delta^{17} \mathrm{O}$ values are simulated in winter $(39.3 \%$ o in July-August). They rapidly decrease by $18 \%$ from midAugust to October, remain stable around 22\%o throughout the summer and slowly start to rise in February, reaching winter values in July.

In the skin layer compartment, the average simulated nitrate mass fraction is $3074 \mathrm{ng} \mathrm{g}^{-1}$, which represents an average mass of $0.8 \mathrm{mgN} \mathrm{m}^{-2}$. Skin layer mass fractions start to rise in June, when the stratospheric nitrate input occurs, and peak at $5706 \mathrm{ng} \mathrm{g}^{-1}$ at the end of December, gradually returning to winter background values $\left(700 \mathrm{ng} \mathrm{g}^{-1}\right)$ in June. We note that only the simulated results are described in Sect. 3.2. The reader may refer to Sect. 3.3 for a comparison of the simulated and observed data, in particular the discrep- ancy between simulated and observed nitrate mass fraction in the skin layer (Fig. 4g). The simulated annual weighted $\delta^{15} \mathrm{~N}$ value is $+34.9 \%$. Simulated $\delta^{15} \mathrm{~N}$ values in the skin layer and atmosphere show similar variations: $\delta^{15} \mathrm{~N}$ values in the skin layer are stable in winter $(+20 \%)$, decrease by $5 \%$ in spring, increase at a rate of approximately $20 \%$ per month in summer, and reach a maximum value of $+60 \%$ o in early February before decreasing at a rate of ca. $10 \%$ o per month in winter. The simulated annual weighted $\Delta^{17} \mathrm{O}$ value is $25.5 \%$. Here, simulated atmospheric $\Delta^{17} \mathrm{O}$ values in the skin layer and atmosphere show similar variations: maximum $\Delta^{17} \mathrm{O}$ values in skin layer are simulated in winter (38.9\%o in July-August), rapidly decrease by $18 \%$ from mid-September to October, and remain stable around $21 \%$ o throughout the summer and slowly start to rise in February, reaching winter values in July.

The comparison of those two compartments shows that the average nitrate mass in the skin layer compartment is 2300 times higher than that in the atmospheric compartment. Also, we observe that nitrate mass fractions in the skin layer start to rise 2 months earlier than atmospheric concentrations do and that the summer maxima is simulated 1 month later. Annual weighted $\delta^{15} \mathrm{~N}$ and $\Delta{ }^{17} \mathrm{O}$ values in the skin layer are shifted by +34.7 and $+1.7 \%$, respectively, compared to the atmospheric value. Variations in $\delta^{15} \mathrm{~N}$ in both compartments are in phase; however, the spring decrease in $\delta^{15} \mathrm{~N}$ values is smaller in the skin layer than in the atmosphere and the increasing rate in summer is 2 times higher. Consequently, the difference between $\delta^{15} \mathrm{~N}$ values in skin layer and atmospheric nitrate varies from $+10 \%$ in winter to $38 \%$ in summer. Variations in $\Delta^{17} \mathrm{O}$ values in both compartments are almost in phase. The difference between $\Delta^{17} \mathrm{O}$ in skin layer and atmospheric nitrate is variable and negative in winter, increases in spring, reaching $+8 \%$, and is stable and slightly negative $(-1 \%)$ in summer.

Figure 5 and Table 5 give the snowpack results for the DC-like realistic simulation: simulated nitrate mass fraction and isotopic composition in the top $5 \mathrm{~cm}$ of snow and in the archived flux as well as the simulated apparent fractionation constants. The simulated nitrate mass in the top $5 \mathrm{~cm}$ (Fig. 5a) shows an average value of $(8.1 \pm 1.6) \mathrm{mgN} \mathrm{m}^{-2}$ (mean $\pm 1 \sigma)$. The simulated $m_{50 \mathrm{~cm}}\left(\mathrm{NO}_{3}^{-}\right)$varies in the 


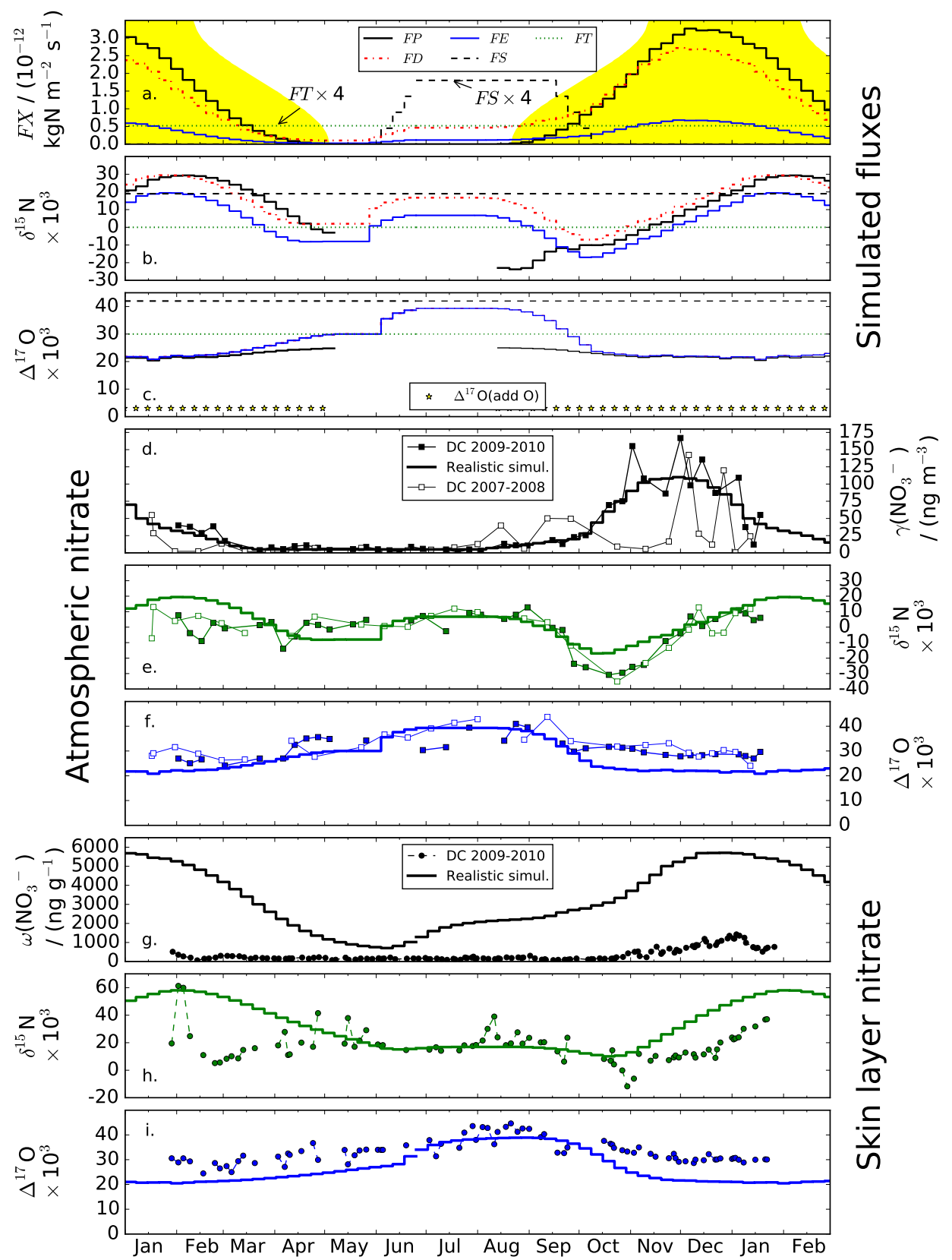

Figure 4. Realistic simulation results and comparison to the observations at Dome C. (a-c) Simulated fluxes (mass and isotopic composition) and $\Delta^{17} \mathrm{O}$ in the additional $\mathrm{O}$ atom (panel c). The legend in panel (a) also applies to panels (b) and (c). The yellow areas in panel (a) represent the day length at Dome C. Note that $\delta^{15} \mathrm{~N}$ and $\Delta^{17} \mathrm{O}$ in FE and FD are equal. (d-f) Simulated and observed concentrations, $\delta^{15} \mathrm{~N}$ and $\Delta^{17} \mathrm{O}$ in atmospheric nitrate. (g-i) Simulated and observed mass fractions, $\delta^{15} \mathrm{~N}$ and $\Delta^{17} \mathrm{O}$ in skin layer nitrate. The 2007-2008 and 2009-2010 observed data originate from Frey et al. (2009) and Erbland et al. (2013), respectively.

range $6.2-11.0 \mathrm{mgN} \mathrm{m}^{-2}$, with its maximum reached by the end of September and its minimum reached by the end of January. The simulated isotopic composition of nitrate in the top $5 \mathrm{~cm}$ shows weighted averages of +100.5 and $23.3 \%$ for $\delta^{15} \mathrm{~N}$ and $\Delta^{17} \mathrm{O}$, respectively (Fig. 5c and $\mathrm{f}$ ). The two time series also show cycles with variations respectively in anti-phase and in phase with variations in $m_{50 \mathrm{~cm}}\left(\mathrm{NO}_{3}^{-}\right)$. $\delta^{15} \mathrm{~N}_{50 \mathrm{~cm}}\left(\mathrm{NO}_{3}^{-}\right)$and $\Delta^{17} \mathrm{O}_{50 \mathrm{~cm}}\left(\mathrm{NO}_{3}^{-}\right)$respectively vary in the 77.4-127 and 20.0-27.4\% ranges.

The simulated ${ }^{15} \mathrm{~N} /{ }^{14} \mathrm{~N}$ apparent fractionation constant shows an annual average of $(-49.5 \pm 3.7) \%$, with weak annual variations (from -43.0 to $-53.6 \%$ ) (Fig. $5 \mathrm{~d}$ ). The annually averaged ${ }^{15} \varepsilon_{\text {app }}$ value is slightly higher than the annual weighted mean ${ }^{15} \varepsilon_{\text {pho }}$ value $\left(-55.1 \%\right.$ ). Compared to ${ }^{15} \varepsilon_{\text {app }}$, 
Table 4. Simulated nitrate concentration and isotopic composition at the air-snow interface in the case of the DC realistic simulation.

\begin{tabular}{lrrr|rrr}
\hline & \multicolumn{3}{c|}{ Atmosphere } & \multicolumn{4}{c}{ Skin layer } \\
& $\gamma\left(\mathrm{NO}_{3}^{-}\right) /\left(\mathrm{ng} \mathrm{m}^{-3}\right)$ & $10^{3} \times \delta^{15} \mathrm{~N}$ & $10^{3} \times \Delta^{17} \mathrm{O}$ & $\omega\left(\mathrm{NO}_{3}^{-}\right) /\left(\mathrm{ng} \mathrm{g}^{-1}\right)$ & $10^{3} \times \delta^{15} \mathrm{~N}$ & $10^{3} \times \Delta^{17} \mathrm{O}$ \\
\hline Average & 31.9 & & & 3074 & & \\
Weighted average & & 0.2 & 23.7 & & 34.9 & 25.5 \\
Min & 5.0 & -17.0 & 20.8 & 707 & 10.1 & 20.5 \\
Max & 110.0 & 19.4 & 39.3 & 5706 & 58.1 & 38.9 \\
\hline
\end{tabular}

${ }^{17} E_{\text {app }}$ shows variations in greater relative amplitude (from 0.7 to $2.4 \%$ o) with an annual average of $(1.4 \pm 0.6) \%$.

Figure 6 shows the specific case of the simulated snow nitrate for the week around 24 December in the case of the DC realistic simulation. Simulated nitrate mass fractions decrease by more than 2 orders of magnitude in the top $15 \mathrm{~cm}$ and $\delta^{15} \mathrm{~N}$ and $\Delta^{17} \mathrm{O}$ values increase and decrease with depth from $40 \%$ o to a mean background value above $290 \%$ o and from $21 \%$ to a mean background value below $18 \%$ at around $20-3 \mathrm{~cm}$ depth, respectively. The simulated profiles are smooth and a small secondary peak can be observed in the mass fraction profile at around $9 \mathrm{~cm}$ depth, a depth which corresponds to 1 year of snow accumulation.

Table 6 gives the simulated nitrate mass fluxes and their isotopic composition in the case of the DC realistic simulation. The FA / FPI ratio for the DC-like simulation is $1.8 \%$, which means that a small fraction of the primary input flux of nitrate is archived below $1 \mathrm{~m}$. The remaining fraction $(\mathrm{FE} / \mathrm{FPI}=1-\mathrm{FA} / \mathrm{FPI}=98.2 \%$ ) is exported outside the atmospheric box. The photolytic, deposition and export fluxes show a peak whose timing follows the sunlit season (Fig. 4a). The annual photolytic flux is $32.1 \times 10^{-6} \mathrm{kgN} \mathrm{m}^{-2} \mathrm{a}^{-1}$ and is compensated for by an annual deposition flux of $32.2 \times 10^{-6} \mathrm{kgN} \mathrm{m}^{-2} \mathrm{a}^{-1}$. Annually, the simulated FD and FP fluxes represent 4 times the primary input flux of nitrate ( $\mathrm{FD} \approx \mathrm{FP} \approx 4 \times \mathrm{FPI})$. In the archived nitrate, the simulated mass fraction, $\delta^{15} \mathrm{~N}$ and $\Delta^{17} \mathrm{O}$ values are constant throughout the season: $23.0 \mathrm{ng} \mathrm{g}^{-1}, 318 \% 0$ and $17.8 \%$, respectively (Fig. 5, Table 6).

\subsubsection{Simulation results across East Antarctica}

Figure 7 shows the results for the TRANSITS simulations across East Antarctica in which only the snow accumulation rate is varied. The simulated ${ }^{15} \mathrm{~N} /{ }^{14} \mathrm{~N}$ apparent fractionation constants are low $((-46.1 \pm 2.2) \% o, n=4)$ for East Antarctic Plateau sites $\left(A \leq 50 \mathrm{~kg} \mathrm{~m}^{-2} \mathrm{a}^{-1}\right.$; Erbland et al., 2013) and close to zero $((-10.3 \pm 9.0) \%, n=3)$ for coastal sites $\left(A \geq 200 \mathrm{~kg} \mathrm{~m}^{-2} \mathrm{a}^{-1}\right)$. Also, simulated plateau sites feature an average ${ }^{17} E_{\text {app }}$ value, which is significantly positive $((+1.0 \pm 0.3) \%$, Fig. $7 \mathrm{~b})$. The simulated archived flux (FA) and $\Delta^{17} \mathrm{O}(\mathrm{FA})$ both decrease with increasing $1 / A$ (Fig. 7e and d). Simulated $\delta^{15} \mathrm{~N}(\mathrm{FA})$ values monotonically increase with increasing $1 / A$.
Figure 8 presents the same results in a different way. Panel a is a "modified Rayleigh plot" where $\ln \left(\delta^{15} \mathrm{~N}(\mathrm{FA})\right.$ +1 ) is represented as a function of $\ln (\mathrm{FA})$ (which equals $\ln (\omega(\mathrm{FA}) \times A))$ instead of $\ln (\omega(\mathrm{FA}))$. In this representation, we observe that the simulated data fall on a line whose slope is -0.064 . Figure $8 \mathrm{~b}$ shows that $\Delta^{17} \mathrm{O}(\mathrm{FA})$ and $\delta^{15} \mathrm{~N}(\mathrm{FA})$ (Fig. $8 \mathrm{~b}$ ) are negatively correlated.

\subsection{Evaluation and discussion}

In this section, we evaluate the model results in light of the observational constraints described above. In particular, we attempt to clearly state those observations which are well reproduced by the model and those which are not. In the sections below, we also discuss the choice of the adjustment parameters which were made to run TRANSITS.

\subsubsection{Validation of the mass loss, diffusion and ${ }^{15} \mathrm{~N} /{ }^{14} \mathrm{~N}$ fractionation process}

The nitrate mass loss is quantitatively represented in the TRANSITS model. Indeed, Fig. 6a shows that nitrate mass fractions decrease by a factor of 10 in the top $1 \mathrm{~cm}$ of the snowpack in agreement with observations. Also, the simulated archived nitrate mass fractions values are consistent with the observations (Fig. 5). This means that the nitrate mass fraction lost by photolysis $(1-f)$ and calculated from the photolytic rate constant $(J$, Eq. 1$)$ is quantitatively simulated by TRANSITS model runs.

Nitrate- $\delta^{15} \mathrm{~N}$ isotopic profiles in snow also show that the ${ }^{15} \mathrm{~N} /{ }^{14} \mathrm{~N}$ fractionation associated with nitrate photolysis is quantitatively represented within the uncertainties. Indeed, the DC realistic simulation reproduces well the depth profile of $\delta^{15} \mathrm{~N}$ in snow nitrate as observed in Fig. 6b, with simulated $\delta^{15} \mathrm{~N}$ values as high as $150 \%$ at $1 \mathrm{~cm}$ depth. First, the simulated ${ }^{15} \mathrm{~N} /{ }^{14} \mathrm{~N}$ apparent fractionation constants are consistent with the observations at Dome C (Fig. 5d) and for plateau sites $\left(A \leq 50 \mathrm{~kg} \mathrm{~m}^{-2} \mathrm{a}^{-1}\right.$, Fig. 7a). This means that the absorption cross sections used for ${ }^{14} \mathrm{NO}_{3}^{-}$and ${ }^{15} \mathrm{NO}_{3}^{-}$ (Berhanu et al., 2014a) and the variables used in the TUVsnow model $\left(\mathrm{O}_{3}\right.$ column $)$ allow a quantitative description of the ${ }^{15} \mathrm{~N} /{ }^{14} \mathrm{~N}$ fractionation constant associated with nitrate photolysis $\left({ }^{15} \varepsilon_{\text {pho }}\right.$, Eq. 3). Secondly, the $\delta^{15} \mathrm{~N}$ values in the archived nitrate are well reproduced by the model: the simulated $\delta^{15} \mathrm{~N}(\mathrm{FA})$ value $(318 \%$ ) compares well with 


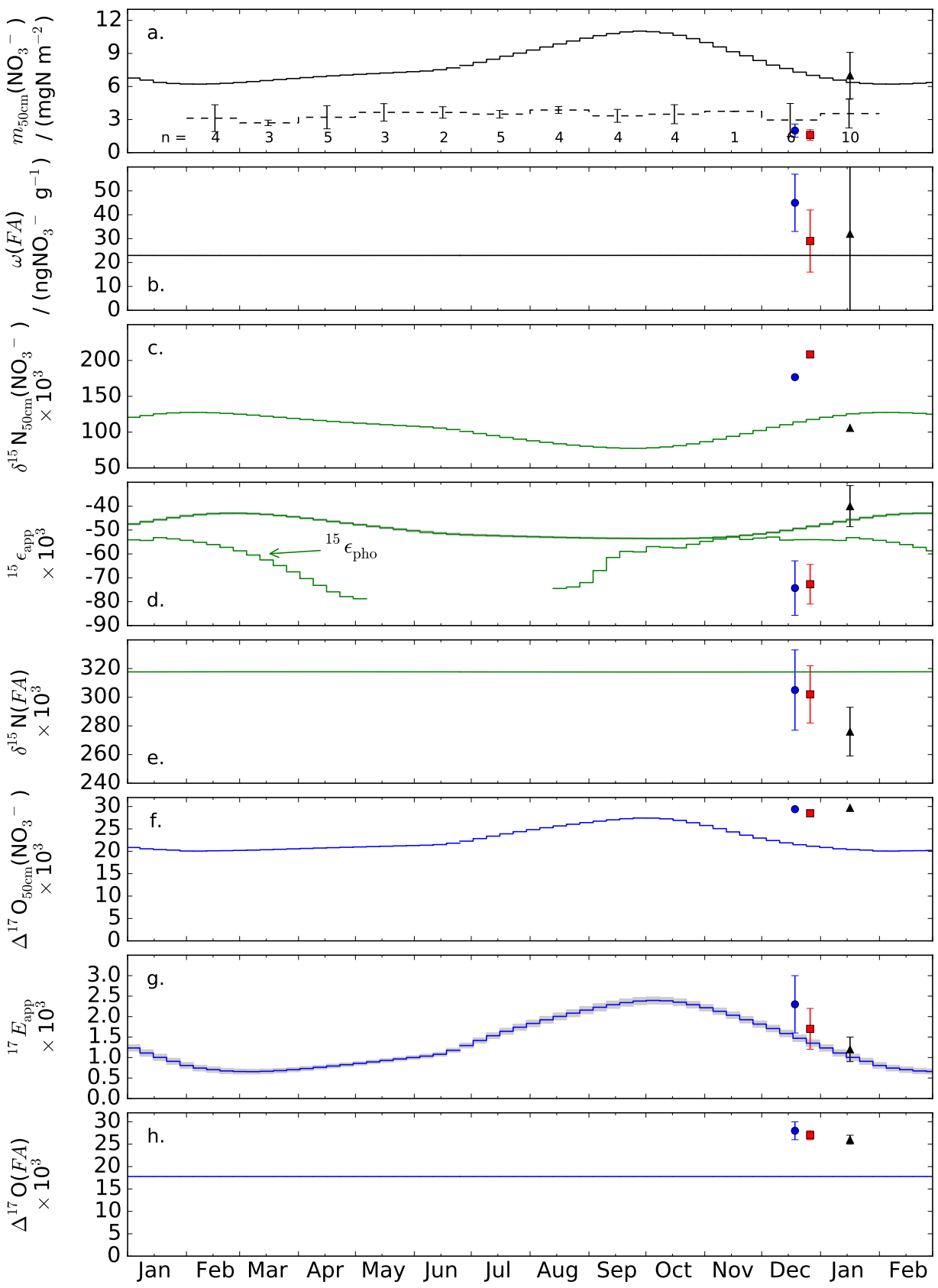

Figure 5. Realistic simulation results for the snowpack and comparison to the observations at Dome C. (a) Nitrate mass in the top $5 \mathrm{~cm}$ (the dashed curve represents the observed monthly values), (b) archived nitrate mass fractions, (c) $\delta^{15} \mathrm{~N}$ of nitrate in the top $5 \mathrm{~cm}$, (d) apparent and photolytic ${ }^{15} \varepsilon$ fractionation constants (in grey, the range $\pm 1 \sigma$ ), (e) $\delta^{15} \mathrm{~N}$ in the archived nitrate, (f) $\Delta^{17} \mathrm{O}$ of nitrate in the top $5 \mathrm{~cm}$, (g) apparent ${ }^{17} E$ fractionation constant (in grey, the range $\pm 1 \sigma$ ) and (h) $\Delta{ }^{17} \mathrm{O}$ in the archived nitrate. In each panel, the observed data from the three DC snow pits (Frey et al., 2009; Erbland et al., 2013) are represented by the same symbols as in Fig. 6.

the observations (from 275 to $300 \%$, Fig. 5f). This is further evidence that the nitrate mass fraction lost by photolysis $(1-f)$ is quantitatively simulated by TRANSITS model runs. Indeed, using a quantum yield of $2.1 \times 10^{-3}$ at $246 \mathrm{~K}$ as in France et al. (2011) leads not only to an unrealistic FA / FPI ratio $(71 \%)$ and $\omega\left(\right.$ FA) value $\left(917 \mathrm{ng} \mathrm{g}^{-1}\right)$ but also to a very small $\delta^{15} \mathrm{~N}(\mathrm{FA})$ value $(+20.3 \%$ ) , which clearly re- flects a weak recycling and an overestimate of primary nitrate trapped in snow. The adjusted photolytic quantum yield of $\Phi=0.026$ allows for computation of a consistent variation range of $\delta^{15} \mathrm{~N}$ in nitrate archived at depth. Given the choice of a modeled cage effect of $f_{\text {cage }}=0.15$, we obtain an apparent modeled quantum yield of $0.85 \times 0.026 \approx 0.022$, a value smaller than the mean value for buried nitrate $(0.05)$ 


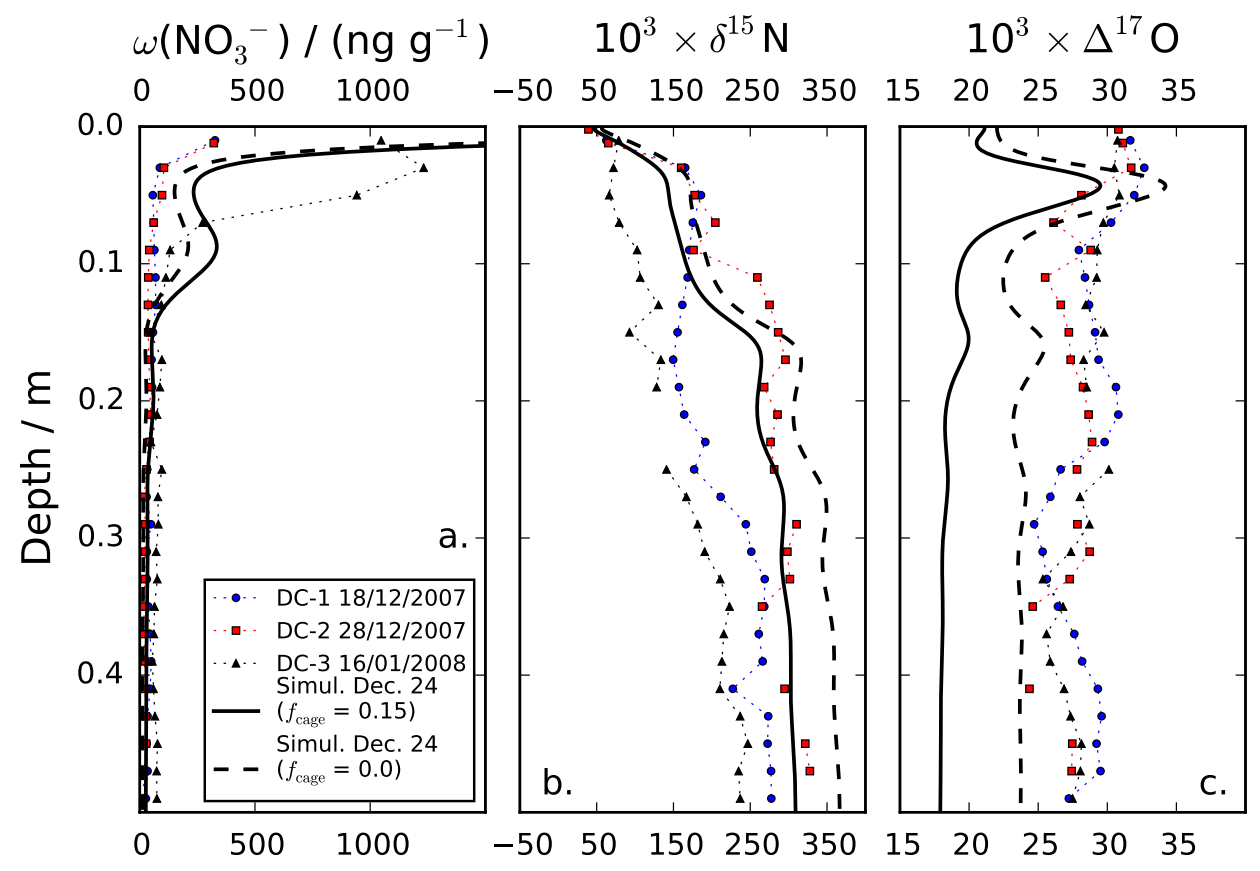

Figure 6. Realistic simulation results: nitrate in the top $50 \mathrm{~cm}$ of the snowpack on 24 December and comparison to the three observed profiles at Dome C in summer 2007-2008 (Frey et al., 2009; Erbland et al., 2013). (a) Nitrate mass fractions, (b) $\delta^{15} \mathrm{~N}$ in nitrate and (c) $\Delta^{17} \mathrm{O}$ in nitrate.

but higher than the smallest value observed for this domain (0.003) (Meusinger et al., 2014).

Additionally, we observe from Fig. 6a that the simulated profiles are smooth and that a small secondary peak can be observed in the simulated mass fraction profile at around $9 \mathrm{~cm}$ depth. Such smooth profiles can only be simulated because nitrate diffusion was taken into account, and turning this process off leads to simulated mass fraction and isotope profiles in the snow showing unrealistic spiky seasonal variations similar to those simulated by Wolff et al. (2002) and France et al. (2011). The secondary peak observed in simulated nitrate mass fraction profiles (at $9 \mathrm{~cm}$ depth, which corresponds to 1 year of snow accumulation) represents nitrate residual from the previous year's skin layer. This is consistent with secondary peaks observed in some snow pits on the Antarctic Plateau, e.g., snow pits S1 (at $1 \mathrm{~cm}$ depth), S2 (at 7 and $17 \mathrm{~cm}$ depth) and S3 (around $1 \mathrm{~cm}$ depth) in the Supplement (Erbland et al., 2013). Since TRANSITS is able to reproduce such a feature, we conclude that a simplified description of nitrate diffusion (i.e., constant diffusion coefficient) is not detrimental.

The adjusted value used for $D$ can be compared to the effective diffusivity of nitric acid in snow (denoted $D_{\text {eff }}$ ) as calculated in Herbert et al. (2006) and by assuming that the snow layers are always undersaturated in nitrate. Such an approach is followed because $\mathrm{HNO}_{3}$ is a sticky gas. According to Herbert et al. (2006), the $D_{\text {eff }}$ is a function of the diffusivity of $\mathrm{HNO}_{3}$ in the interstitial air, which depends on temperature and pressure (Massmann, 1998). Using a specific surface area of snow of $38 \mathrm{~m}^{2} \mathrm{~kg}^{-1}$ (Gallet et al., 2011), a snow density of $300 \mathrm{~kg} \mathrm{~m}^{-3}$, the median temperature and pressure for DC summer 2012 (Kukui et al., 2014) and a partition coefficient in the uptake of $\mathrm{HNO}_{3}$ on ice (Crowley et al., 2010), we find $D_{\text {eff }}=7.3 \times 10^{-12} \mathrm{~m}^{2} \mathrm{~s}^{-1}$. Our adjusted value for $D\left(1.0 \times 10^{-11} \mathrm{~m}^{2} \mathrm{~s}^{-1}\right)$ is close to the effective diffusivity of nitric acid in snow (denoted $D_{\text {eff }}$ ) and more than 3 orders of magnitude higher than the diffusion coefficient of nitrate ion in a single monocrystal of ice calculated at the same temperature $\left(2.6 \times 10^{-15} \mathrm{~m}^{2} \mathrm{~s}^{-1}\right.$; Thibert and Dominé, 1998), which means that the macroscopic mobility of nitrate in the snowpack is mostly the consequence of $\mathrm{HNO}_{3}$ mobility in the interstitial air. We note that our description of nitrate diffusion in the snowpack is basic and that the picture may well be more complicated with, for example, wind pumping effects and temperature gradients in snow.

\subsubsection{Validation of the cage effects}

The choice of a non-zero value for $f_{\text {cage }}$ allows for reproduction of the positive apparent ${ }^{17} \mathrm{O}$-excess fractionation constant $\left({ }^{17} E_{\text {app }}\right)$ which is observed at DC (from $(+1.2 \pm 0.3) \%$ to $(+2.3 \pm 0.7) \%$ in summer, Fig. $5 \mathrm{~g})$ and on the Antarctic Plateau (Frey et al., 2009; Erbland et al., 2013). Indeed, Fig. $5 \mathrm{~g}$ shows that the simulated ${ }^{17} E_{\text {app }}$ values at DC are positive, while a TRANSITS model run with the cage effects switched off (i.e., $f_{\text {cage }}=0$ ) leads to a simulated mean December/January ${ }^{17} E_{\text {app }}$ value of almost zero: $(+0.3 \pm 0.2) \%$ (date not shown). The simulation across East 


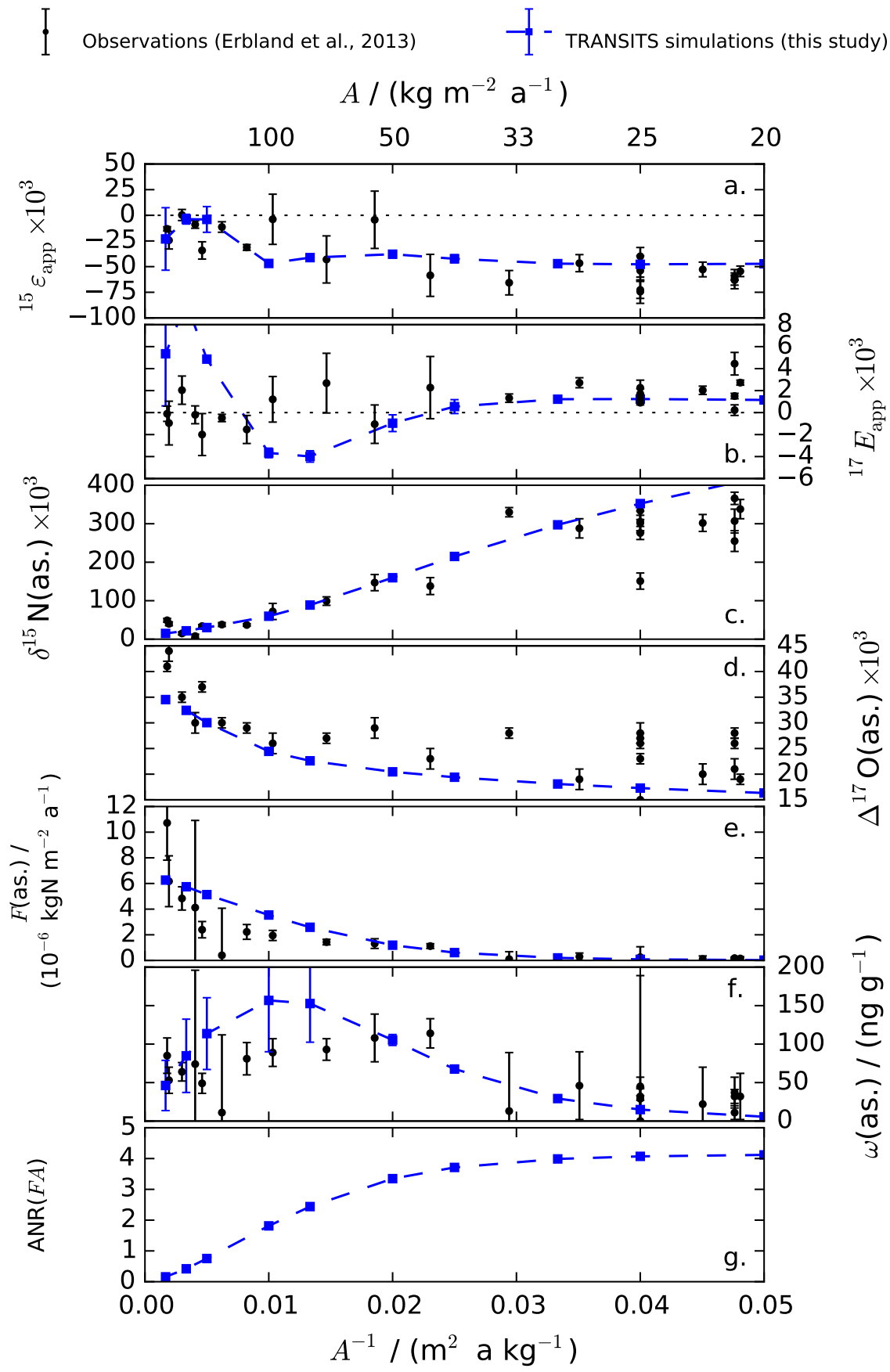

Figure 7. Reduced data in the TRANSITS simulations across East Antarctica and in the observations (Erbland et al., 2013) as a function of the snow accumulation rates (top $x$ axis) and their inverse (bottom $x$ axis). (a, b) ${ }^{15} \mathrm{~N} /{ }^{14} \mathrm{~N}$ and ${ }^{17} \mathrm{O}$-excess apparent fractionation constants (simulated dots and errors bars represent the mean and standard deviation values over the December/January period), (c, d) asymptotic (observed) and archived (simulated) $\delta^{15} \mathrm{~N}$ and $\Delta^{17} \mathrm{O}$ values (simulated dots represent annual average values), (e) asymptotic and archived nitrate mass, (f) asymptotic and archived nitrate mass fractions (simulated dots and errors bars represent the mean and standard deviation values over the whole year), and (g) average number of recyclings in the archived nitrate (ANR(FA)).

Antarctica confirms the ability of the model to reproduce the sensitivity of $\Delta^{17} \mathrm{O}$ to the nitrate mass loss (Fig. 7b). Indeed, for sites with $A \leq 50 \mathrm{~kg} \mathrm{~m}^{-2} \mathrm{a}^{-1}$, the model calculates a mean ${ }^{17} E_{\text {app }}$ value of $(+1.0 \pm 0.3) \%$ for the De-
cember/January period, while the observed average value is $(+2.0 \pm 1.2) \%$ o (mean $\pm 1 \sigma, n=10)$. The model therefore confirms the decreasing contribution of cage recombination 

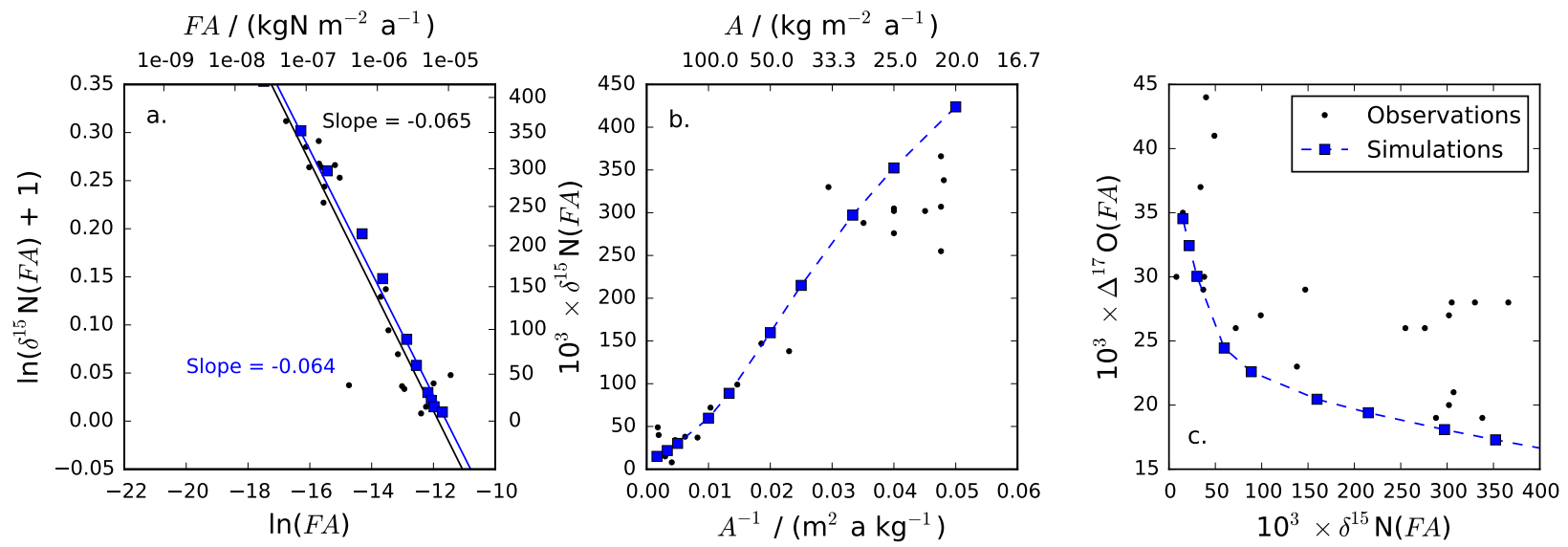

Figure 8. Realistic simulation with varying snow accumulation rates (blue squares) versus observations along the D10-Dome C-Vostok route (black dots). (a) Modified Rayleigh plot. The two lines are linear fit to the data and the slopes are given in the respective colors. (b) $\delta^{15} \mathrm{~N}(\mathrm{FA})$ versus the inverse of the snow accumulation rates. (c) $\Delta^{17} \mathrm{O}(\mathrm{FA})$ versus $\delta^{15} \mathrm{~N}(\mathrm{FA})$.

effects to $\Delta^{17} \mathrm{O}\left(\mathrm{NO}_{3}^{-}\right)$as originally observed in the lab by McCabe et al. (2005).

Figure $6 \mathrm{c}$ shows that a non-zero value for $f_{\text {cage }}$ allows for generation of decreasing $\Delta^{17} \mathrm{O}$ profiles in snow in accordance with the observations in three snow pits from DC and with the simulated and observed positive ${ }^{17} E_{\text {app }}$ values. While this subtle depth trend is reproduced by the model, we observe from the same figure that, quantitatively, the choice of a non-zero value for $f_{\text {cage }}$ is detrimental to the reproduction of the $\Delta^{17} \mathrm{O}$ values of nitrate in the top $5 \mathrm{~cm}$ of snow. Indeed, modeled $\Delta^{17} \mathrm{O}$ values in the $40-50 \mathrm{~cm}$ depth range are approximately 18 and $23.5 \%$ in the cases where the cage effects are switched on and off, respectively, in comparison with observed $\Delta^{17} \mathrm{O}$ values in the $27-30 \%$ range. We refer the reader to Sect. 3.3.8, where the ability of the model to quantitatively reproduce the observed $\Delta{ }^{17} \mathrm{O}$ values is discussed.

\subsubsection{Validation of the macroscopic fluxes}

The primary input flux of nitrate to the air-snow system (FPI) derived from Muscari and de Zafra (2003) (and from our assumption FT $=$ FS) is realistic. Indeed, simulated and observed East Antarctica data almost fall on the same line of slope -0.065 in the modified Rayleigh plot (Fig. 8a). In this representation, changing FPI leads to the horizontal shift of the simulated data, thus confirming the realistic value of FPI $=8.2 \times 10^{-6} \mathrm{kgN} \mathrm{m}^{-2} \mathrm{a}^{-1}$. We note that our simulation in East Antarctica is very simple because it only takes into account changes in snow accumulation rates, which are large on the D10-DC-Vostok route. A more sophisticated simulation along this line is beyond the scope of the present study because it would require including a radiative transfer model such as TUV-snow (or TARTES; Libois et al., 2014) in TRANSITS in order to deal with latitudinal and elevation changes. Also, the simulation should take into account boxes from Vostok to D10 with the exchange of nitrate horizontally exported from the center of the continent towards the coast, basically changing our 1-D model into a 2-D model.

The maximum value of the photolytic flux (FP) simulated for DC is $3.27 \times 10^{-12} \mathrm{kgN} \mathrm{m}^{-2} \mathrm{~s}^{-1}$ (Fig. 4a, Table 6), a value around 40 times higher than that obtained by France et al. (2011). This difference is not surprising since we are using a quantum yield 12 times higher than France et al. (2011). The different scaling may be explained by the differences in the complexities of the two models (TRANSITS includes recycling and a net export). The observed median $\mathrm{NO}_{x}$ emission fluxes are $1.6 \times 10^{-13} \mathrm{kgN} \mathrm{m}^{-2} \mathrm{~s}^{-1}$ and $3.7 \times 10^{-13} \mathrm{kgN} \mathrm{m}^{-2} \mathrm{~s}^{-1}$ over the 22 December 2009 to 28 January 2010 period (Frey et al., 2013) and the 1 December 2011 to 12 January 2012 period (Frey et al., 2015), respectively. Our computed median $\mathrm{NO}_{2}$ fluxes over the same periods are $2.8 \times 10^{-12} \mathrm{kgN} \mathrm{m}^{-2} \mathrm{~s}^{-1}$ and $3.3 \times 10^{-12} \mathrm{kgN} \mathrm{m}^{-2} \mathrm{~s}^{-1}$, i.e., values respectively 18 and 9 times higher than in the observations by Frey et al. (2013, 2015).

The discrepancy between simulated and observed FP values may be explained by the fact that FP represents the potential flux of $\mathrm{NO}_{2}$ emitted from the snow to the atmosphere, i.e., an upper limit when comparing to the observed $\mathrm{NO}_{2}$ flux (measured between 0.01 and $1 \mathrm{~m}$ above the snowpack; Frey et al., 2013, 2015). TRANSITS does not take into account various potential processes affecting $\mathrm{NO}_{x}$ emission from snow, such as gas-phase diffusion or chemical conversion prior to emission and forced ventilation from the snowpack (France et al., 2011; Frey et al., 2013; Meusinger et al., 2014). Future improvements to the model could include an explicit representation of the vertical transport of $\mathrm{NO}_{2}$ within and outside the snowpack with the following processes: $\mathrm{NO}_{x}$ diffusion, wind pumping, chemical conversion and deposition prior to the net emission from the snow, the latter de- 


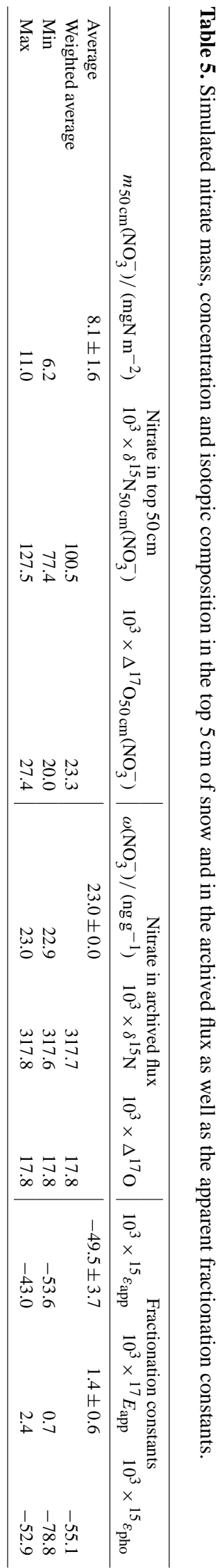

pending on oxidant levels in firn air $\left(\mathrm{HO}_{x}, \mathrm{O}_{3}\right.$, and maybe halogens; Zatko et al., 2013). Another improvement could be the modeling of two nitrate domains (photolabile and buried nitrate; Meusinger et al., 2014).

We note that, if HONO production is greater than assumed at Dome $\mathrm{C}$, following the recent laboratory study of Scharko et al. (2014), this will not change the main conclusions of this study. Indeed, the photolytically produced HONO will be photolyzed to form $\mathrm{NO}$ in the atmosphere and this $\mathrm{NO}$ would simply enter the $\mathrm{NO} / \mathrm{NO}_{2}$ cycles, where oxygen isotopes are reset.

The parameterization of $\mathrm{HNO}_{3}$ deposition is simplistic since it solves the mass-balance equation (Eq. 4) in order to reproduce the nitrate concentration in the atmosphere. A sensitivity test of TRANSITS has been run using nitrate atmospheric concentrations 10 times higher than the ideal DC time series used for the DC realistic simulation. The higher nitrate concentration in the atmosphere had no significant impact on any of the nitrate reservoirs both in terms of mass and isotopic composition. Indeed, in the case of the DC realistic simulation, the atmospheric nitrate mass represents $1 / 2300$ and $1 / 22500$ of nitrate mass in the skin layer and in the top $5 \mathrm{~cm}$, respectively. Future improvements to the model could use a physical description of the deposition of $\mathrm{HNO}_{3}$ using, for example, a vertical deposition velocity.

Hereafter, the ratio FA / FPI is termed the "nitrate trapping efficiency" because it reflects the fraction of nitrate that is trapped below the photic zone. In the DC realistic simulation, the nitrate trapping efficiency is $1.8 \%$ (Table 6), which means that only a small fraction of the primary nitrate is archived. Consequently, the net export of nitrate is significant $(\mathrm{FE}=98.2 \%$ of the nitrate of primary origin $=$ $8.05 \times 10^{-6} \mathrm{kgN} \mathrm{m}^{-2} \mathrm{a}^{-1}$, Table 6) and reflects the chosen adjusted value of $f_{\exp }(0.2)$. To the best of our knowledge, there is no observation that could independently corroborate this FE value because it would require the direct measurement of this flux. However, we point out that a non-zero $f_{\text {exp }}$ parameter is necessary to reproduce realistic $\delta^{15} \mathrm{~N}$ values both in the atmosphere and skin layer. Indeed, when running the model with $f_{\exp }=0, \delta^{15} \mathrm{~N}$ values in those compartments become highly negative $(\leq-120 \%$ ), which is clearly not realistic when compared to the observations (Fig. 4e and h) and what is seen in Frey et al. (2009). Also, in such conditions, the model does not converge within a reasonable time and simulated nitrate endlessly builds up in the photic zone.

The parameter $f_{\exp }$ can, however, be related to physical variables. Indeed, it represents the competition between the export of $\mathrm{NO}_{y}\left(\mathrm{NO}_{2}\right.$ or $\left.\mathrm{HNO}_{3}\right)$ and the deposition of (to make it simple) $\mathrm{HNO}_{3}$. Let us consider atmospheric $\mathrm{NO}_{2}$ and $\mathrm{HNO}_{3}$ at steady state. The deposition of $\mathrm{NO}_{2}$ is neglected because it is a factor of $8.0 \pm 3.2$ slower than that of $\mathrm{HNO}_{3}$ (Zhang et al., 2009). Also, oxidation by $\mathrm{OH}$ is considered to be the only channel of $\mathrm{NO}_{2}$ oxidation (an assumption valid in summer). Following the approach of Jacob (1999), a summertime value for $f_{\exp }$ can be approached by considering the 
Table 6. Simulated nitrate mass fluxes and their isotopic composition in the case of the DC realistic simulation.

\begin{tabular}{|c|c|c|c|c|c|c|c|c|c|c|}
\hline \multirow[t]{2}{*}{ Flux } & \multirow[t]{2}{*}{$\begin{array}{r}\text { Annual flux } \\
/\left(10^{-6} \mathrm{kgN} \mathrm{m}^{-2} \mathrm{a}^{-1}\right)\end{array}$} & \multicolumn{3}{|c|}{$\begin{array}{c}\text { Seasonal flux } \\
/\left(10^{-12} \mathrm{kgN} \mathrm{m}^{-2} \mathrm{~s}^{-1}\right)\end{array}$} & \multicolumn{3}{|c|}{$\begin{array}{c}\text { Seasonal } \\
10^{3} \times \delta^{15} \mathrm{~N}\end{array}$} & \multicolumn{3}{|c|}{$\begin{array}{c}\text { Seasonal } \\
10^{3} \times \Delta^{17} \mathrm{O}\end{array}$} \\
\hline & & Mean & Min & Max & Mean & Min & Max & Mean & Min & $\operatorname{Max}$ \\
\hline FP & 32.07 & 1.02 & 0.00 & 3.27 & 12.6 & -23.8 & 29.3 & 21.7 & 20.4 & 25.0 \\
\hline FD & 32.22 & 1.02 & 0.10 & 2.72 & 13.9 & -7.0 & 29.4 & 24.8 & 20.8 & 39.3 \\
\hline $\mathrm{FE}$ & 8.05 & 0.26 & 0.03 & 0.68 & 3.9 & -17.0 & 19.4 & 24.8 & 20.8 & 39.3 \\
\hline FA & 0.15 & 0.00 & 0.00 & 0.00 & 317.7 & 317.6 & 317.8 & 17.8 & 17.8 & 17.8 \\
\hline FS & 4.10 & 0.13 & 0.00 & 0.45 & 19.0 & 19.0 & 19.0 & 42.0 & 42.0 & 42.0 \\
\hline FT & 4.10 & 0.13 & 0.13 & 0.13 & 0.0 & 0.0 & 0.0 & 30.0 & 30.0 & 30.0 \\
\hline
\end{tabular}

chemical lifetime of $\mathrm{NO}_{2}$ with respect to its oxidation by $\mathrm{OH}$, the residence time of atmospheric $\mathrm{NO}_{2}$ against horizontal export and that of atmospheric $\mathrm{HNO}_{3}$ against deposition and horizontal export processes. Using kinetic rate constants from Atkinson et al. (2004), $T, P$, wind speeds and $\mathrm{OH}$ mixing ratios for mean summertime conditions at DC (Kukui et al., 2014), $\mathrm{HNO}_{3}$ dry deposition velocity from Huey et al. (2004), and vertical and horizontal characteristic dimensions of $100 \mathrm{~m}$ (average summertime boundary layer height, Gallée et al., 2015) and $400 \mathrm{~km}$ (Antarctic Plateau width), respectively, we obtain $f_{\exp }=0.20$, a value which equals the value used to adjust the model but which is rather fortuitous. Indeed, we acknowledge that this calculation suffers from a number of uncertainties; for example, using kinetic rate constants of $\mathrm{NO}_{2}+\mathrm{OH}$ from Sander et al. (2006), we obtain $f_{\text {exp }}=0.36$. Future improvements to the model could aim at a physical parameterization of the nitrate export.

\subsubsection{Validation of the residence time in the photic zone and calculation of the average number of recyclings}

Results from the East Antarctica simulations show that the observed linear $\delta^{15} \mathrm{~N}(\mathrm{FA})$ versus $1 / A$ relationship (Freyer et al., 1996; Erbland et al., 2013) is very well reproduced (Fig. 7c). This demonstrates that the residence time of nitrate in the snowpack zone of active photochemistry is treated in a realistic manner in the model. When snow accumulation rates get very low $\left(A<20 \mathrm{~kg} \mathrm{~m}^{-2} \mathrm{a}^{-1}\right)$, simulated $\delta^{15} \mathrm{~N}(\mathrm{FA})$ values do not seem to reach an asymptotic value as observed in the field where $\delta^{15} \mathrm{~N}$ (as.) seems to reach a plateau not exceeding $360 \%$ (Fig. 7c). This observed feature could be the result of the different nitrate locations on snow grains, with buried nitrate (Meusinger et al., 2014), whose photolysis constitutes a lower limit in the photolysis loss process.

Nitrate recycling at the air-snow interface at DC is illustrated by the simulated macroscopic photolytic and deposition fluxes at the snowpack surface. Indeed, FP and FD almost equilibrate, and these annual fluxes are 4 times higher than the annual primary input of nitrate (FPI, Table 6).
Here, our main focus is on nitrate which is archived below the zone of active photochemistry, because only that is ultimately archived in ice cores. One key issue to determine is the "average number of recyclings" undergone by the archived nitrate (hereafter denoted ANR(FA)). To this end, a new tracer, denoted CYCL, has been introduced in the TRANSITS model. In a given box (snow layer or atmosphere), CYCL represents the average number of recyclings undergone by nitrate in the considered box. The CYCL variable follows a numerical treatment comparable to that of $\delta^{15} \mathrm{~N}$ and $\Delta^{17} \mathrm{O}$, i.e., a "recycling" (instead of an isotopic) mass balance, diffusion and the calculation of CYCL values in the macroscopic fluxes (FP, FD, FE, FA). The CYCL value for primary nitrate is set to 0 , and CYCL variables in the boxes are incremented by 1 each time $\mathrm{NO}_{2}$ molecules cross the air-snow interface. ANR(FA) is calculated as a massweighted average of the CYCL values of the 52 snow layers which are archived below $1 \mathrm{~m}$ over the course of 1 year, in order to average out any seasonal variability.

Following the above approach for the Dome $\mathrm{C}$ simulation, we obtain $\operatorname{ANR}(\mathrm{FA})=4.0$ for the last layer before leaving the photic zone, which means that, on average, the archived nitrate at Dome $\mathrm{C}$ has undergone 4.0 recyclings (i.e., loss, local oxidation, deposition). We note that this number of recyclings represents an average value for the archive nitrate. Considering individual ions in the archived nitrate, the range of the number of recyclings must be wide since some ions may well have traveled through the entire snowpack zone of active photochemistry without being recycled, while some underwent many recyclings.

Figure $7 \mathrm{~g}$ shows the ANR(FA) values calculated for the 10 simulated sites in East Antarctica. We observe that ANR(FA) is proportional to $1 / A$ for $A \geq 50 \mathrm{~kg} \mathrm{~m}^{-2} \mathrm{a}^{-1}$, which means that the burial of nitrate (i.e., the residence time of nitrate in the photic zone) determines the $\operatorname{ANR}(\mathrm{FA})$ value. On the Antarctic Plateau, where snow accumulations rates are below this threshold value, ANR(FA) reaches a plateau on the order of four recyclings. Concurrently, we observe that FP remains constant at $32.8 \times 10^{-6} \mathrm{kgN} \mathrm{m}^{-2} \mathrm{a}^{-1}$ (data not shown) because increasing residence time of nitrate in the photic zone with decreasing snow accumulation rates leads to a nitrate 
mass fraction profile in snow which becomes more asymmetric, with most of the nitrate getting confined in a thinner layer at the top. As a result, FP levels off due to the negative feedback of the decreasing nitrate mass fractions at depth. Figure $7 \mathrm{~g}$ clearly shows the following relationship between ANR(FA) and FP: ANR(FA) $=\frac{\text { FP }}{\text { FPI }}$. This finding represents an independent confirmation of the definition given by Davis et al. (2008) on the basis of the macroscopic yearly primary and photolytic fluxes: the "nitrogen recycling factor", NRF, which is the ratio of nitrogen emission and nitrogen deposition. While we are satisfied to end up with the Davis et al. (2008) expression for ANR(FA) using our independent model-based tracer experiment, it must be noted that we define ANR as the average number of recyclings undergone by the archived nitrate, while Davis et al. (2008) define it as the "nitrogen recycling factor within a photochemical season".

\subsubsection{Validation of the nitrate mass in each compartment}

Nitrate mass in the different compartments is reasonably well reproduced by the model. Indeed, the simulated average nitrate mass in the atmospheric compartment represents $1 / 22500$ of that in the top $5 \mathrm{~cm}$ of snow, and this is consistent with observations in 2009-2010 where this ratio is $1 / 8300$ (Tables 4 and 5, considering a constant boundary layer height of $50 \mathrm{~m}$ ). Also, the annual variations in nitrate mass fractions in the skin layer are well reproduced by the model: deviations from the winter background values occur during the sunlit season, reaching a maximum in December (Fig. 4g). However, we note that the period of high values above background is longer (September to April) for the simulation than in the observations (October/February). Lastly, simulated nitrate mass in the top $5 \mathrm{~cm}$ of snow has been shown to increase in winter and decrease during the sunlit season (Fig. 5a), similar to the observed data: the average winter $m_{50 \mathrm{~cm}}\left(\mathrm{NO}_{3}^{-}\right)$ value $\left((3.6 \pm 0.5) \mathrm{mgN} \mathrm{m}^{-2}\right.$, May to November) is higher than the average summer value $\left((3.2 \pm 1.2) \mathrm{mgN} \mathrm{m}^{-2}\right.$, December to April). In winter, the input and output to the nitrate reservoir in the top $5 \mathrm{~cm}$ of snow are the deposition and archiving fluxes, respectively. During this season, the deposition flux is greater than the archiving flux, which leads to an increase in $m_{50 \mathrm{~cm}}\left(\mathrm{NO}_{3}^{-}\right)$. When the sunlit season starts, the additional photolysis output flux starts, causing the sum $\mathrm{FA}+\mathrm{FP}$ to exceed FD and thus $m_{50 \mathrm{~cm}}\left(\mathrm{NO}_{3}^{-}\right)$to decrease.

Additionally, the simulated average mass ratio between the skin layer and the top $5 \mathrm{~cm}$ of snow is $10 \%$ (Tables 4 and 5), a value approximately 3 times higher than the 2009-2010 observed value ( $3 \%$, considering a snow density of $300 \mathrm{~kg} \mathrm{~m}^{-3}$ for the skin layer snow). This discrepancy is accompanied by a factor of 2.4 between simulated and observed annual average $m_{50 \mathrm{~cm}}\left(\mathrm{NO}_{3}^{-}\right)$values $\left((8.1 \pm 1.6) \mathrm{mgN} \mathrm{m}^{-2}\right.$ versus $(3.4 \pm 1.0) \mathrm{gN} \mathrm{m}^{-2}$, Fig. 5a) and by a factor of 7.9 between simulated and observed annual average mass fractions in the skin layer (3074 $\mathrm{ng} \mathrm{g}^{-1}$ versus $390 \mathrm{ng} \mathrm{g}^{-1}$, Fig. 4g). Nitrate masses in the top $5 \mathrm{~cm}$ and in the skin layer are therefore higher in the DC simulation than in the observations, and nitrate in the skin layer is more concentrated in the simulation.

Fully resolving these discrepancies is beyond the scope of this paper. However, we first note that lower observed skin layer mass fractions could be linked to heterogeneities in sampling the skin layer (whose thickness is $(4 \pm 2) \mathrm{mm}$; Erbland et al., 2013), especially when considering that different overwintering volunteers were involved in this task. For instance, sampling $6 \mathrm{~mm}$ instead of $4 \mathrm{~mm}$ could lead to the sampling of a more diluted skin layer. However, we acknowledge that this sampling issue would have a limited impact on the observed skin layer mass fractions. Secondly, higher simulated annual $m_{50 \mathrm{~cm}}\left(\mathrm{NO}_{3}^{-}\right)$values could be the result of the time response of the modeled snowpack to past changes in primary input fluxes. Indeed, when run in the DC realistic simulation with a multiplication of FPI by a factor of 10 after 25 years of simulation, TRANSITS shows a time response of approximately 21 years. This means that the snowpack requires 21 years to reach stable $m_{50 \mathrm{~cm}}\left(\mathrm{NO}_{3}^{-}\right)$values again. As a consequence, the different $m_{50 \mathrm{~cm}}\left(\mathrm{NO}_{3}^{-}\right)$value observed today at Dome $\mathrm{C}$ could reflect changes in primary input flux conditions as far back as one or two decades in the past. A third explanation involves the absence of a snow erosion process during which wind blows away a significant fraction of the non-cohesive skin layer. This process would decrease nitrate mass fractions in the skin layer as observed in the field around 10 January 2010 (Erbland et al., 2013) and, in turn, decrease nitrate mass fractions in the snow layers below.

\subsubsection{Validation of the $\delta^{15} \mathrm{~N}$ values in each compartment}

In Sect. 3.2.1, we have seen that the simulated $\delta^{15} \mathrm{~N}$ profiles in snow are consistent with the observations. In particular, apparent ${ }^{15} \mathrm{~N} /{ }^{14} \mathrm{~N}$ fractionation constants are well reproduced leading the simulation of realistic $\delta^{15} \mathrm{~N}(\mathrm{FA})$ values. In this section, we compare the simulated and observed time series of $\delta^{15} \mathrm{~N}$ in the atmospheric and skin layer nitrate.

Overall, the annual variations in $\delta^{15} \mathrm{~N}$ values in skin layer and atmospheric nitrate are generally well reproduced by the model, although some discrepancies can be noted Fig. 4e and h). For example, the winter observed $\delta^{15} \mathrm{~N}$ values and $10 \%$ o shift between atmosphere and snow are well simulated, supporting the choice of the ${ }^{15} \mathrm{~N} /{ }^{14} \mathrm{~N}$ fractionation constant associated with the deposition of nitric acid $(+10 \%)$, the positive sign of ${ }^{15} \varepsilon_{\text {dep }}$ being consistent with a dry deposition of $\mathrm{HNO}_{3}$. Also, the spring variations and timing of atmospheric $\delta^{15} \mathrm{~N}$ are well reproduced. Indeed, the lowest $\delta^{15} \mathrm{~N}$ values in the atmospheric nitrate occur in October (simulated: $-25.3 \%$; observed: $-17.0 \%$, Fig. $4 \mathrm{e}$ ), when the stratospheric input has stopped and when the UV radiation becomes significant enough to encourage the production of isotopically depleted $\mathrm{NO}_{x}$ from the snowpack. The return to positive atmospheric $\delta^{15} \mathrm{~N}\left(\mathrm{NO}_{3}^{-}\right)$values in summer is faster 
at Dome $\mathrm{C}$ than has been observed at DDU, and this feature has been attributed to the longer exposure time of nitrate at the snow surface at Dome C (Savarino et al., 2007; Frey et al., 2009). TRANSITS confirms this suggestion when run with the higher snow accumulation rate which characterizes DDU (data not shown). At Dome C, shortly after the decrease, $\delta^{15} \mathrm{~N}$ values rapidly start to rise again because the nitrate in snow becomes more enriched in ${ }^{15} \mathrm{~N}$ and the extracted $\mathrm{NO}_{2}$ has rising $\delta^{15} \mathrm{~N}$ values as well. With large $\theta$ values at the end of the summer, the apparent ozone column crossed by the UV rays is more important and the photolytic fractionation constant $\left({ }^{15} \varepsilon_{\text {pho }}\right)$ becomes more negative (Fig. $\left.5 \mathrm{~d}\right)$. This leads to decreasing $\delta^{15} \mathrm{~N}$ values extracted from the snowpack even if the enrichment does not stop there. Finally, wintertime values of $\delta^{15} \mathrm{~N}$ are reached back by the end of April/beginning of May, when the nitrate photolysis stops.

The simulated annual variation in skin layer $\delta^{15} \mathrm{~N}$ is also consistent with the observations. However, the spring decrease observed in 2009-2010 is more marked than the simulation one (25 and $5 \%$, respectively, Fig. $4 \mathrm{~h}$ ). One reason is that the simulated $\delta^{15} \mathrm{~N}$ values in skin layer start to rise 1.5 months earlier than in the observations (Fig. 4h). Although simulated $\delta^{15} \mathrm{~N}$ values start to rise earlier, we note that the summer increasing rate in skin layer $\delta^{15} \mathrm{~N}$ values is similar in the simulations and in the observations (approximately $+20 \%$ per month). One consequence of the 1.5 -month delay between simulated and observed skin layer $\delta^{15} \mathrm{~N}$ values is that the $\delta^{15} \mathrm{~N}$ difference between skin layer and atmospheric nitrate at the end of the summer is greater in the simulation than it is for the observation (approximately $+40 \%$ versus $+20 \%$ ). Focusing on the beginning of the skin layer, $\delta^{15} \mathrm{~N}$ records (Fig. 4h) show that the end of summer 20082009 was different than the next year, with differences up to $40 \%$ o between the simulation and observation. In particular, the large observed variations which lead to skin layer $\delta^{15} \mathrm{~N}$ values as high as $+60 \%$ (Erbland et al., 2013) are not reproduced by the model. This could be the result of snow sampling effects (i.e., local spatial heterogeneity or different sampling of the operator in the field).

\subsubsection{Photolytically driven dynamic equilibrium at the air-snow interface}

The simulated variations in $\Delta^{17} \mathrm{O}$ in the atmospheric and skin layer compartments are consistent with the observations - i.e., $\Delta^{17} \mathrm{O}$ decreases from high winter values to the lowest values in the middle of summer (Fig. $4 \mathrm{f}$ and $\mathrm{i}$ ). The model also reproduces well the small negative difference between the atmospheric and skin layer annual weighted $\Delta^{17} \mathrm{O}$ values (simulated: $-1.2 \%$; observed: $-2.3 \%$ ). When considering the annual variability of the difference in $\Delta^{17} \mathrm{O}$ in the atmosphere and skin layer, the model reproduces well the important shift in early October (simulated: $-8 \%$; observed: $-7 \%$ ) as well as the small negative shift by the end of the summer (simulated: approximately $-2 \%$; observed: approximately $-2 \%$ ).

The above observations show that TRANSITS is able to qualitatively reproduce the $\Delta^{17} \mathrm{O}$ variations in nitrate for each compartment. Concurrent variability in $\Delta^{17} \mathrm{O}$ in atmospheric and skin layer nitrate indicates equilibrium at the airsnow interface. The simulated and observed differences between $\Delta^{17} \mathrm{O}$ in the atmosphere and skin layer are the result of their respective nitrate reservoirs and indicate that the isotopic equilibrium is dynamic. Further evidence for the different size reservoir is that the (oxygen and nitrogen) isotope time series in the skin layer are smoother than in the atmosphere (Fig. 4).

The photolytic and deposition fluxes in summer show that there is an intense nitrate recycling at the air-snow interface during this season (Fig. 4a), a feature which is confirmed by our calculation of the average number of recyclings undergone by the archived nitrate $(\mathrm{ANR}(\mathrm{FA})=4.0)$. The local signature of $\mathrm{NO}_{2}$ cycling and oxidation harbored by $\Delta^{17} \mathrm{O}$ is therefore incorporated in skin layer nitrate. Given the good qualitative agreement between the simulated and observed $\Delta^{17} \mathrm{O}$ in skin layer nitrate throughout the year, we conclude that TRANSITS has a realistic representation of the local cycling and oxidation of $\mathrm{NO}_{2}$ in the atmosphere.

We also observe that TRANSITS reproduces well the $\Delta^{17} \mathrm{O}(\mathrm{FA}) / \delta^{15} \mathrm{~N}(\mathrm{FA})$ anti-correlation and general trend in the case of the simulation across East Antarctica (Fig. 8c). This anti-correlation is partly the result of the cage recombination effects, but some of it is also due to the greater incorporation of the summertime isotopic signature of the local cycling and oxidation of the photolytically produced $\mathrm{NO}_{2}$. On the same figure, the observations show a large scattering of approximately $5 \%$ when compared to data simulated by TRANSITS. One reason for that is the inability of the model to reproduce variations in $\Delta^{17} \mathrm{O}$ in nitrate below $2 \mathrm{~cm}$, which can be as high as $5 \%$ (Fig. 6c). Such variations may be linked to variability in ozone column, snow accumulation, local atmospheric chemistry, and primary inputs of nitrate from one year to another which are not accounted for by TRANSITS. McCabe et al. (2007) first observed such 2 3 -year period cycles in a $6 \mathrm{~m}$ snow pit from the South Pole and attributed these cycles to variability in the stratospheric ozone column or to stratospheric nitrate import; the same periodicity in $\Delta^{17} \mathrm{O}$ is found in DC surface snow (Frey et al., 2009; Erbland et al., 2013). Future work should investigate the impact of the variations in the ozone column on the $\Delta^{17} \mathrm{O}$ in the archived nitrate.

Quantitatively speaking, $\Delta^{17} \mathrm{O}$ values in the atmosphere, the skin layer, the top $5 \mathrm{~cm}$ of snow and the archived nitrate are not well reproduced. Indeed, the simulated annual weighted $\Delta^{17} \mathrm{O}$ values in the atmosphere and skin layer are approximately $6 \%$ ower than in the observations $(23.7 \%$ o versus $29.4 \%$ and $25.5 \%$ versus $31.7 \%$, respectively). The same is observed for simulated $\Delta^{17} \mathrm{O}_{50 \mathrm{~cm}}\left(\mathrm{NO}_{3}^{-}\right)$and 
$\Delta^{17} \mathrm{O}$ (FA) values (Fig. $5 \mathrm{f}$ and h). From Fig. $4 \mathrm{f}$ and i, we observe that wintertime $\Delta^{17} \mathrm{O}$ values in atmospheric and skin layer nitrate are reasonably well reproduced, while most of the discrepancies are observed in summer.

\subsubsection{On the discrepancies between simulated and observed $\Delta^{17} \mathrm{O}$ values}

In the previous section, we showed that the model reproduces well the winter $\Delta^{17} \mathrm{O}$ values as well as the variations in $\Delta^{17} \mathrm{O}$ values in the different compartments. However, a quantitative transcription of the information harbored by the oxygen isotopes is not achieved yet by TRANSITS. In particular, the summer $\Delta^{17} \mathrm{O}$ values are 8 to $10 \%$ o lower in the simulations than in the observations (Fig. 4). We note that a number of simplifications have been made in the description of the local cycling and oxidation of $\mathrm{NO}_{2}$, thus leading to the simulation of $\Delta^{17} \mathrm{O}$ values which must be considered as lower bounds.

First, the local oxidation of $\mathrm{NO}_{2}$ has been assumed to only occur through the daytime channel, i.e., through the oxidation by $\mathrm{OH}$. In order to verify this hypothesis, we calculate $r\left(\mathrm{OH}\right.$ vs. $\left.\mathrm{O}_{3}\right)=v(\mathrm{OH}) /\left(v(\mathrm{OH})+v\left(\mathrm{O}_{3}\right)\right)$, the relative apportioning of the daytime and nighttime $\mathrm{NO}_{2}$ oxidation channel, with the assumption that the latter occurs through $\mathrm{NO}_{2}+\mathrm{O}_{3}$. For the calculation of $r\left(\mathrm{OH}\right.$ vs. $\left.\mathrm{O}_{3}\right)$, we use kinetic rate constants from Atkinson et al. (2004) and ozone mixing ratios from Legrand et al. (2009), and $\mathrm{OH}$ mixing ratios are extrapolated from $J\left(\mathrm{NO}_{2}\right)$ calculated by TRANSITS and using the relationship $[\mathrm{OH}] /\left(\right.$ molecule $\left.\mathrm{m}^{-3}\right)=$ $2.5 \times 10^{14} \times J\left(\mathrm{NO}_{2}\right) / \mathrm{s}^{-1}$ (Kukui et al., 2014). For the realistic DC simulation, $r\left(\mathrm{OH}\right.$ vs. $\left.\mathrm{O}_{3}\right)$ is higher than 0.95 from the fourth week after sunrise to the second week before sunset, i.e., for more than $90 \%$ of the sunlit season. We also note that for the periods when $r\left(\mathrm{OH}\right.$ vs. $\left.\mathrm{O}_{3}\right)<0.95$, the actinic flux is at maximum $6 \%$ of the maximum actinic flux calculated for summer solstice. The calculation of an FP-weighted average of $r\left(\mathrm{OH}\right.$ vs. $\left.\mathrm{O}_{3}\right)$ gives $99 \%$, which means that over the sunlit season, the daytime oxidation channel of $\mathrm{NO}_{2}$ is almost 100 times faster than the nighttime oxidation channel. This result supports our choice of the simple representation of $\mathrm{NO}_{2}$ oxidation (by $\mathrm{OH}$ only) in TRANSITS and cannot explain the discrepancy in the $\Delta{ }^{17} \mathrm{O}$ values simulated in summer. However, we acknowledge that species such as halogen oxides (denoted $\mathrm{XO}$ ) could compete with $\mathrm{OH}$ in the oxidation of $\mathrm{NO}_{2}$, thus importing high $\Delta{ }^{17} \mathrm{O}$ values (Savarino et al., 2015).

Secondly, the calculation of $\Delta^{17} \mathrm{O}(\mathrm{OH})$ has been simplified by assuming a constant value throughout the entire sunlit season. Given the low temperatures at the beginning and end of the sunlit season, we acknowledge that $\Delta^{17} \mathrm{O}(\mathrm{OH})$ values may be higher at these periods because of the less efficient isotopic exchange in the removal of the $\Delta^{17} \mathrm{O}$ by $\mathrm{OH}$ inherited during its formation and because of the potential higher contribution of ozone photolysis in its production (Morin et al., 2011).
Thirdly, the cycling of $\mathrm{NO}_{2}$ is assumed to be in photochemical steady state and therefore $\Delta^{17} \mathrm{O}\left(\mathrm{NO}_{2}\right.$, PSS $)$ can be calculated following Eq. (7). For the DC realistic simulation, the computed $\alpha$ variable varies in the range $0.80-1$, with the minimum value calculated a few weeks after summer solstice, when the $\mathrm{O}_{3}$ mixing ratio reaches its minimum (Legrand et al., 2009), and the maximum value calculated at the beginning and end of the sunlit season. The FP-weighted annual average value of $\alpha$ is 0.86 , which shows that the Leighton cycle is significantly perturbed by $\mathrm{HO}_{2}$ and $\mathrm{CH}_{3} \mathrm{O}_{2}$ and that the transfer of the ${ }^{17} \mathrm{O}$ excess harbored by ozone to $\mathrm{NO}_{2}$ is not $100 \%$ efficient. The hypothesis of an annually constant $\mathrm{BrO}$ mixing ratio of $2.5 \mathrm{pptv}$ is crude because it must be lower at the beginning and end of the sunlit season. However, we observe that $\mathrm{BrO}$ marginally contributes to $\alpha$ at these periods. Also, while a TRANSITS simulation with $\alpha$ set to 1 allows a better agreement with the observations, the simulated $\Delta^{17} \mathrm{O}$ values are still too low (e.g., in this case, the minimum summertime $\Delta^{17} \mathrm{O}$ values in skin layer, atmospheric and archived nitrate are 24.3, 25.4 and $20.0 \%$, respectively). This small experiment indicates that our current knowledge of the $\mathrm{NO}_{x}$ processing at Dome $\mathrm{C}$ is not complete and that some of our hypothesis should not be valid. In particular, the hypothesis of the photochemical steady state of $\mathrm{NO}_{x}$ could be questioned. Indeed, we note that the $\mathrm{NO}_{x} / \mathrm{HO}_{x}$ chemistry at Dome $\mathrm{C}$ is not yet completely understood (Kukui et al., 2014, and OPALE special issue) and a nitrogen species $\left(\mathrm{HNO}_{4}\right.$ or unknown species) is expected to disturb the $\mathrm{NO}_{x}$ photochemical cycle, leading to the high $\mathrm{NO}_{2} / \mathrm{NO}$ ratio observed by Frey et al. (2015), and/or to participate in the oxidation of $\mathrm{NO}_{2}$ (via, for example, XO; Savarino et al., 2015).

Fourthly, the $\Delta{ }^{17} \mathrm{O}$ value associated with the stratospheric flux of nitrate could be higher than the $42 \%$ value used in our simulations and initially suggested by Savarino et al. (2007). In particular, it could explain the 2-3-year period observed in $\Delta^{17} \mathrm{O}\left(\mathrm{NO}_{3}^{-}\right)$from snow pits at the South Pole (McCabe et al., 2007) and at Dome C (Frey et al., 2009; Erbland et al., 2013). Also, the model would benefit from a better description of the timing of the long-distance transport flux of nitrate and the time series of the $\Delta^{17} \mathrm{O}$ value associated with it, both of which were set constant throughout the season in our simulations.

While a certain amount of isotopic information is still required to produce more realistic simulations at Dome $\mathrm{C}$, we acknowledge that the most critical requirement is a better understanding of the $\mathrm{NO}_{x}$ chemistry on the Antarctic Plateau. Integrating a more realistic chemistry in TRANSITS will probably amplify the intense $\mathrm{NO} / \mathrm{NO}_{2}$ cycling in the atmosphere and not fundamentally change the nature of the processes at play at the air-snow interface of DC. However, we anticipate that the type of archived information below the photic zone will not change, mostly because the seasonal $\Delta{ }^{17} \mathrm{O}$ variations in atmospheric and skin layer nitrate are well reproduced. 


\section{A framework for the interpretation of nitrate isotope records in ice cores}

In Sect. 3, we ran a DC realistic simulation as well as simulations representing various sites in East Antarctica. We have shown that the model reproduced reasonably well the available mass and isotopic observations. While a quantitative reproduction of $\Delta^{17} \mathrm{O}$ values in atmospheric and skin layer nitrate could not be achieved (mostly because of a lack of understanding of the $\mathrm{NO}_{x}$ chemistry at Dome C), we have shown that variations in $\Delta^{17} \mathrm{O}$ values in these compartments were well reproduced.

In this section, we develop a framework for the interpretation of nitrate records in ice cores in the case where Dome $\mathrm{C}$ conditions apply. To this end, a large number of sensitivity tests of the TRANSITS model were run. Potentially measurable quantities in ice cores are $\omega(\mathrm{FA}), \delta^{15} \mathrm{~N}(\mathrm{FA})$ and $\Delta^{17} \mathrm{O}$ (FA) (e.g., Hastings et al., 2005; Frey et al., 2009). Given snow accumulation rates derived independently, one can also obtain $\mathrm{FA}=\omega(\mathrm{FA}) \times A$.

\subsection{Parameters and variables controlling FA and $\delta^{15} \mathbf{N}(\mathbf{F A})$}

\subsubsection{Sensitivity tests: description and results}

The sensitivity of the model is tested in simple cases where single variables and parameters are changed. For each simulation, the model was run for 25 years (i.e., until convergence). The realistic simulation for DC is used as the reference simulation. Table 5 provides an overview of the variations imposed on the tested variables and parameters. The five following variables and parameters have been set to 0 (Table 5): ${ }^{15} \varepsilon_{\text {dep }}, \Delta \Delta^{17} \mathrm{O}(\mathrm{FS}), \Delta{ }^{17} \mathrm{O}(\mathrm{FT}), \Delta{ }^{17} \mathrm{O}(\mathrm{OH})$ and $\Delta^{17} \mathrm{O}\left(\mathrm{O}_{3}\right)_{\text {bulk. }}$. The $\delta^{15} \mathrm{~N}(\mathrm{FS})$ and $\delta^{15} \mathrm{~N}(\mathrm{FT})$ parameters have been changed to 119 and $100 \%$, respectively. The parameters FPI and $h_{\mathrm{AT}}$ were multiplied by a factor of 10 . The mixing ratios of $[\mathrm{BrO}],\left[\mathrm{O}_{3}\right],\left[\mathrm{HO}_{2}\right]$ and $\left[\mathrm{CH}_{3} \mathrm{O}_{2}\right]$ were multiplied by a factor of 2 . The nine following variables and parameters have been changed by $+20 \%$ : FS / FPI, $f_{\text {cage }}, f_{\text {exp }}$, $A, \rho, k, q, \Phi$ and $D$. The sensitivity to the snow accumulation distribution in the year has been tested by running the model with summer snow accumulation rates 2 times higher than the winter rates and vice versa. The sensitivity to $T$ has been tested by shifting the observed atmospheric temperature time series by $-10 \mathrm{~K}$. The model sensitivity to the ozone column has been run for four simulations: with constant ozone columns of 100, 300 and 500 DU as well as with an ozone hole of 100 DU from August to November and an ozone column of $300 \mathrm{DU}$ the rest of the time. Last, the sensitivity of the model to the atmospheric nitrate concentrations has been tested by running it with concentrations 10 times higher than in the realistic DC simulation. The total number of simulations is then 31 , which includes the reference simulation.
For each test, the following outputs were calculated: FA, FA / FPI, $\delta^{15} \mathrm{~N}(\mathrm{FA})$ and $\Delta^{17} \mathrm{O}(\mathrm{FA})$. The description and results of the tests scenarios are given in Table 5. To give an example and a guideline for reading Table 5, we describe the result for the test where the snow accumulation rate was changed. The value used in the reference simulation is $28 \mathrm{~kg} \mathrm{~m}^{-2} \mathrm{a}^{-1}$, and that of the tested scenario is $20 \%$ greater (i.e., $33.6 \mathrm{~kg} \mathrm{~m}^{-2} \mathrm{a}^{-1}$ ). Table 5 indicates that such an increase in $A$ leads to an increase in the archived nitrate mass flux from 1.77 to $3.90 \%$ of the primary nitrate mass flux. $\Delta{ }^{17} \mathrm{O}$ in the archived nitrate is increased by $0.8 \%$. Conversely, $\delta^{15} \mathrm{~N}$ in the archived nitrate is decreased by $53.8 \%$, from 317.7 to $263.9 \%$.

Table 5 shows that two parameters and variables have no impact at all on the archived nitrate: $h_{\mathrm{AT}}$ and $\gamma\left(\mathrm{NO}_{3}^{-}\right)$. The reason is that the nitrate mass in the atmospheric box is negligible when compared to the nitrate reservoir in snow as discussed previously (Sect. 3.3.5). The parameter FPI is the only one affecting FA, while FA and FPI are linearly linked (i.e., FA / FPI remains constant), but this does not modify $\delta^{15} \mathrm{~N}(\mathrm{FA})$. The $\delta^{15} \mathrm{~N}$ signatures in the primary nitrate sources $\left(\delta^{15} \mathrm{~N}(\mathrm{FS})\right.$ and $\delta^{15} \mathrm{~N}(\mathrm{FT})$ and the ${ }^{15} \mathrm{~N} /{ }^{14} \mathrm{~N}$ fractionation constant associated with deposition $\left({ }^{15} \varepsilon_{\text {dep }}\right)$ have an impact on $\delta^{15} \mathrm{~N}(\mathrm{FA})$. Likewise, some parameters only impact $\Delta^{17} \mathrm{O}(\mathrm{FA})$, such as the $\Delta^{17} \mathrm{O}$ signature in the primary nitrate sources $\left(\Delta^{17} \mathrm{O}(\mathrm{FS})\right.$ and $\left.\Delta^{17} \mathrm{O}(\mathrm{FT})\right), \Delta^{17} \mathrm{O}$ of bulk ozone, $\Delta{ }^{17} \mathrm{O}$ of $\mathrm{OH}$, and parameters and variables driving the local cycling and oxidation of $\mathrm{NO}_{2}:\left[\mathrm{O}_{3}\right],[\mathrm{BrO}],\left[\mathrm{HO}_{2}\right],\left[\mathrm{CH}_{3} \mathrm{O}_{2}\right]$ and $T$.

At the same time, the other parameters and variables impact FA, FA / FPI, $\delta^{15} \mathrm{~N}(\mathrm{FA})$ and $\Delta^{17} \mathrm{O}$ (FA). These are $f_{\text {cage }}$, $f_{\exp }, A, \rho, k, q, \Phi, D, \mathrm{FS} / \mathrm{FPI}$, the snow accumulation distribution and the $\mathrm{O}_{3}$ column.

\subsubsection{Modified Rayleigh plots}

From ice cores, one can measure $\delta^{15} \mathrm{~N}(\mathrm{FA}), \Delta^{17} \mathrm{O}$ (FA), $\omega(\mathrm{FA})$ and the annual snow accumulation rates $(A)$, thus allowing the calculation of $\mathrm{FA}=\omega(\mathrm{FA}) \times A$. In this section and the following, we attempt to provide an interpretation for $\delta^{15} \mathrm{~N}(\mathrm{FA})$ values measured from ice cores. To this end, we use a data representation which we term "modified Rayleigh plot", where $\ln \left(\delta^{15} \mathrm{~N}(\mathrm{FA})+1\right)$ is plotted against $\ln (\mathrm{FA})$ rather than $\ln (\omega(\mathrm{FA}))$, since it includes the variability in $A$ in contrast to $\omega(\mathrm{FA})$. Figure 9 summarizes the results obtained for most of the sensitivity tests which impact FA / FPI, FA and $\delta^{15} \mathrm{~N}(\mathrm{FA})$, i.e., tests where the following variables are changed: $\Phi, A, \rho, k, q, f_{\text {cage }}, f_{\text {exp }}, D$, FS / FPI, FPI, $\mathrm{O}_{3}$ column and the snow accumulation distribution in the year. The thick black dashed curve in Fig. 9 represents the DC realistic simulation in which $\Phi$ is varied to obtain changes in FA and $\delta^{15} \mathrm{~N}(\mathrm{FA})$. The curve is almost linear, with a slope of -0.064 passing through the "starting point", whose coordinates are $\left(\ln (\mathrm{FPI}), \ln \left(\delta^{15} \mathrm{~N}(\mathrm{FPI})+1\right)\right)$. For instance, this means that a 


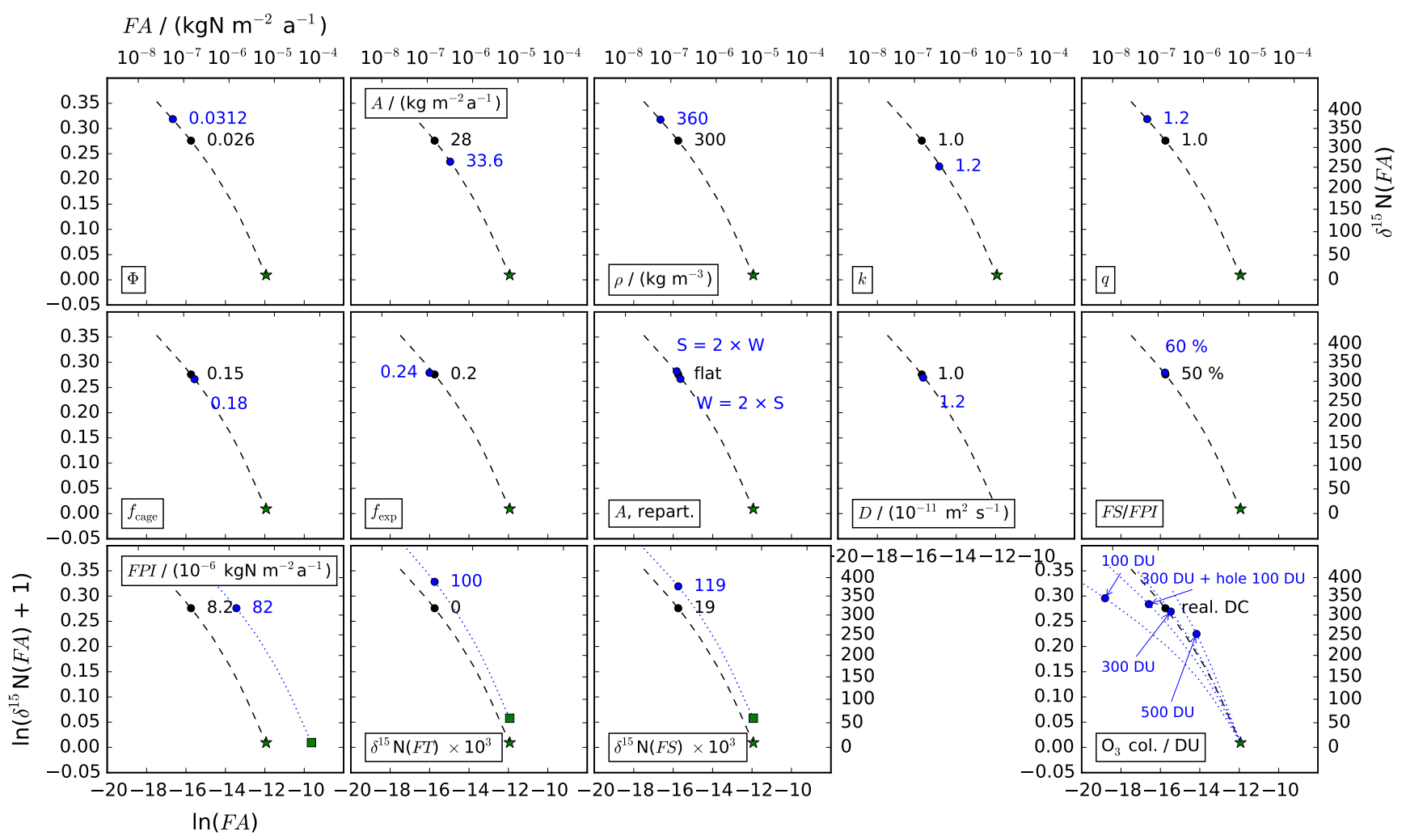

Figure 9. Modified Rayleigh plots of the sensitivity tests to the TRANSITS model. Only the tests which imply significant changes in FA and $\delta^{15} \mathrm{~N}(\mathrm{FA})$ are shown. The green star represents the starting point, whose coordinates are $\left(\ln (\mathrm{FPI}), \ln \left(\delta^{15} \mathrm{~N}(\mathrm{FA})+1\right)\right)$, and the thick dashed lines represent the curve which is obtained for the realistic DC simulation ( $\Phi$ varied). The other dashed blue curves represent the consequences of a change in the starting point (squares) or in the ozone column.

decrease in the archived flux (FA, i.e., changes in FA / FPI) corresponds to an increase in $\delta^{15} \mathrm{~N}(\mathrm{FA})$.

Most of the sensitivity simulation outputs fall on the thick dashed black curve, which represents the DC realistic simulation. We also observe from Fig. 9 that some simulations fall on curves which have different slopes or which have the same slope but different starting points. The parameters and variables are therefore sorted into 3 groups: those which control the "starting point", those which control the slope in the modified Rayleigh plot and those which control the horizontal and vertical distances from the starting point, i.e., the final position on the curve.

\subsubsection{Controls on the "starting point"}

Figure 9 shows that the starting point is determined by FPI and $\delta^{15} \mathrm{~N}(\mathrm{FT})$ and $\delta^{15} \mathrm{~N}(\mathrm{FS})$. On the one hand, changes in FPI lead to a horizontal shift of the starting point (green star in Fig. 9) and, all other things being equal, to a horizontal shift of the entire line in this plot. On the other hand, changes in the $\delta^{15} \mathrm{~N}$ value in the primary input $\left(\delta^{15} \mathrm{~N}(\mathrm{FT})\right.$ and $\left.\delta^{15} \mathrm{~N}(\mathrm{FS})\right)$ lead to a vertical shift of the starting point and the entire curve. Changes in the $f_{\exp }$ also result in a slight horizontal shift of the simulated "archived point". Indeed, $f_{\exp }$ sets the net horizontal export of nitrate from the atmospheric box, which results in more or less of the primary input flux lost through this process. In the case of an increasing $f_{\exp }$ parameter, the "apparent" FPI is therefore shifted to lower FPI values.

Sensitivity tests where $\delta^{15} \mathrm{~N}(\mathrm{FT})$ and $\delta^{15} \mathrm{~N}(\mathrm{FS})$ were shifted by $+100 \%$ show that significant amounts of the nitrogen signatures of the primary nitrate inputs are preserved (71 and $58 \%$, respectively, Table 5), even if the recycling of nitrate has led to a $300 \%$ increase in $\delta^{15} \mathrm{~N}(\mathrm{FA})$. Therefore, $\delta^{15} \mathrm{~N}(\mathrm{FA})$ harbors a fraction of the nitrogen isotopic signature of the primary inputs of nitrate, but we note that it remains almost insignificant given the observed low variability of $\delta^{15} \mathrm{~N}(\mathrm{FT})([-10,+10] \%$; Morin et al., 2009).

\subsubsection{Controls on the slope}

Figure 9 shows that only the ozone column controls the slope of the curve. The spectral distribution of the actinic flux determines the ${ }^{15} \mathrm{~N} /{ }^{14} \mathrm{~N}$ fractionation constant associated with nitrate photolysis $\left({ }^{15} \varepsilon_{\text {pho }}\right)$ (Frey et al., 2009) and hence the slope of the curve. In the case of the DC reference simulation, a yearly mean apparent fractionation constant $\left({ }^{15} \varepsilon_{\text {app }}\right)$ of $-55.1 \%$ was calculated for ${ }^{15} \varepsilon_{\text {pho }}$ ranging from -52.9 
Table 7. Overview of the TRANSITS results for the sensitivity tests.

\begin{tabular}{|c|c|c|c|c|c|c|c|c|c|}
\hline \multirow{2}{*}{$\begin{array}{l}\text { Tested } \\
\text { variable } \\
\text { Realistic simulation }\end{array}$} & \multirow{2}{*}{$\begin{array}{l}\text { Tested values } \\
\text { (reference value) }\end{array}$} & \multicolumn{2}{|c|}{$\begin{array}{c}\text { FA / } \\
\left(10^{-6} \mathrm{kgN} \mathrm{m}^{2} \mathrm{a}^{-1}\right) \\
(\text { abs. diff. })\end{array}$} & \multicolumn{2}{|c|}{$\begin{array}{l}10^{2} \times \text { FA / FPI } \\
(\text { abs. diff. })\end{array}$} & \multicolumn{2}{|c|}{$\begin{array}{c}10^{3} \times \delta^{15} \mathrm{~N}(\mathrm{FA}) \\
(\text { abs. diff. })\end{array}$} & \multicolumn{2}{|c|}{$\begin{array}{c}10^{3} \times \Delta^{17} \mathrm{O}(\mathrm{FA}) \\
\text { (abs. diff.) }\end{array}$} \\
\hline & & 0.15 & & 1.77 & & 317.7 & & 17.8 & \\
\hline$h_{\mathrm{AT}} / \mathrm{m}$ & $500(\mathbf{5 0})$ & 0.15 & $(=)$ & 1.77 & $(=)$ & 317.7 & $(=)$ & 17.8 & $(=)$ \\
\hline$\gamma\left(\mathrm{NO}_{3}^{-}\right) /\left(\mathrm{ng} \mathrm{m}^{-3}\right)$ & $\begin{array}{l}\text { Real. ideal. DC } \times 10 \\
(\text { Real. ideal. DC) }\end{array}$ & 0.15 & $(=)$ & 1.77 & $(=)$ & 317.7 & $(=)$ & 17.8 & $(=)$ \\
\hline FP / $\left(10^{-6} \mathrm{kgN} \mathrm{m}^{-2} \mathrm{a}^{-1}\right)$ & $82(\mathbf{8 . 2})$ & 1.45 & $(+1.31)$ & 1.77 & $(=)$ & 317.7 & $(=)$ & 17.8 & $(=)$ \\
\hline $10^{3} \times \delta^{15} \mathrm{~N}(\mathrm{FS})$ & $+119(+19)$ & 0.15 & $(=)$ & 1.77 & $(=)$ & 376.0 & $(+58.4)$ & 17.8 & $(=)$ \\
\hline $10^{3} \times \delta^{15} \mathrm{~N}(\mathrm{FT})$ & $+100(0)$ & 0.15 & $(=)$ & 1.77 & $(=)$ & 388.5 & $(+70.9)$ & 17.8 & $(=)$ \\
\hline $10^{3} \times{ }^{15} \varepsilon_{\text {dep }}$ & $0(+10)$ & 0.15 & $(=)$ & 1.77 & $(=)$ & 303.5 & $(-14.2)$ & 17.8 & $(=)$ \\
\hline $10^{3} \times \Delta^{17} \mathrm{O}(\mathrm{FS})$ & $0(\mathbf{4 2})$ & 0.15 & $(=)$ & 1.77 & $(=)$ & 317.7 & $(=)$ & 16.0 & $(-1.8)$ \\
\hline $10^{3} \times \Delta^{17} \mathrm{O}(\mathrm{FT})$ & $0(\mathbf{3 0})$ & 0.15 & $(=)$ & 1.77 & $(=)$ & 317.7 & $(=)$ & 15.1 & $(-2.7)$ \\
\hline $10^{3} \times \Delta^{17} \mathrm{O}\left(\mathrm{O}_{3}\right)_{\text {bulk }}$ & $0(\mathbf{2 5 . 2})$ & 0.15 & $(=)$ & 1.77 & $(=)$ & 317.7 & $(=)$ & 7.4 & $(-10.4)$ \\
\hline $10^{3} \times \Delta^{17} \mathrm{O}(\mathrm{OH})$ & $0(\mathbf{3})$ & 0.15 & $(=)$ & 1.77 & $(=)$ & 317.7 & $(=)$ & 17.2 & $(-0.6)$ \\
\hline$[\mathrm{BrO}] / \mathrm{pptv}$ & $5.0(\mathbf{2 . 5})$ & 0.15 & $(=)$ & 1.77 & $(=)$ & 317.7 & $(=)$ & 18.2 & $(+0.4)$ \\
\hline$\left[\mathrm{HO}_{2}\right]$ & Est. DC × $10($ Est. DC $)$ & 0.15 & $(=)$ & 1.77 & $(=)$ & 317.7 & $(=)$ & 16.6 & $(-1.2)$ \\
\hline$\left[\mathrm{CH}_{3} \mathrm{O}_{2}\right]$ & Est. DC $\times 10($ Est. DC $)$ & 0.15 & $(=)$ & 1.77 & $(=)$ & 317.7 & $(=)$ & 17.3 & $(-0.5)$ \\
\hline$\left[\mathrm{O}_{3}\right] / \mathrm{ppbv}$ & Obs. DC $\times 10($ Obs. DC $)$ & 0.15 & $(=)$ & 1.77 & $(=)$ & 317.7 & $(=)$ & 18.6 & $(+0.8)$ \\
\hline$T / \mathrm{K}$ & Obs. DC-10 (Obs. DC) & 0.15 & $(=)$ & 1.77 & $(=)$ & 317.7 & $(=)$ & 17.5 & $(-0.3)$ \\
\hline FS / FPI & $0.6(\mathbf{0 . 5})$ & 0.14 & $(-0.0)$ & 1.73 & $(-0.04)$ & 322.4 & $(+4.7)$ & 17.8 & $(=)$ \\
\hline$f_{\text {cage }}$ & $0.18(\mathbf{0 . 1 5})$ & 0.17 & $(+0.03)$ & 2.11 & $(+0.34)$ & 305.5 & $(-12.2)$ & 16.8 & $(-1.0)$ \\
\hline$f_{\exp }$ & $0.24(\mathbf{0 . 2})$ & 0.11 & $(-0.03)$ & 1.36 & $(-0.41)$ & 322.1 & $(+4.5)$ & 18.1 & $(+0.4)$ \\
\hline$A /\left(\mathrm{kg} \mathrm{m}^{-2} \mathrm{a}^{-1}\right)$ & $33.6(\mathbf{2 8})$ & 0.32 & $(+0.17)$ & 3.90 & $(+2.13)$ & 263.9 & $(-53.8)$ & 18.6 & $(+0.8)$ \\
\hline$\rho /\left(\mathrm{kg} \mathrm{m}^{-3}\right)$ & $360(300)$ & 0.06 & $(-0.09)$ & 0.72 & $(-1.05)$ & 373.8 & $(+56.1)$ & 17.0 & $(-0.8)$ \\
\hline$k$ & $1.2(\mathbf{1 . 0})$ & 0.35 & $(+0.21)$ & 4.28 & $(+2.51)$ & 252.0 & $(-65.6)$ & 18.8 & $(+1.1)$ \\
\hline$q$ & $1.2(\mathbf{1 . 0})$ & 0.06 & $(-0.09)$ & 0.70 & $(-1.07)$ & 375.2 & $(+57.5)$ & 16.9 & $(-0.9)$ \\
\hline$\Phi$ & $0.0336(\mathbf{0 . 0 2 6})$ & 0.06 & $(-0.09)$ & 0.70 & $(-1.07)$ & 375.2 & $(+57.5)$ & 16.9 & $(-0.9)$ \\
\hline$D /\left(10^{-11} \mathrm{~m}^{2} \mathrm{~s}^{-1}\right)$ & $1.2(\mathbf{1 . 0})$ & 0.16 & $(+0.01)$ & 1.89 & $(+0.12)$ & 309.4 & $(-8.2)$ & 17.9 & $(+0.1)$ \\
\hline \multirow[t]{2}{*}{ Accumulation distribution } & Winter $=2 \times$ summer & 0.16 & $(+0.02)$ & 1.98 & $(+0.21)$ & 306.1 & $(-11.6)$ & 18.0 & $(+0.3)$ \\
\hline & $\begin{array}{l}\text { Summer }=2 \times \text { winter } \\
\text { (flat) }\end{array}$ & 0.13 & $(-0.01)$ & 1.64 & $(-0.13)$ & 325.9 & $(+8.2)$ & 17.6 & $(-0.2)$ \\
\hline \multirow[t]{4}{*}{$\mathrm{O}_{3}$ column } & $100 \mathrm{DU}$ flat & 0.01 & $(-0.14)$ & 0.08 & $(-1.69)$ & 344.1 & $(+26.4)$ & 15.3 & $(-2.5)$ \\
\hline & 300 DU flat & 0.19 & $(+0.05)$ & 2.33 & $(+0.56)$ & 309.1 & $(-8.6)$ & 18.1 & $(+0.3)$ \\
\hline & 500 DU flat & 0.70 & $(+0.56)$ & 8.58 & $(+6.81)$ & 252.1 & $(-65.5)$ & 19.6 & $(+1.8)$ \\
\hline & $\begin{array}{l}300 \text { DU / } 100 \text { DU hole } \\
\text { (real. DC) }\end{array}$ & 0.06 & $(-0.08)$ & 0.76 & $(-1.01)$ & 328.3 & $(+10.6)$ & 16.9 & $(-0.9)$ \\
\hline
\end{tabular}

to $-78.8 \%$ (Table 5 ). The variability of the curvature of the thick black curve representing the DC reference simulation in Fig. 9 is linked to the greater incorporation of the summertime value of ${ }^{15} \varepsilon_{\text {pho }}$ (Fig. $5 \mathrm{~d}$ ): when FA / FPI increases, ${ }^{15} \varepsilon_{\text {pho }}$ becomes less negative and the curvature decreases. Therefore, the slope of the thick dashed lines in the modified Rayleigh plots is slightly more negative $(-0.064=-64 \%$ o than ${ }^{15} \varepsilon_{\text {app }}$.

Lower ozone columns have a strong impact on FA and $\delta^{15} \mathrm{~N}$ (FA): FA is lower, while $\delta^{15} \mathrm{~N}$ (FA) is higher (Fig. 9). The first effect is explained by higher amounts of UV radiation which reach the ground and therefore increase the photolysis rates. The second effect is linked to the fact that a lower ozone column leads to less negative ${ }^{15} \varepsilon_{\text {pho }}$ values, as observed in spring during the ozone hole period (Figs. 3 and 5d). Indeed, a lower ozone column allows UV radiations of shorter wavelengths in the $280-350 \mathrm{~nm}$ range to reach the ground, i.e., a shift to the blue of the UV spectra, therefore resulting in less negative ${ }^{15} \varepsilon_{\text {pho }}$ values (Frey et al., 2009). Referring to Eq. (2), our sensitivity tests reveals that changes in the ozone column result in changes in UV flux (i.e., in $f$ ) which over-weight the effect due to the UV spectra shift (i.e., in $\left.{ }^{15} \varepsilon_{\text {pho }}\right)$. From our sensitivity tests, we also observe that an ozone hole in late winter/spring (August to November) significantly imprints $\delta^{15} \mathrm{~N}$ (FA) (Fig. 9). Therefore, we suggest that $\delta^{15} \mathrm{~N}(\mathrm{FA})$ archived over the last decades at Dome $\mathrm{C}$ and other East Antarctic Plateau sites could potentially be im- 
printed by changes in the ozone column, especially in spring, when stratospheric ozone destruction processes occur.

\subsubsection{Controls on the distance from the starting point and along the slope}

In the modified Rayleigh plot, the horizontal distance from the starting point is $\ln (\mathrm{FA})-\ln (\mathrm{FPI})=\ln (\mathrm{FA} / \mathrm{FPI})-$ i.e., the horizontal distance from the starting point is directly linked to the trapping efficiency. This quantity is therefore equivalent to the $f$ term used in Eq. (2) because it reflects the nitrate fraction remaining in snow below the photic zone. The trapping efficiency and the intensity of the photolysis are linked because a more intense photolysis is necessary to lead to a lower nitrate trapping efficiency.

In the modified Rayleigh plot, the vertical distance from the starting point is $\ln \left(\delta^{15} \mathrm{~N}(\mathrm{FA})+1\right)-\ln \left(\delta^{15} \mathrm{~N}(\mathrm{FPI})+1\right)$. Figure 9 shows that, at first order, the vertical and horizontal distance from the starting point are linked by the slope. This means that, at a given slope in the modified Rayleigh plot, i.e., at a given spectral distribution of the actinic flux, $\ln \left(\delta^{15} \mathrm{~N}(\mathrm{FA})+1\right)$ is linearly linked with $\ln (\mathrm{FA} / \mathrm{FPI})$, i.e., $\delta^{15} \mathrm{~N}(\mathrm{FA})$ is linked with the trapping efficiency.

Our sensitivity tests have shown that the nitrate trapping efficiency is controlled by $\Phi, A, \rho, k, q, f_{\text {cage }}, f_{\text {exp }}, D$, FS / FPI, $\mathrm{O}_{3}$ column and the snow accumulation distribution in the year. Indeed, $\Phi, f_{\text {cage }}, q$ and $\mathrm{O}_{3}$ column are key parameters and variables in controlling the photolytic mass loss, while $A, \rho, k, D$ and the seasonality in snow accumulation determine nitrate exposure time to the actinic flux. Considering the seasonality of snow accumulation, we observe that it plays a minor role in setting FA / FPI and hence $\delta^{15} \mathrm{~N}(\mathrm{FA})$. The reason is that, in DC conditions, nitrate residence time in the photic zone is very long and set by the other parameters and variables at play in the photolytic process. The same applies to the FS / FPI ratio: the impact on nitrate trapping efficiency is small.

The case of the export flux parameter, $f_{\text {exp }}$, is different. Indeed, it does not impact the residence time of nitrate in the photic zone, nor does it impact its photolytic loss. However, an increase in $f_{\text {exp }}$ results in a greater export of atmospheric nitrate, which is depleted in ${ }^{15} \mathrm{~N}$ with respect to nitrate in snow (data not shown in Table 5). In fact, the increase in $f_{\text {exp }}$ also leads to higher $\delta^{15} \mathrm{~N}(\mathrm{FA})$ and $\delta^{15} \mathrm{~N}(\mathrm{FE})$ values. In the two simulations tested, $\delta^{15} \mathrm{~N}(\mathrm{FE})$ is always smaller than $\delta^{15} \mathrm{~N}(\mathrm{FPI})$, which means that the "removal" of nitrate featuring $\delta^{15} \mathrm{~N}(\mathrm{FE}) \leq \delta^{15} \mathrm{~N}(\mathrm{FPI})$ is compensated for by the increase in $\delta^{15} \mathrm{~N}$ in the archived nitrate. This increase in $\delta^{15} \mathrm{~N}(\mathrm{FA})$ is therefore not due to an increased photolysis intensity but to the isotopic mass balance.

The parameters and variables $\Phi, k, A, \rho$ and $q$ have the largest impact on the nitrate trapping efficiency (FA / FPI), which mostly impacts $\delta^{15} \mathrm{~N}(\mathrm{FA})$. The fact that they control FA / FPI and $\delta^{15} \mathrm{~N}(\mathrm{FA})$ to a similar extent is not surprising since $k, A, \rho$ and $q$ are intimately linked together in deter- mining the residence time in the photic layer and thus the exposure time of nitrate to near-surface conditions.

In this paper, the model does not aim at representing the counter ion of nitrate. However, we acknowledge that the diffusion of nitrate may be different depending on the nature of its counter-ion $\left(\mathrm{H}^{+}\right.$or, for example, $\left.\mathrm{Ca}^{2+}\right)$, especially when glacial conditions are considered (Röthlisberger et al., 2000).

\subsubsection{Method to interpret FA and $\delta^{15} \mathrm{~N}(\mathrm{FA})$ measured in ice cores}

In this section we summarize our recommended approach to interpret nitrate isotope records in ice cores. The approach presented here is valid provided that pieces of evidence show that the nitrate recycling (i.e., loss, local oxidation and deposition) observed today has also occurred in the past. In glacial conditions, nitrate archived in ice cores is mostly associated with calcium ions and it is known that dust inputs to Antarctica were high (Wolff et al., 2010). In such conditions, it is likely that atmospheric nitrate fixed to dust particles which could eventually be embedded in a snow crystal, thus increasing nitrate cage recombination effects and significantly hampering the release of nitrate photo-products to the atmosphere. The ice-core interpretation method present here must therefore be followed in the case where elevated $\delta^{15} \mathrm{~N}(\mathrm{FA})$ values are measured, thus providing an evidence for the efficient photolytic nitrate removal from snow.

Information potentially accessible from ice cores are $\omega(\mathrm{FA})$ and $\delta^{15} \mathrm{~N}(\mathrm{FA})$. Knowledge on the past snow accumulation rates (deduced from other proxies) allow the calculation of $\mathrm{FA}=\omega(\mathrm{FA}) \times A$. If FA and $\delta^{15} \mathrm{~N}(\mathrm{FA})$ data align in the modified Rayleigh plot, one can deduce that the ozone column is likely to have remained constant through time, and its value can be inferred from the slope of the curve (e.g., lower right panel in Fig. 9). In this case as well, FPI is likely to have remained constant through time and its value can be retrieved, provided that $\delta^{15} \mathrm{~N}(\mathrm{FPI})$ has remained constant as well and that one can assume its value. If the data do not align in the modified Rayleigh plot, it is likely that either the ozone column or FPI, or both, has varied over time. If an assumption on the ozone column can be made, or if this information can be obtained from other considerations, one can determine past changes in FPI provided that an assumption on $\delta^{15} \mathrm{~N}(\mathrm{FPI})$ can be made. Figure 11 gives a schematic of the method to determine FPI from the measurement of $\omega(\mathrm{FA})$ and $\delta^{15} \mathrm{~N}(\mathrm{FA})$ in ice cores. As discussed above, a portion of $\delta^{15} \mathrm{~N}(\mathrm{FT})$ and $\delta^{15} \mathrm{~N}(\mathrm{FS})$ is left in $\delta^{15} \mathrm{~N}(\mathrm{FA})$. However, $\delta^{15} \mathrm{~N}(\mathrm{FT})$ and $\delta^{15} \mathrm{~N}(\mathrm{FS})$ are small when compared to the ca. $250 \%$ added under the effect of nitrate recycling at the airsnow interface, thereby erasing information on $\delta^{15} \mathrm{~N}(\mathrm{FT})$ and $\delta^{15} \mathrm{~N}(\mathrm{FS})$. In other words, $\delta^{15} \mathrm{~N}(\mathrm{FA})$ is almost insensitive to change in $\delta^{15} \mathrm{~N}(\mathrm{FT})$ and $\delta^{15} \mathrm{~N}(\mathrm{FS})$. 


\subsection{Parameters and variables controlling $\Delta^{17} \mathrm{O}(\mathrm{FA})$}

The parameters and variables controlling $\Delta^{17} \mathrm{O}(\mathrm{FA})$ can be sorted into four groups:

- $f_{\text {cage, }}$ which controls the cage effects;

- those which impact FA / FPI, which sets the magnitude of loss and hence the magnitude of the cage effects;

- $\Delta^{17} \mathrm{O}(\mathrm{FT})$ and $\Delta^{17} \mathrm{O}(\mathrm{FS})$, which set $\Delta^{17} \mathrm{O}$ in the primary source of nitrate;

- $\Delta{ }^{17} \mathrm{O}\left(\mathrm{O}_{3}\right)_{\text {bulk }}, \Delta^{17} \mathrm{O}(\mathrm{OH}),[\mathrm{BrO}],\left[\mathrm{HO}_{2}\right],\left[\mathrm{CH}_{3} \mathrm{O}_{2}\right]$, $\left[\mathrm{O}_{3}\right]$ and $T$, which set $\Delta^{17} \mathrm{O}$ in the secondary source of nitrate in the atmosphere.

\subsubsection{Correction of the reduction in $\Delta^{17} \mathrm{O}(\mathrm{FA})$ imposed by cage effects}

We have shown that cage recombination effects following nitrate photolysis in snow lead to positive simulated ${ }^{17} E_{\text {app }}$ values in snow. For instance, for DC realistic conditions (i.e., for $f_{\text {cage }}=0.15$ and FA $\left./ \mathrm{FPI}=1.8 \%\right), \Delta{ }^{17} \mathrm{O}(\mathrm{FA})$ is reduced by $\approx 6 \%$ because of cage effects (Fig. $6 \mathrm{c}$ ). To calculate the reduction in $\Delta^{17} \mathrm{O}(\mathrm{FA})$ as a result of cage recombination effects, we have run TRANSITS in the DC realistic simulation by varying $\Phi$ from 0 to 0.036 and with an $f_{\text {cage }}$ parameter set to 0 and 0.15 in order to switch the cage effects on and off, respectively.

We denote $\Delta^{17} \mathrm{O}$ (FA, corr.), the $\Delta^{17} \mathrm{O}(\mathrm{FA})$ value corrected from cage effects, which was estimated here by setting $f_{\text {cage }}=0$. Figure $10 \mathrm{c}$ shows that, for $\ln (\mathrm{FA} / \mathrm{FPI})<-2$ (i.e., FA $/$ FPI $<14 \%$ ), the $\Delta^{17} \mathrm{O}$ (FA, corr.)/ $\Delta^{17} \mathrm{O}$ (FA) ratio is linear with $\ln (\mathrm{FA} / \mathrm{FPI}): \Delta^{17} \mathrm{O}$ (FA, corr. $) / \Delta^{17} \mathrm{O}$ (FA) $=-0.063 \times \ln (\mathrm{FA} / \mathrm{FPI})+1.052$. In Sect. 4.1.6, we have shown that the FA / FPI ratio can be retrieved from the measurement of $\delta^{15} \mathrm{~N}(\mathrm{FA})$ given a hypothesis on the $\mathrm{O}_{3}$ column and $\delta^{15} \mathrm{~N}(\mathrm{FPI})$. Using this approach, $\Delta^{17} \mathrm{O}(\mathrm{FA})$ is corrected from the cage effect.

From Fig. 10b, we observe that $\Delta^{17} \mathrm{O}$ (FA, corr.) reaches a plateau at around $23.5 \%$ o for low nitrate trapping efficiencies $(\ln (\mathrm{FA} / \mathrm{FPI})<-3$, i.e., FA / FPI $<5 \%)$. Although we anticipate that $\Delta^{17} \mathrm{O}$ (FA, corr.) is mostly controlled by the local cycling and oxidation of $\mathrm{NO}_{2}$ (as previously observed from sensitivity tests), there is still the need to separate the $\Delta{ }^{17} \mathrm{O}$ impact of local cycling and oxidation of $\mathrm{NO}_{2}$ from those of $\Delta^{17} \mathrm{O}(\mathrm{FT})$ and $\Delta^{17} \mathrm{O}(\mathrm{FS})$.

\subsubsection{Contributors to $\Delta^{17} \mathrm{O}(\mathrm{FA}$, corr.)}

In this section, we consider $\Delta^{17} \mathrm{O}(\mathrm{FT}), \quad \Delta^{17} \mathrm{O}(\mathrm{FS})$, $\Delta{ }^{17} \mathrm{O}\left(\mathrm{NO}_{2}\right.$, PSS $)$ and $\Delta^{17} \mathrm{O}$ (add. $\left.\mathrm{O}\right)$, which impact $\Delta^{17} \mathrm{O}$ (FA, corr.). To determine the scaled contributions of the variable $\Delta^{17} \mathrm{O}(X)$, we have run the TRANSITS model with this variable set to 0 . We denote $\overline{\Delta^{17} O \text { (FA) }}$ the $\Delta^{17} \mathrm{O}$ (FA) value obtained when $\Delta^{17} \mathrm{O}(X)$ has been set to 0. From the previous section, we can calculate $\overline{\Delta^{17} \mathrm{O} \text { (FA, corr.) }}$ based on the computed FA / FPI value. For $\Delta^{17} \mathrm{O}(X)$, we calculate the scaled contribution to $\Delta^{17} \mathrm{O}(\mathrm{FA}$, corr. ) as $\left(\Delta^{17} \mathrm{O}\right.$ (FA, corr. $\left.)-\overline{\left.\Delta^{17} \mathrm{O} \text { (FA, corr. }\right)}\right) / \Delta^{17} \mathrm{O}(X)$.

Figure 10d shows the obtained scaled contributions to $\Delta{ }^{17} \mathrm{O}$ (FA, corr.). For example, for $\ln (\mathrm{FA} / \mathrm{FPI})<-3$, we observe that the statistical contribution of the variable $\Delta^{17} \mathrm{O}\left(\mathrm{NO}_{2}\right.$, PSS) to the budget of $\Delta^{17} \mathrm{O}$ (FA, corr.) is $55 \%$, which means that if $\Delta^{17} \mathrm{O}\left(\mathrm{NO}_{2}\right.$, PSS $)=20 \%$, then this variable will contribute to $\Delta^{17} \mathrm{O}$ (FA, corr.) by as much as $0.55 \times 20=11 \%$. For the same nitrate trapping efficiency, $\Delta^{17} \mathrm{O}(\mathrm{FT})$ contributes much less, i.e., by $13 \%$ of $\Delta^{17} \mathrm{O}(\mathrm{FT})$, which is to say by $3.9 \%$ o for $\Delta^{17} \mathrm{O}(\mathrm{FT})=30 \%$ 。

From the same panel, we observe that, for $\ln$ (FA / FPI $<$ -2 , the scaled contributions of $\Delta{ }^{17} \mathrm{O}\left(\mathrm{NO}_{2}\right.$, PSS $)$ and $\Delta{ }^{17} \mathrm{O}$ (add. O) to $\Delta^{17} \mathrm{O}$ (FA, corr.) are greater than 50 and $25 \%$ of their respective values, i.e., a sum which is 3 times the scaled contributions of $\Delta^{17} \mathrm{O}(\mathrm{FT})$ and $\Delta^{17} \mathrm{O}(\mathrm{FS})$, which contribute to less than 14 and $11 \%$ of their respective values. This means that, in the conditions tested (i.e., low trapping efficiencies which characterize the Antarctic Plateau), $\Delta^{17} \mathrm{O}$ (FA, corr.) is poorly controlled by $\Delta^{17} \mathrm{O}$ (FS) and $\Delta^{17} \mathrm{O}(\mathrm{FT})$ and dominated by local cycling and oxidation of $\mathrm{NO}_{2}$. We note that, for very low nitrate trapping efficiencies $(\ln (\mathrm{FA} / \mathrm{FPI})<-3)$, the sum of the scaled contributions of $\Delta^{17} \mathrm{O}\left(\mathrm{NO}_{2}\right.$, PSS $)+\Delta^{17} \mathrm{O}($ add. $\mathrm{O})$ and of $\Delta^{17} \mathrm{O}(\mathrm{FS})$ $+\Delta^{17} \mathrm{O}(\mathrm{FT})$ reaches a plateau at 82 and $18 \%$, respectively. From Fig. 10a, we observe that these plateaus are consistent with $\operatorname{ANR}(\mathrm{FA})$ values $(\approx \mathrm{FD} / \mathrm{FPI})$ around 4 , i.e., the archived nitrate has been recycled four times on average and is therefore mostly secondary nitrate which has been locally reformed.

For low nitrate trapping efficiencies, we also observe that the scaled contribution of $\Delta^{17} \mathrm{O}(\mathrm{FT})$ increases while that of $\Delta^{17} \mathrm{O}(\mathrm{FS})$ decreases. This is linked to the preferential incorporation, yet small, of the local $\Delta{ }^{17} \mathrm{O}$ signature on the summertime primary source of nitrate.

Figure 10e represents an application of what precedes in the case of Dome C, i.e., using $\Delta^{17} \mathrm{O}(\mathrm{FT})=30 \%, \Delta^{17} \mathrm{O}(\mathrm{FS})$ $=42 \%, \Delta^{17} \mathrm{O}\left(\mathrm{NO}_{2}\right.$, PSS $)=31.3 \%$ and $\Delta^{17} \mathrm{O}$ (add. O) $=3 \%$. Figure 10f reproduces the relationship between $\delta^{15} \mathrm{~N}(\mathrm{FA})$ and FA / FPI as a function of ozone column. In the case of the present-day DC conditions (realistic DC $\mathrm{O}_{3}$ column and $\delta^{15} \mathrm{~N}(\mathrm{FA})$ in range $[151,334] \%$, Fig. 7c), we find that the relative contribution of $\Delta{ }^{17} \mathrm{O}\left(\mathrm{NO}_{2}\right.$, PSS $), \Delta^{17} \mathrm{O}$ (add. O), $\Delta{ }^{17} \mathrm{O}$ (FT) and $\Delta \Delta^{17} \mathrm{O}$ (FS) to $\Delta^{17} \mathrm{O}$ (FA, corr.) are in the following ranges: [52, 55], [26, 28], [11, 13] and [5, 9] \%, respectively. In DC conditions, $\Delta{ }^{17} \mathrm{O}$ (FA, corr.) therefore harbors almost two-thirds of the oxygen isotope signature of the local cycling and oxidation of $\mathrm{NO}_{2}$ and the remaining signature of primary inputs of nitrate is small. This is such because the archived nitrate has undergone 4.0 cycles before being ultimately trapped in snow below the photic zone (Fig. 10a). 


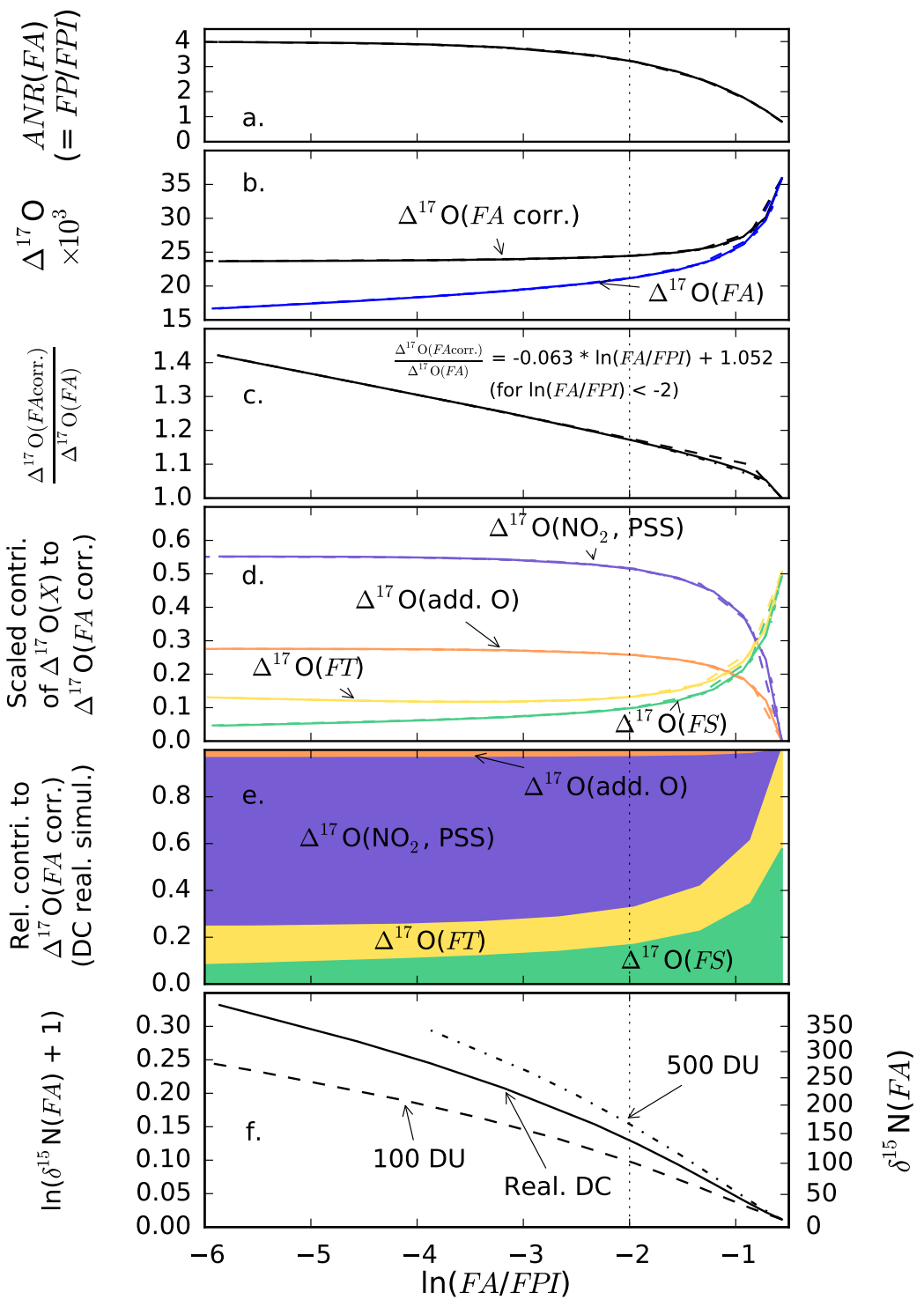

Figure 10. TRANSITS simulations of the reduction in $\Delta^{17} \mathrm{O}(\mathrm{FA})$ under the cage recombination effects and scaled contributions to $\Delta^{17} \mathrm{O}(\mathrm{FA}$, corr.) as a function of nitrate trapping efficiency $(\ln (\mathrm{FA} / \mathrm{FPI})$ ). (a) Average number of recyclings undergone by the archived nitrate $(\mathrm{ANR}(\mathrm{FA}))$, (c) $\Delta^{17} \mathrm{O}(\mathrm{FA})$ with and without cage effect and (d) the associated $\Delta^{17} \mathrm{O}$ (FA. corr.) $/ \Delta^{17} \mathrm{O}(\mathrm{FA})$ ratio, (e) the scaled contributions of $\Delta^{17} \mathrm{O}\left(\mathrm{NO}_{2}\right.$. PSS $), \Delta^{17} \mathrm{O}$ (add. O), $\Delta^{17} \mathrm{O}(\mathrm{FT})$ and $\Delta^{17} \mathrm{O}(\mathrm{FS})$, (f) the relative contributions to $\Delta^{17} \mathrm{O}(\mathrm{FA}$, corr.) in the DC case $\left(\Delta^{17} \mathrm{O}\left(\mathrm{NO}_{2}\right.\right.$. PSS $)=31.3 \%$ o, $\Delta^{17} \mathrm{O}($ add. $\mathrm{O})=3 \%, \Delta^{17} \mathrm{O}(\mathrm{FT})=30 \%$ and $\Delta^{17} \mathrm{O}(\mathrm{FS})=42 \%$ ) , and $(\mathrm{g}) \delta^{15} \mathrm{~N}(\mathrm{FA})$ as a function of the ozone column. Note that for panels (a-e), the curves for the three $\mathrm{O}_{3}$ column case are almost superimposed. The vertical dashed line at $\ln (\mathrm{FA} / \mathrm{FPI})=-2$ represents a threshold value below which the $\Delta^{17} \mathrm{O}(\mathrm{FA}$, corr. $) / \Delta^{17} \mathrm{O}(\mathrm{FA})$ ratio is linear with $\ln (\mathrm{FA} / \mathrm{FPI})$.

\subsubsection{Method to interpret $\Delta^{17} \mathrm{O}(\mathrm{FA}$, corr.) derived from ice-core measurements}

In this section, we suggest a method to interpret $\Delta^{17} \mathrm{O}(\mathrm{FA})$ values measured from ice cores. In Sect. 4.2.1, we have provided a method to correct $\Delta^{17} \mathrm{O}$ (FA) from cage effects from the knowledge of the variations in nitrate trapping efficiency (FA / FPI), which, we note, can be determined from $\delta^{15} \mathrm{~N}(\mathrm{FA})$ values and hypothesis on past variations in $\delta^{15} \mathrm{~N}(\mathrm{FPI})$ and in the ozone column (see also Fig. 11). In this way, we obtain a time series of $\Delta^{17} \mathrm{O}$ (FA, corr.) in the past, a variable which is only influenced by past changes in $\Delta{ }^{17} \mathrm{O}\left(\mathrm{NO}_{2}\right.$, PSS $), \Delta^{17} \mathrm{O}$ (add. O), $\Delta{ }^{17} \mathrm{O}$ (FT) and $\Delta^{17} \mathrm{O}$ (FS) and that of their scaled contributions, as shown in the previous section.

To determine the variations in the scaled contributions of $\Delta \Delta^{17} \mathrm{O}\left(\mathrm{NO}_{2}\right.$, PSS $), \Delta^{17} \mathrm{O}$ (add. $\left.\mathrm{O}\right), \Delta{ }^{17} \mathrm{O}(\mathrm{FT})$ and $\Delta^{17} \mathrm{O}$ (FS), we use the nitrate trapping efficiency determined in Sect. 4.1.6. Assumptions on or evidence of past changes in one or several of the four variables controlling $\Delta^{17} \mathrm{O}(\mathrm{FA}$, 


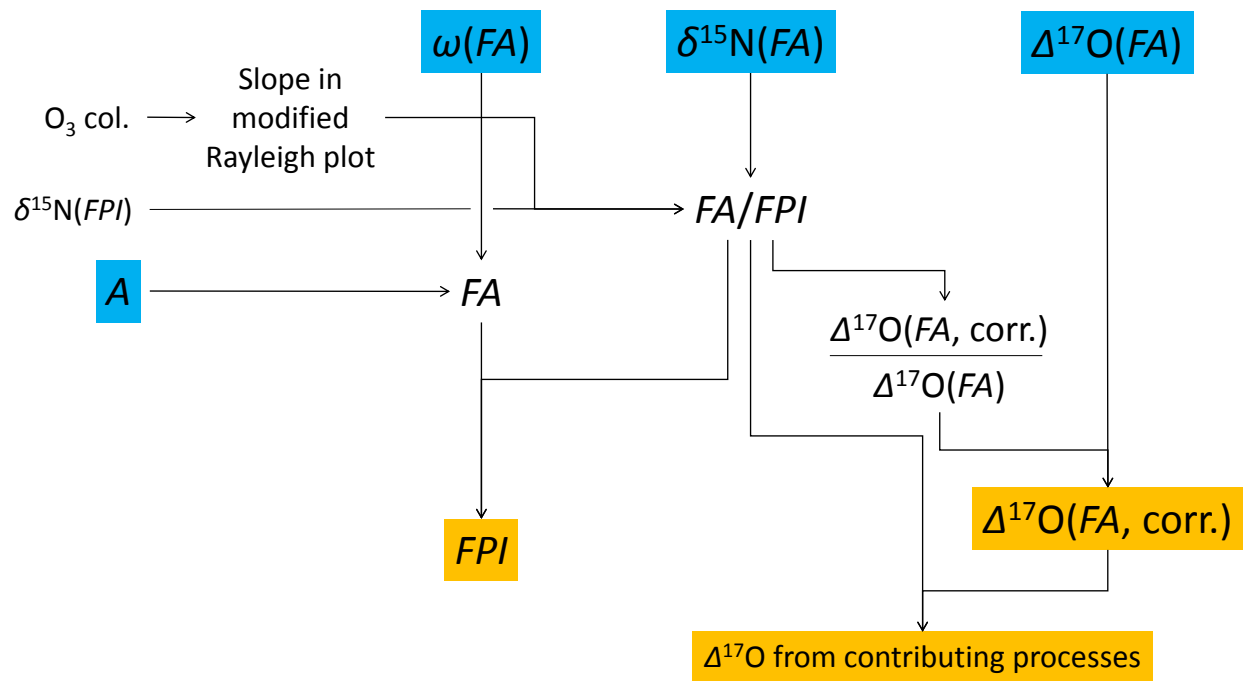

Figure 11. Schematic of the suggested method to retrieve information about the variables in the orange boxes using the measurement of $\omega(\mathrm{FA}), \delta^{15} \mathrm{~N}(\mathrm{FA}), \Delta^{17} \mathrm{O}(\mathrm{FA})$ and the annual snow accumulation rates accessible in ice cores.

corr.) (i.e., $\Delta^{17} \mathrm{O}\left(\mathrm{NO}_{2}\right.$, PSS $), \Delta^{17} \mathrm{O}\left(\right.$ add. O), $\Delta{ }^{17} \mathrm{O}(\mathrm{FT})$ and $\Delta^{17} \mathrm{O}(\mathrm{FS})$ ) allow for past changes in the other ones to be determined. For instance, assuming that $\Delta^{17} \mathrm{O}$ (add. O), $\Delta^{17} \mathrm{O}(\mathrm{FT})$ and $\Delta^{17} \mathrm{O}(\mathrm{FS})$ have remained constant over time allows for determination of past changes in the local cycling of $\mathrm{NO}_{2}$ above the East Antarctic Plateau.

Figure 11 gives a schematic of the method to determine $\Delta^{17} \mathrm{O}$ (FA, corr.) as well as in the scaled contributions of $\Delta \Delta^{17} \mathrm{O}\left(\mathrm{NO}_{2}\right.$, PSS $), \Delta^{17} \mathrm{O}$ (add. O), $\Delta^{17} \mathrm{O}(\mathrm{FT})$ and $\Delta^{17} \mathrm{O}$ (FS) from the measurement of $\omega(\mathrm{FA}), A, \delta^{15} \mathrm{~N}(\mathrm{FA})$ and $\Delta^{17} \mathrm{O}(\mathrm{FA})$ in ice cores.

If we assume that modern conditions in East Antarctica have prevailed in the past, we anticipate from Fig. 10 that almost two-thirds of the variations $\Delta^{17} \mathrm{O}$ (FA, corr.) are the result of variations in $\Delta^{17} \mathrm{O}\left(\mathrm{NO}_{2}\right.$, PSS $)$ and $\Delta^{17} \mathrm{O}$ (add. O). In this case, the potential for $\Delta^{17} \mathrm{O}$ (FA, corr.) to trace past changes in atmospheric oxidation at the global scale is weak. However, in such conditions, $\Delta^{17} \mathrm{O}$ (FA, corr.) would instead hold information about the local and summertime atmospheric oxidation above the East Antarctic Plateau.

\section{Summary and conclusions}

The TRANSITS model is a conceptual, multi-layer, 1-D isotopic model which represents the air-snow transfer of nitrate and its isotopic composition on the Antarctic Plateau at a time resolution of around 1 week. It rests on the conceptual model initially proposed by Davis et al. (2008) and on the fact that nitrate photolysis is the process dominating nitrate mass loss at the low-accumulation sites which characterize the Antarctic Plateau (Frey et al., 2013; Erbland et al., 2013). The particularity of TRANSITS is its representation of the isotopic composition of nitrate $\left(\delta^{15} \mathrm{~N}\right.$ and $\left.\Delta^{17} \mathrm{O}\right)$.
When using a realistic scenario representing the Dome C conditions, the model reproduces well the variations in concentrations and isotopic time series observed in the atmospheric and skin layer compartments, thus supporting the theory of Davis et al. (2008). While the nitrogen isotope ratio is well reproduced by the model, the simulated $\Delta^{17} \mathrm{O}$ data in the air-snow interface are lower than the observations. This has been attributed to simplifications in the description of the local cycling and oxidation of $\mathrm{NO}_{2}$. One consequence is that simulated $\Delta^{17} \mathrm{O}$ values in the snowpack and in the archived nitrate are lower than the observations. Nevertheless, cage recombination effects occurring in snow are well reproduced by the model, as shown by the agreement between the simulated and observed values of the apparent fractionation constant $\left({ }^{17} E_{\text {app }}\right)$. The representation of nitrate diffusion within the snowpack allows for nitrate mass fraction and isotope depth profiles to be simulated, which are consistent with observations. Under the DC realistic simulation conditions, the quantum yield imposed to reproduce the observations $(0.026)$ is compatible with the idea that nitrate lies in two different domains (Meusinger et al., 2014). The comparison of the simulated and observed $\mathrm{NO}_{2}$ fluxes shows that the simulation is 9 to 18 times higher than the observed flux at Dome $\mathrm{C}$ in 2009-2010 and 2011-2012. This discrepancy could result from the simplifications made in the model regarding the fates of the nitrate photolysis products.

TRANSITS has been used to investigate the spatial variability in the mass and isotopic composition of the nitrate archived from the Antarctic coast to the plateau (Dome C to Vostok) obtained from 21 snow pits collected from 2007 to 2010 (Erbland et al., 2013). Using the realistic simulation and the snow accumulation range observed on the zone of interest (from 20 to $600 \mathrm{~kg} \mathrm{~m}^{-2} \mathrm{a}^{-1}$ ), we have shown that, in presentday conditions, changes in snow accumulation rates are suf- 
ficient to explain the first-order variations in $\delta^{15} \mathrm{~N}$ in the archived nitrate. This suggests that the principles at the heart of the model (i.e., photolytic mass loss, isotopic fractionation and exposure time of nitrate) are adequate. Moreover, the use of a nitrate primary input flux of $8.2 \times 10^{-6} \mathrm{kgN} \mathrm{m}^{-2} \mathrm{a}^{-1}$ is consistent with the observations.

We proposed some improvements and guidelines for future work on the TRANSITS model. First, the model requires that $\mathrm{NO}_{x}$ chemistry at Dome $\mathrm{C}$ be fully understood, in particular the high $\mathrm{NO}_{2}$ / NO ratio observed (Frey et al., 2015). Then, the model will benefit from the measurements of $\Delta{ }^{17} \mathrm{O}(\mathrm{NO}), \Delta^{17} \mathrm{O}\left(\mathrm{NO}_{2}\right)$ or $\Delta{ }^{17} \mathrm{O}$ in other key species participating in the oxidation scheme $\left(\mathrm{HO}_{2}, \mathrm{RO}_{2}, \mathrm{BrO}\right)$. Additional processes or mechanisms could be implemented, such as nitrate pools featuring different photolytic capacities, modeled by a different quantum yield that would vary in space and time. Some additional parameters could also be taken into account, such as the latitude of the simulated site, to better represent plateau sites other than Dome C. The radiative transfer model TARTES (Libois et al., 2013) could be explicitly incorporated into TRANSITS. This would allow the modeling of the $e$-folding attenuation depth dependence with respect to the physical and chemical properties of the snowpack. The explicit representation of the export and depositions fluxes (using horizontal and vertical air mass velocities, respectively) could also be explored as well as the explicit description of the erosion of the snow surface by the wind.

A framework for the interpretation of nitrate isotope records in ice cores is proposed. From ice cores, the following data are accessible: $\omega(\mathrm{FA}), \delta^{15} \mathrm{~N}(\mathrm{FA}), \Delta{ }^{17} \mathrm{O}(\mathrm{FA})$ and the annual snow accumulation rates. The interpretation framework described in this paper will be applicable to ice-core records which display proof of significant nitrate recycling, e.g., on the basis of elevated $\delta^{15} \mathrm{~N}(\mathrm{FA})$ values. In this case, sensitivity tests have shown that $\delta^{15} \mathrm{~N}(\mathrm{FA})$ is the result of a ${ }^{15} \mathrm{~N} /{ }^{14} \mathrm{~N}$ fractionation constant which is set by the UV radiation spectrum (i.e., set by the ozone column above the site of interest). Indeed, the ozone column controls the slope in the "modified Rayleigh plot" introduced in this study. At a given ozone column, $\delta^{15} \mathrm{~N}(\mathrm{FA})$ is controlled by (1) the nitrate trapping efficiency (i.e., the ratio of the archived flux versus the primary nitrate inputs, FA / FPI), which determines the exposure time of nitrate and thus the intensity of nitrate recycling and, to a lesser extent, by (2) the $\delta^{15} \mathrm{~N}$ of the primary sources of nitrate whose variations are negligible in comparison to the change produced by the photolysis loss.

We have observed that the major controls on FA / FPI are the photolytic quantum yield $(\Phi)$, the annual snow accumulation rate $(A)$, the snow density $(\rho)$, the photic zone compression factor $(k)$ and the actinic flux enhancement factor $(q)$, with equivalent relative impacts.

Given a constant actinic flux spectrum, the archived flux (FA) is primarily controlled by the primary input flux and the trapping efficiency. Therefore, the plot of FA versus $\delta^{15} \mathrm{~N}(\mathrm{FA})$ in the modified Rayleigh space is a good candidate to track modern or past changes in the spectral distribution of the UV received at ground, i.e., changes in the ozone column but also changes in the solar UV spectra. At a given spectral distribution of the actinic flux, past variations in FPI can be reconstructed from FA and $\delta^{15} \mathrm{~N}(\mathrm{FA})$ if $\delta^{15} \mathrm{~N}(\mathrm{FPI})$ is known or assumed.

From the nitrate trapping efficiency (FA / FPI), we have shown that we can deduce $\Delta^{17} \mathrm{O}$ (FA, corr.), which represents the $\Delta^{17} \mathrm{O}$ value in the archived flux corrected from the cage recombination effects. To achieve this correction, the potential impact of nitrate speciation (association to $\mathrm{H}^{+}$ or, for example, $\mathrm{Ca}^{2+}$ ) on the cage effect should be considered (e.g., during glacial conditions). The variable $\Delta^{17} \mathrm{O}$ (FA, corr.) is controlled by $\Delta^{17} \mathrm{O}\left(\mathrm{NO}_{2}\right.$, PSS), $\Delta^{17} \mathrm{O}$ (add. O), $\Delta^{17} \mathrm{O}(\mathrm{FT})$ and $\Delta^{17} \mathrm{O}(\mathrm{FS})$ and the scaled contributions of each of these four variables have been determined as a function of FA/FPI. We have shown that these contributions are independent of the ozone column. Under the modern DC conditions, we have shown that the isotope mass balance of $\Delta^{17} \mathrm{O}$ (FA, corr.) can be written as [52, $55] \% \times \Delta^{17} \mathrm{O}\left(\mathrm{NO}_{2}, \mathrm{PSS}\right)+[26,28] \% \times \Delta^{17} \mathrm{O}($ add. $\mathrm{O})+$ $[11,13] \% \times \Delta^{17} \mathrm{O}(\mathrm{FT})+[5,9] \% \times \Delta^{17} \mathrm{O}(\mathrm{FS})$. These proportions result from the intense recycling cycles (on average, 4.0) present at low-accumulation sites. As a consequence, $\Delta{ }^{17} \mathrm{O}$ (FA, corr.) is mostly driven by the $\Delta^{17} \mathrm{O}$ signature acquired during the summertime and local processing of $\mathrm{NO}_{2}$ in the DC atmosphere and only weakly by the $\Delta^{17} \mathrm{O}$ signature of the primary nitrate fluxes (FT and FS).

If the modern DC conditions applied to the past as well (i.e., important loss by photolysis followed by the local recycling of nitrate), $\Delta{ }^{17} \mathrm{O}$ (FA, corr.) obtained from ice cores drilled on the East Antarctic Plateau is expected to deliver information about the oxidative chemistry occurring at the local and summertime scale rather than at the global scale. The reverse should therefore also be true. High-accumulation sites with limited photolytic loss should deliver information about the oxidative chemistry of $\mathrm{NO}_{x}$ at the remote scale.

Acknowledgements. This research received the financial support of the Agence Nationale de la Recherche (ANR), through the VANISH (contract ANR-07-VULN-013) and OPALE (contract ANR09-BLAN-0226) projects (J. Erbland, J. Savarino). It was partly conducted in the framework of the International Associated Laboratory (LIA) "Climate and Environments from Ice Archives" 20122016, linking several Russian and French laboratories and institutes. J. L. France and M. D. King gratefully acknowledge NERC for support through grants NE/F0004796/1 and NE/F010788, NERC FSF for support and expertise through grants 555.0608 and 584.0609, and Royal Holloway Earth Sciences research strategy fund awards. Partial funding was also received from LICENCE (LEFE-CHAT), a scientific program of the Institut National des Sciences de l'Univers (INSU/CNRS), as well as from the IPICS program (CNRS) and from IPEV (program NITEDC - 1011) (J. Erbland, J. Savarino). LGGE and CNRM-GAME/CEN are part of LabEx OSUG@2020 (ANR10 LABX56). We thank F. Dominé, G. Picard and D. Voisin 
for helpful discussions on light penetration in snow and modeling; C. Carmagnola, G. Picard, F. Dupont and N. Champollion, who shared their knowledge on Python; M. Zatko for discussions about nitrate diffusion and the number of recyclings; and the overwintering volunteers (S. Lafont, I. Bourgeois, S. Aubin, A. Barbero and C. Lenormant) for the sample collection at Concordia-Dome $\mathrm{C}$ from 2010 to 2013. Last, we thank the reviewers for their help in improving the manuscript. Eric Wolff is deeply acknowledged for his fundamental contribution to calculate the recycling effect.

The authors encourage the use of the TRANSITS model. It is available upon request from the correspondence author.

Edited by: S. Preunkert

\section{References}

Alexander, B., Hastings, M. G., Allman, D. J., Dachs, J., Thornton, J. A., and Kunasek, S. A.: Quantifying atmospheric nitrate formation pathways based on a global model of the oxygen isotopic composition $\left(\Delta^{17} \mathrm{O}\right)$ of atmospheric nitrate, Atmos. Chem. Phys., 9, 5043-5056, doi:10.5194/acp-9-5043-2009, 2009.

Atkinson, R., Baulch, D. L., Cox, R. A., Crowley, J. N., Hampson, R. F., Hynes, R. G., Jenkin, M. E., Rossi, M. J., and Troe, J.: Evaluated kinetic and photochemical data for atmospheric chemistry: Volume $\mathrm{I}-$ gas phase reactions of $\mathrm{O}_{\mathrm{x}}, \mathrm{HO}_{\mathrm{x}}, \mathrm{NO}_{\mathrm{x}}$ and $\mathrm{SO}_{\mathrm{x}}$ species, Atmos. Chem. Phys., 4, 1461-1738, doi:10.5194/acp-41461-2004, 2004.

Atkinson, R., Baulch, D. L., Cox, R. A., Crowley, J. N., Hampson, R. F., Hynes, R. G., Jenkin, M. E., Rossi, M. J., Troe, J., and IUPAC Subcommittee: Evaluated kinetic and photochemical data for atmospheric chemistry: Volume II - gas phase reactions of organic species, Atmos. Chem. Phys., 6, 3625-4055, doi:10.5194/acp-6-3625-2006, 2006.

Atkinson, R., Baulch, D. L., Cox, R. A., Crowley, J. N., Hampson, R. F., Hynes, R. G., Jenkin, M. E., Rossi, M. J., and Troe, J.: Evaluated kinetic and photochemical data for atmospheric chemistry: Volume III - gas phase reactions of inorganic halogens, Atmos. Chem. Phys., 7, 981-1191, doi:10.5194/acp-7-981-2007, 2007.

Berhanu, T. A., Meusinger, C., Erbland, J., Jost, R., Bhattacharya, S. K., Johnson, M. S. and Savarino, J.: Laboratory study of nitrate photolysis in Antarctic snow. II. Isotope effects and wavelength dependence, J. Chem. Phys., 140, 244306, doi:10.1063/1.4882899, 2014a.

Berhanu, T. A., Savarino, J., Erbland, J., Vicars, W. C., Preunkert, S., Martins, J. F., and Johnson, M. S.: Isotopic effects of nitrate photochemistry in snow: a field study at Dome C, Antarctica, Atmos. Chem. Phys. Discuss., 14, 33045-33088, doi:10.5194/acpd-14-33045-2014, 2014 b.

Blunier, T., Floch, G. L., Jacobi, H.-W., and Quansah, E.: Isotopic view on nitrate loss in Antarctic surface snow, Geophys. Res. Lett., 32, L13501, doi:10.1029/2005GL023011, 2005.

Boxe, C. S. and Saiz-Lopez, A.: Multiphase modeling of nitrate photochemistry in the quasi-liquid layer (QLL): implications for $\mathrm{NO}_{\mathrm{x}}$ release from the Arctic and coastal Antarctic snowpack, Atmos. Chem. Phys., 8, 4855-4864, doi:10.5194/acp-8-4855-2008, 2008.

Chan, H. G., King, M. D., and Frey, M. M.: The impact of parameterising light penetration into snow on the photochemical pro- duction of $\mathrm{NO}_{x}$ and $\mathrm{OH}$ radicals in snow, Atmos. Chem. Phys., 15, 7913-7927, doi:10.5194/acp-15-7913-2015, 2015.

Chance, K. and Kurucz, R. L.: An improved high-resolution solar reference spectrum for Earth's atmosphere measurements in the ultraviolet, visible, and near infrared, J. Quant. Spectrosc. Ra., 111, 1289-1295, 2010.

Chu, L. and Anastasio, C.: Quantum yields of hydroxyl radical and nitrogen dioxide from the photolysis of nitrate on ice, J. Phys. Chem., 107, 9594-9602, 2003.

Chu. L. and Anastasio, C.: Temperature and wavelength dependence of nitrite photolysis in frozen and aqueous solutions, Environ. Sci Technol., 41, 3626-3632, 2007.

Crowley, J. N., Ammann, M., Cox, R. A., Hynes, R. G., Jenkin, M. E., Mellouki, A., Rossi, M. J., Troe, J., and Wallington, T. J.: Evaluated kinetic and photochemical data for atmospheric chemistry: Volume V - heterogeneous reactions on solid substrates, Atmos. Chem. Phys., 10, 9059-9223, doi:10.5194/acp-10-90592010, 2010.

Davis, D. D., Seelig, J., Huey, G., Crawford, J., Chen, G., Wang, Y., Buhr, M., Helmig, D., Neff,W., Arimoto, D. B. R., and Eisele, F.: A reassessment of Antarctic plateau reactive nitrogen based on ANTCI 2003 airborne and ground based measurements, Atmos. Environ., 42, 2831-2848, doi:10.1016/j.atmosenv.2007.07.039, 2008.

Dominé, F. and Shepson, P. B.: Air-snow interactions and atmospheric chemistry, Science, 297, 1506-1510, 2002

Dominé, F., Taillandier, A.-S., Houdier, S., Parrenin, F., Simpson, W. R., and Douglas, T. A.: Interactions between snow metamorphism and climate physical and chemical aspects, in: Physics and Chemistry of Ice, edited by: Kuhs, W. F., Royal Society of Chemistry, Cambridge, UK, 22-46, 2007.

EPICA community members: Eight glacial cycles from an Antarctic ice core, Nature, 429, 623-628, doi:10.1038/nature02599, 2004.

Erbland, J., Vicars, W. C., Savarino, J., Morin, S., Frey, M. M., Frosini, D., Vince, E., and Martins, J. M. F.: Air-snow transfer of nitrate on the East Antarctic Plateau - Part 1: Isotopic evidence for a photolytically driven dynamic equilibrium in summer, Atmos. Chem. Phys., 13, 6403-6419, doi:10.5194/acp-136403-2013, 2013.

France, J. L., King, M. D., Frey, M. M., Erbland, J., Picard, G., Preunkert, S., MacArthur, A., and Savarino, J.: Snow optical properties at Dome C (Concordia), Antarctica; implications for snow emissions and snow chemistry of reactive nitrogen, Atmos. Chem. Phys., 11, 9787-9801, doi:10.5194/acp-11-97872011, 2011.

Frey, M. M., Savarino, J., Morin, S., Erbland, J., and Martins, J. M. F.: Photolysis imprint in the nitrate stable isotope signal in snow and atmosphere of East Antarctica and implications for reactive nitrogen cycling, Atmos. Chem. Phys., 9, 8681-8696, doi:10.5194/acp-9-8681-2009, 2009.

Frey, M. M., Brough, N., France, J. L., Anderson, P. S., Traulle, O., King, M. D., Jones, A. E., Wolff, E. W., and Savarino, J.: The diurnal variability of atmospheric nitrogen oxides (NO and $\mathrm{NO}_{2}$ ) above the Antarctic Plateau driven by atmospheric stability and snow emissions, Atmos. Chem. Phys., 13, 3045-3062, doi:10.5194/acp-13-3045-2013, 2013.

Frey, M. M., Roscoe, H. K., Kukui, A., Savarino, J., France, J. L., King, M. D., Legrand, M., and Preunkert, S.: Atmospheric nitrogen oxides ( $\mathrm{NO}$ and $\mathrm{NO}_{2}$ ) at Dome $\mathrm{C}$, East Antarctica, dur- 
ing the OPALE campaign, Atmos. Chem. Phys., 15, 7859-7875, doi:10.5194/acp-15-7859-2015, 2015.

Freyer, H. D., Kobel, K., Delmas, R. J., Kley, D., and Legrand, M. R.: First results of ${ }^{15} \mathrm{~N} /{ }^{14} \mathrm{~N}$ ratios in nitrate from alpine and polar ice cores, Tellus, 48B, 93-105, 1996.

Frezzotti, M., Pourchet, M., Flora, O., Gandolfi, S., Gay, M., Urbini, S., Vincent, C., Becagli, S., Gragnani, R., Proposito, M., Severi, M., Traversi, R., Udisti, R., and Fily, M.: New estimations of precipitation and surface sublimation in East Antarctica from snow accumulation measurements, Clim. Dynam., 23, 803-813, doi:10.1007/s00382-004-0462-5, 2004.

Gallée, H., Preunkert, S., Argentini, S., Frey, M. M., Genthon, C., Jourdain, B., Pietroni, I., Casasanta, G., Barral, H., Vignon, E., Amory, C., and Legrand, M.: Characterization of the boundary layer at Dome C (East Antarctica) during the OPALE summer campaign, Atmos. Chem. Phys., 15, 62256236, doi:10.5194/acp-15-6225-2015, 2015.

Gallet, J.-C., Domine, F., Arnaud, L., Picard, G., and Savarino, J.: Vertical profile of the specific surface area and density of the snow at Dome C and on a transect to Dumont D'Urville, Antarctica - albedo calculations and comparison to remote sensing products, The Cryosphere, 5, 631-649, doi:10.5194/tc-5-6312011, 2011.

Hastings, M. G., Sigman, D. M. and Steig, E. J.: Glacial/Interglacial changes in the isotopes of nitrate from the GISP2 ice core, Global Biogeochem. Cy., 19, GB4024, doi:10.1029/2005GB002502, 2005.

Herbert, B. M. J., Halsall, C. J., Jones, K. C., and Kallenborn, R.: Field investigation into the diffusion of semi-volatile organic compounds into fresh and aged snow, Atmos. Environ., 40, 1385-1393, 2006.

Huey, L. G., Tanner, D. J., Slusher, D. L., Dibb, J. E., Arimoto, R., Chen, G., Davis, D., Buhr, M. P., Nowak, J. B., Mauldin III, R. L., Eisele, F. L., and Kosciuch, E.: CIMS measurements of $\mathrm{HNO}_{3}$ and $\mathrm{SO}_{2}$ at the South Pole during ICAT 2000, Atmos. Environ., 38, 5411-5421, doi:10.1016/j.atmosenv.2004.04.037, 2004.

Jacob, D. J.: Introduction to Atmospheric Chemistry, Princeton University Press, Princeton, NJ, USA, 1999.

Jarvis, J. C., Steig, E. J., Hastings, M. G., and Kunasek, S. A.: Influence of local photochemistry on isotopes of nitrate in Greenland snow, Geophys. Res. Lett., 35, L21804, doi:10.1029/2008GL035551, 2008.

Jarvis, J. C., Hastings, M. G., Steig, E. J., and Kunasek, S. A.: Isotopic ratios in gas-phase $\mathrm{HNO}_{3}$ and snow nitrate at Summit, Greenland, J. Geophys. Res., 114, D17301, doi:10.1029/2009JD012134, 2009.

Kaempfer, T. U. and Plapp, M.: Phase-field modeling of dry snow metamorphism, Physical Review E., 79, 031502, doi:10.1103/PhysRevE.79.031502, 2009.

King, M. D. and Simpson, W. R.: Extinction of UV radiation in Arctic snow at Alert, Canada $\left(82^{\circ} \mathrm{N}\right)$, J. Geophys. Res., 106, 12499-12507, 2001.

Kukui, A., Legrand, M., Preunkert, S., Frey, M. M., Loisil, R., Gil Roca, J., Jourdain, B., King, M. D., France, J. L., and Ancellet, G.: Measurements of $\mathrm{OH}$ and $\mathrm{RO}_{2}$ radicals at Dome C, East Antarctica, Atmos. Chem. Phys., 14, 12373-12392, doi:10.5194/acp-14-12373-2014, 2014.

Kunasek, S. A., Alexander, B., Steig, E. J., Hastings, M. G., Gleason, D. J., and Jarvis, J. C.: Measurements and modeling of
$\Delta^{17} \mathrm{O}$ of nitrate in snowpits from Summit, Greenland, J. Geophys. Res., 113, D24302, doi:10.1029/2008JD010103, 2008.

Lee-Taylor, J. and Madronich, S.: Calculation of actinic fluxes with a coupled atmosphere-snow radiative transfer model, J. Geophys. Res., 107, 4796, doi:10.1029/2002JD002084, 2002.

Legrand, M. R. and Delmas, R. J.: Relative contributions of tropospheric and stratospheric sources to nitrate in Antarctic snow, Tellus, 38B, 236-249, 1986.

Legrand, M. R. and Kirchner, S.: Origins and variations of nitrate in South Polar precipitation, J. Geophys. Res., 95, 3493-3507, 1990.

Legrand, M., Preunkert, S., Jourdain, B., Gallee, H., Goutail, F., Weller, R., and Savarino, J.: Year-round record of surface ozone at coastal (Dumont d'Urville) and inland (Concordia) sites in East Antarctica, J. Geophys. Res.-Atmos., 114, D20306, doi:10.1029/2008JD011667, 2009.

Liao, W. and Tan, D.: 1-D Air-snowpack modeling of atmospheric nitrous acid at South Pole during ANTCI 2003, Atmos. Chem. Phys., 8, 7087-7099, doi:10.5194/acp-8-7087-2008, 2008.

Libois, Q., Picard, G., France, J. L., Arnaud, L., Dumont, M., Carmagnola, C. M., and King, M. D.: Influence of grain shape on light penetration in snow, The Cryosphere, 7, 1803-1818, doi:10.5194/tc-7-1803-2013, 2013.

Libois, Q., Picard, G., Arnaud, L., Morin, S., and Brun, E.: Modeling the impact of snow drift on the decameter-scale variability of snow properties on the Antarctic Plateau, J. Geophys. Res. Atmos., 119, 11662-11681, doi:10.1002/2014JD022361, 2014.

Massmann, W. J.: A review of the molecular diffusivities of $\mathrm{H}_{2} \mathrm{O}$, $\mathrm{CO}_{2}, \mathrm{CH}_{4}, \mathrm{CO}, \mathrm{O}_{3}, \mathrm{O}_{2}, \mathrm{NH}_{3}, \mathrm{~N}_{2} \mathrm{O}, \mathrm{NO}$ and $\mathrm{NO}_{2}$ in air, $\mathrm{O}_{2}$ and $\mathrm{N}_{2}$ near STP, Atmos. Environ., 32, 1111-1127, 1998.

McCabe, J. R., Boxe, C. S., Colussi, A. J., Hoffman, M. R., and Thiemens, M. H.: Oxygen isotopic fractionation in the photochemistry of nitrate in water and ice, J. Geophys. Res., 110, 9 pp., doi:10.1029/2004JD005484, 2005.

McCabe, J. R., Thiemens, M. H., and Savarino, J.: A record of ozone variability in South Pole Antarctic snow: The role of nitrate oxygen isotopes, J. Geophys. Res., 112, D12303, doi:10.1029/2006JD007822, 2007.

Meusinger, C., Berhanu, T. A., Erbland, J., Savarino, J., and Johnson, M. S.: Laboratory study of nitrate photolysis in Antarctic snow. I. Observed quantum yield, domain of photolysis, and secondary chemistry, J. Chem. Phys., 140, 244305, doi:10.1063/1.4882898, 2014

Michalski, G., Scott, Z., Kabiling, M., and Thiemens, M. H.: First measurements and modeling of $\Delta^{17} \mathrm{O}$ in atmospheric nitrate, Geophys. Res. Lett., 30, 1870, doi:10.1029/2003GL017015, 2003.

Morin, S., Savarino, J., Bekki, S., Gong, S., and Bottenheim, J. W.: Signature of Arctic surface ozone depletion events in the isotope anomaly $\left(\Delta^{17} \mathrm{O}\right)$ of atmospheric nitrate, Atmos. Chem. Phys., 7 , 1451-1469, doi:10.5194/acp-7-1451-2007, 2007.

Morin, S., Savarino, J., Frey, M. M., Yan, N., Bekki, S., Bottenheim, J. W., and Martins, J. M. F.: Tracing the origin and fate of $\mathrm{NO}_{x}$ in the Arctic atmosphere using stable isotopes in nitrate, Science, 322, 730-732, doi:10.1126/science.1161910, 2008.

Morin, S., Savarino, J., Frey, M. M., Dominé, F., Jacobi, H. W., Kaleschke, L., and Martins, J. M. F.: Comprehensive isotopic composition of atmospheric nitrate in the Atlantic Ocean bound- 
ary layer from $65^{\circ} \mathrm{S}$ to $79^{\circ} \mathrm{N}, \mathrm{J}$. Geophys. Res., 114, D05303, doi:10.1029/2008JD010696, 2009.

Morin, S., Sander, R., and Savarino, J.: Simulation of the diurnal variations of the oxygen isotope anomaly $\left(\Delta^{17} \mathrm{O}\right)$ of reactive atmospheric species, Atmos. Chem. Phys., 11, 3653-3671, doi:10.5194/acp-11-3653-2011, 2011.

Muscari, G. and de Zafra, R. L.: Evolution of the $\mathrm{NO}_{y}-\mathrm{N}_{2} \mathrm{O}$ correlation in the Antarctic stratosphere during 1993 and 1995, J. Geophys. Res., 108, 4428, doi:10.1029/2002JD002871, 2003.

Riikonen, S., Parkkinen, P., Halonen, L., and Gerber, R. B.: Ionization of Acids on the Quasi-Liquid Layer of Ice, J. Phys. Chem. A, 118, 5029-5037, doi:10.1021/jp505627n, 2014.

Röthlisberger, R., Hutterli, M. A., Sommer, S., Wolff, E. W., and Mulvaney, R.: Factors controlling nitrate in ice-cores: evidence from the Dome C deep ice core, J. Geophys. Res., 105, 2056520572, 2000.

Sander, S. P., Friedl, R R., Golden, D. M., Kurylo, M. J., Moortgat, G. K., Keller-Rudek, H., Wine, P. H., Ravishankara, A. R., Kolb, C. E., Molina, M. J., Finlayson-Pitts, B. J., Huie, R. E., and Orkin, V. L.: Chemical Kinetics and Photochemical Data for Use in Atmospheric Studies, Evaluation Number 15, JPL Publication 06-2, Jet Propulsion Laboratory, Pasadena, CA, 2006.

Savarino, J., Kaiser, J., Morin, S., Sigman, D. M., and Thiemens, M. H.: Nitrogen and oxygen isotopic constraints on the origin of atmospheric nitrate in coastal Antarctica, Atmos. Chem. Phys., 7, 1925-1945, doi:10.5194/acp-7-1925-2007, 2007.

Savarino, J., Bhattacharya, S. K., Morin, S., Baroni, M., and Doussin, J.-F.: The $\mathrm{NO}+\mathrm{O}_{3}$ reaction: a triple oxygen isotope perspective on the reaction dynamics and atmospheric implications for the transfer of the ozone isotope anomaly, J. Chem. Phys., 128, 194303, doi:10.1063/1.2917581, 2008.

Savarino, J., Vicars, W. C., Legrand, M., Preunkert, S., Jourdain, B., Frey, M. M., Kukui, A., Caillon, N., and Gil Roca, J.: Oxygen isotope mass balance of atmospheric nitrate at Dome $\mathrm{C}$, East Antarctica, during the OPALE campaign, Atmos. Chem. Phys. Discuss., 15, 24041-24083, doi:10.5194/acpd-15-240412015, 2015

Scharko, N. K., Berke, A. E., and Raff, J. D.: Release of Nitrous Acid and Nitrogen Dioxide from Nitrate Photolysis in Acidic Aqueous Solutions, Environ. Sci. Technol., 48, 11991-12001, doi:10.1021/es503088x, 2014.

Seinfeld, J. and Pandis, S.: Atmospheric Chemistry and Physics, Wiley Interscience, 1998.

Swain, M. R. and Gallée, H.: Antarctic Boundary Layer Seeing, Publications of the Astronomical Society of the Pacific, 118, 1190-1197, 2006.

Thibert, E. and Dominé, F.: Thermodynamics and kinetics of the solid solution of $\mathrm{HNO}_{3}$ in ice, J. Phys. Chem. B, 102, 44324439, 1998.
Thomas, J. L., Stutz, J., Lefer, B., Huey, L. G., Toyota, K., Dibb, J. E., and von Glasow, R.: Modeling chemistry in and above snow at Summit, Greenland - Part 1: Model description and results, Atmos. Chem. Phys., 11, 4899-4914, doi:10.5194/acp-11-48992011, 2011.

Traversi, R., Udisti, R., Frosini, D., Becagli, S., Ciardini, V., Funke, B., Lanconelli, C., Petkov, B., Scarchilli, C., Severi, M., and Vitale, V.: Insights on nitrate sources at Dome C (East Antarctic Plateau) from multi-year aerosol and snow records, Tellus B, 66, 22550, doi:10.3402/tellusb.v66.22550, 2014.

Wagenbach, D., Graf, W., Minikin, A., Trefzer, U., Kipfstuhl, J., Oerter, H., and Blindow, N.: Reconnaissance of chemical and isotopic firn properties on top of Berkner Island, Antarctica, Ann. Glaciol., 20, 307-312, 1994.

Wang, Y., Choi, Y., Zeng, T., Davis, D., Buhr, M., Huey, L. G., and Neff, W.: Assessing the photochemical impact of snow $\mathrm{NO}_{x}$ emissions over Antarctica during ANTCI 2003, Atmos. Environ., 41, 3944-3958, doi:10.1016/j.atmosenv.2007.01.056, 2007.

Wolff, E.: Ice core studies of global biogeochemical cycles, chap. Nitrate in polar ice, Springer-Verlag, New York, 195-224, 1995.

Wolff, E. W., Jones, A. E., Martin, T. J., and Grenfell, T. C.: Modelling photochemical $\mathrm{NO}_{x}$ production and nitrate loss in the upper snowpack of Antarctica, Geophys. Res. Lett., 29, 1944, doi:10.1029/2002GL015823, 2002.

Wolff, E. W., Jones, A. E., Bauguitte, S. J.-B., and Salmon, R. A.: The interpretation of spikes and trends in concentration of nitrate in polar ice cores, based on evidence from snow and atmospheric measurements, Atmos. Chem. Phys., 8, 5627-5634, doi:10.5194/acp-8-5627-2008, 2008.

Wolff, E. W., Barbante, C., Becagli, S., Bigler, M., Boutron, C. F., Castellano, E., de Angelis, M., Federer, U., Fischer, H., Fundel, F., Hansson, M., Hutterli, M., Jonsell, U., Karlin, T., Kaufmann, P., Lambert, F., Littot, G. C., Mulvaney, R., Röthlisberger, R., Ruth, U., Severi, M., Siggaard-Andersen, M. L., Sime, L. C., Steffensen, J. P., Stocker, T. F., Traversi, R., Twarloh, B., Udisti, R., Wagenbach, D., and Wegner, A.: Changes in environment over the last 800000 years from chemical analysis of the EPICA Dome C ice core, Quaternary Sci. Rev., 29, 285-295, doi:10.1016/j.quascirev.2009.06.013, 2010.

Zatko, M. C., Grenfell, T. C., Alexander, B., Doherty, S. J., Thomas, J. L., and Yang, X.: The influence of snow grain size and impurities on the vertical profiles of actinic flux and associated $\mathrm{NO}_{\mathrm{x}}$ emissions on the Antarctic and Greenland ice sheets, Atmos. Chem. Phys., 13, 3547-3567, doi:10.5194/acp-13-35472013, 2013.

Zhang, L., Vet, R., O'Brien, J. M., Mihele, C., Liang, Z., and Wiebe, A.: Dry deposition of individual nitrogen species at eight Canadian rural sites. J. Geophys. Res., 114, D02301, doi:10.1029/2008JD010640, 2009. 